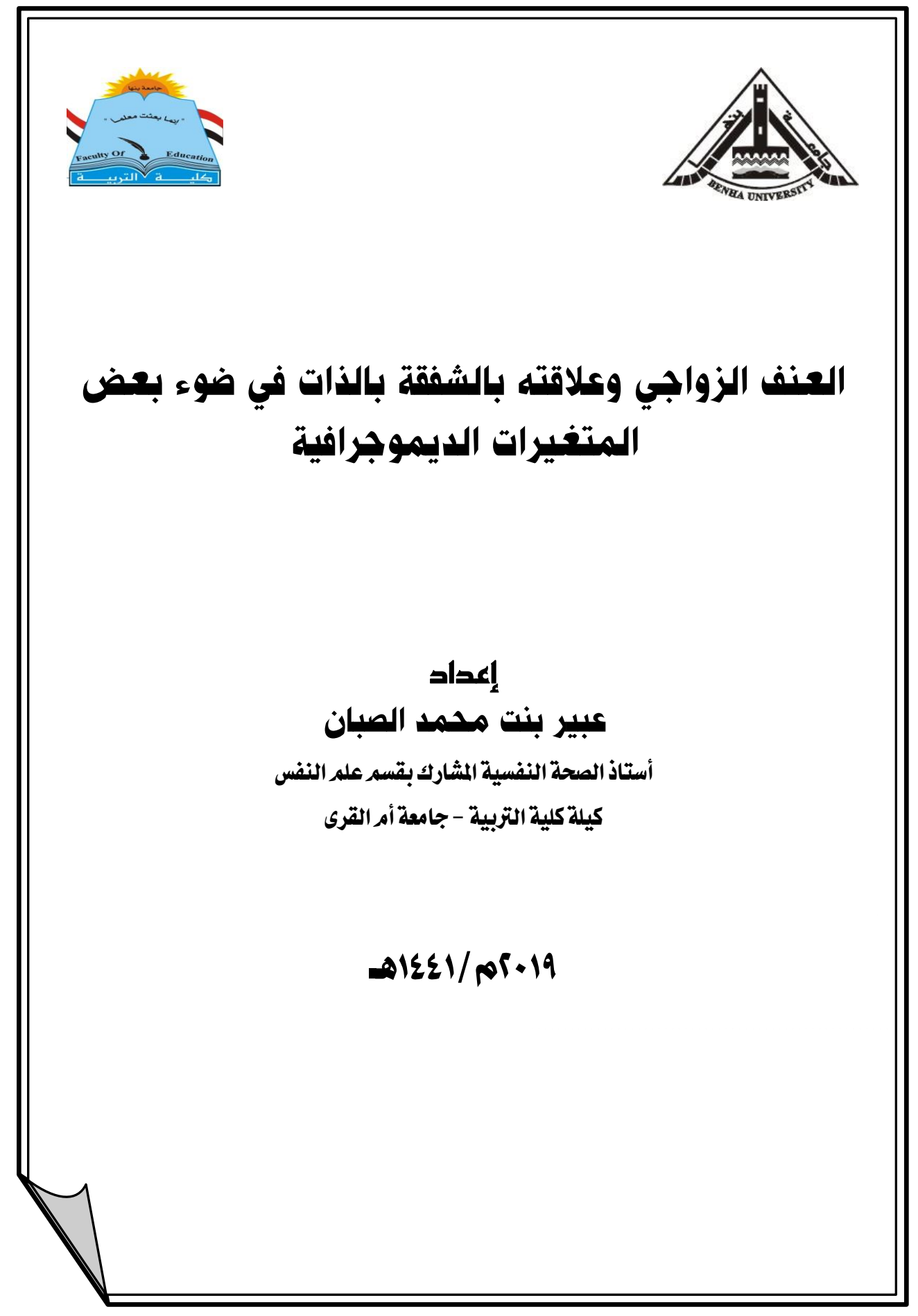




\title{
العنف الزواجي وعلاقته بالشفقة بالذات في ضوء بعض المتفيرات الديموجرافية
}

\author{
إعـداد \\ عبير بنت محمد الصبان \\ أستاذ الصحة النفسية المشارك بقسم علم النفس النس \\ كلية التزبية - جامعة أم القرى النمارية
}

الملاخص :

هدف البحث إلى الكثف عن مستوى العنف الزواجي والثشقة بالذات، والوزن النسبي لأبعاد الثفقة بالذات

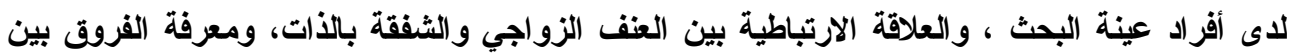

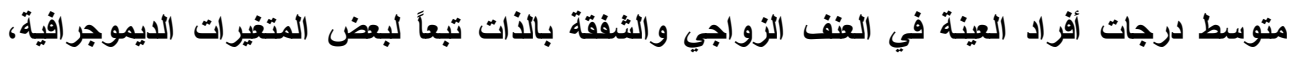

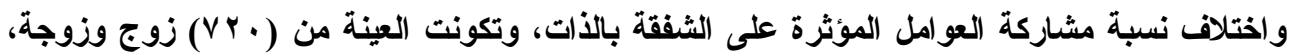

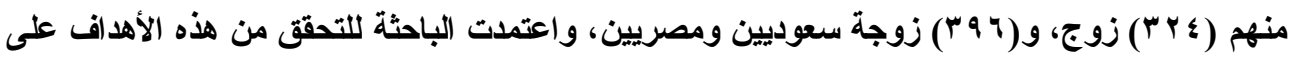
مقياس العنف الزواجي نسخة (للزوج، الزوجة) من إعدادها، ومقياس الثفقة بالذات إعداد (Neff (2003)

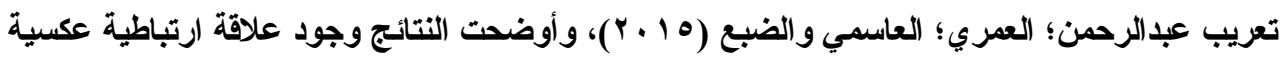

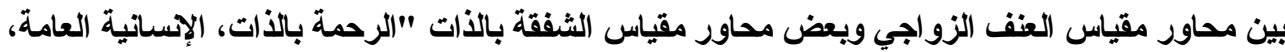

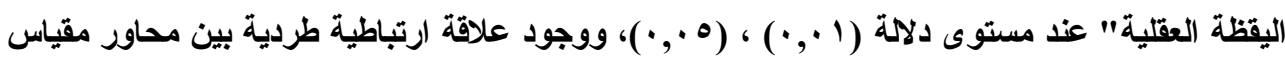

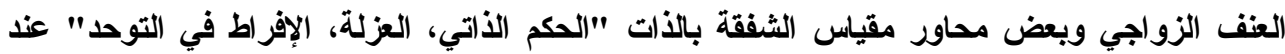

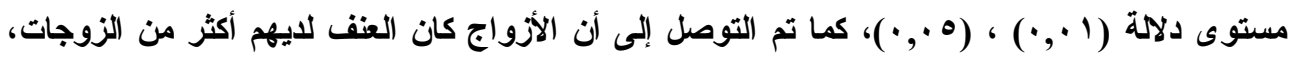

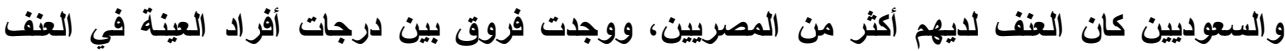

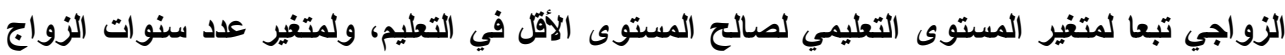

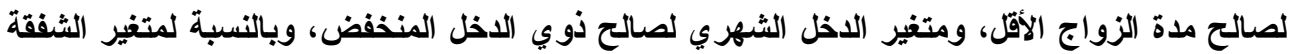

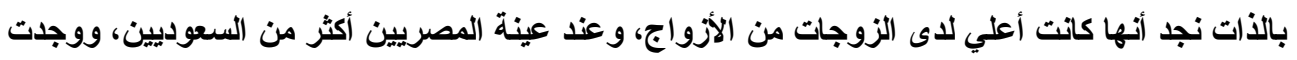

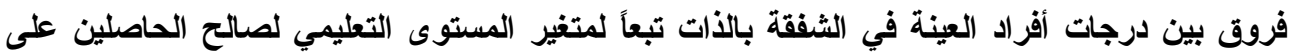

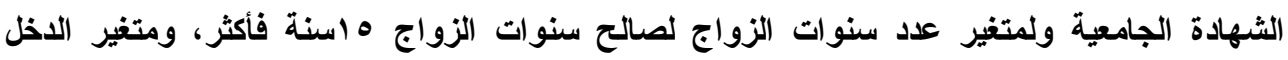

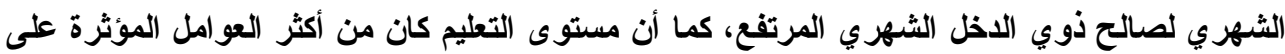

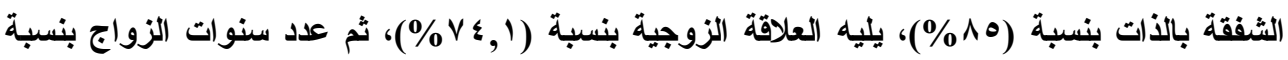
)

الكلمات المفتاحية : العنف الزو اجيـ الثفقة بالذات. 


\section{Spousal Violence and its Relation to Self-Compassion in Light of} Some Demographic Variables

\section{Ahstract}

This study aimed to reveal the relationship between marital violence and selfCompassion, and to specify the differences in spousal violence and self-Compassion, in accordance to some demographic variables. In addition, the study considered the variation in the influencing factors contribution rate to self-Compassion. The study sample included (720) husbands and wives of Saudi and Egyptian spouses, consisting of (324) husbands and (396) wives. To realize the study's objectives, the researcher developed and used the spousal violence scale with distinct husband and wife versions. The self-Compassion scale (Neff, 2003) was also used, translated to Arabic by Abd AlRahman, Ali Al-Amri, Al-Asmi and Al-Dabae (2015). The results indicated a negative relation between the factors of the spousal violence scale and some of the selfCompassion scale factors including self-mercy, general humanity and mental alertness with a significance level $(0,01),(0,05)$. On the other hand, a positive correlation was found between the factors of the spousal violence scale and other self- Compassion factors including autonomy, isolation and excessive autism, with a significance level $(0,01),(0,05)$. The results also indicated that husbands were more violent than wives, and Saudis were more violent than Egyptian. Differences were found in violence scores among respondent couples depending on their education level in favour of the lower level of education. Differences dependent on the number of marriage years were also noticed in favour of shorter marriage periods. In addition, couples' monthly income also affected the violence scores in favour of low income couples. With respect to the self-Compassion, high scores were noticed among wives compared to husbands. Egyptian respondents scored higher self-Compassion scores compared to Saudis. There were differences in self-Compassion scores depending on respondents' educational levels in favour to respondents who holding Master and PhD degrees. Self-Compassion score differences were also found depending on the number of marriage years in favour to fifteen years marriage old and more and the monthly income variable in favour of high income couples. Educational level was the most influencing factors on self-Compassion with $(85 \%)$, followed by the martial relationship with $(74,1 \%)$, the number of marriage years $(68.1 \%)$ and finally, the least influencing factor was kinship relationship $(62,7 \%)$.

Keywords: Spousal Violence - Self-Compassion. 


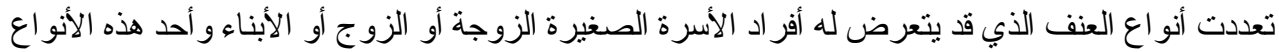

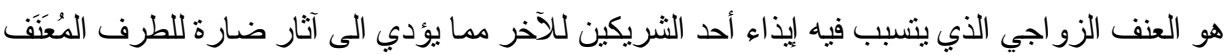

$$
\text { ومن يعيش معله في منزل و احد. }
$$

وقد يؤثر العنف الزو اجي على الصحة النفسية للزوجين وعلى سلوكهم نتيجة الخلافات المستمرة وضعف

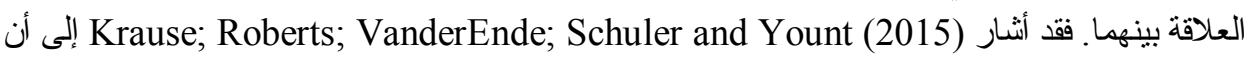

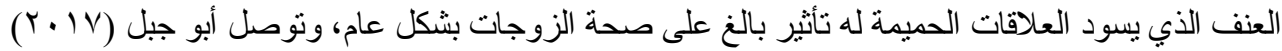

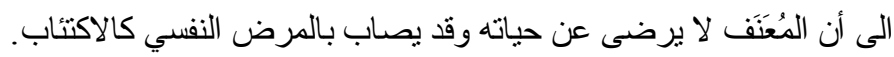

وذكر Rafi ;Shameem and Shazia (2018) أن العنف الذي تتعرض له الزوجة يعتبر مشكلة خطيرة

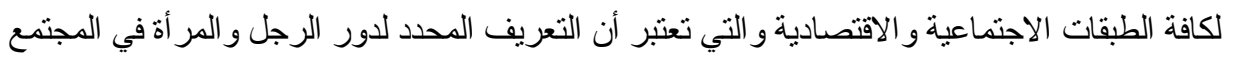

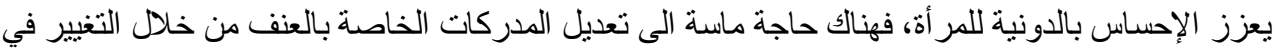
السياسة التعليمبة.

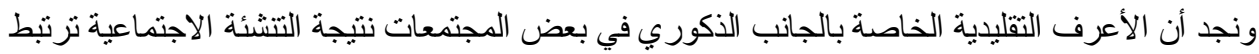
بشكل إيجابي بالعنف البذني الموجه من الزوج نحو الزوجة (Cheung \& Choi 2016)، (عبيد ، 17 • ب). وفي مجتمعات أخرى تتعرض العديد من الزوجات للمعاملة القاسية من الأزو اج مما يؤدي الىى وفاتهن،

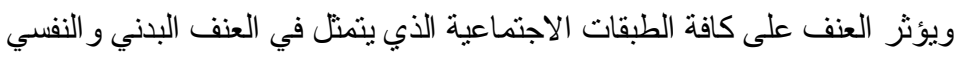

و الجنسي (Oluremi,2016)

ويلاحظ أن ظاهرة العنف بين الزوجين انتشرت في كثير من دول العالم ونتاولها الباحثين من زوايا

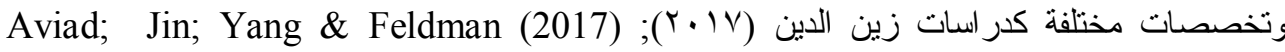
Yucel_(2018) Karim \& Swahnberg (2018); Haviv; Shagan \& Shushan (2018); ; Murshid \& Murshid, (2018); Haack; Pressi \& Falcke (2018) ; Begiato (2018) ;

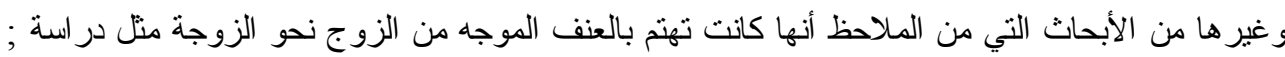

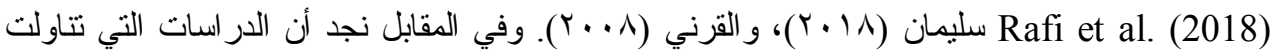
العنف الموجه من الزوجة نحو الزوج نادرة على حد علم الباحثة.

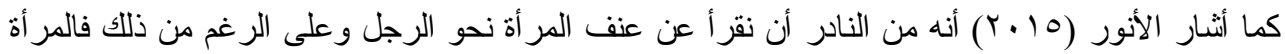

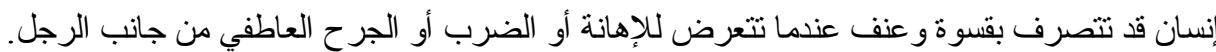

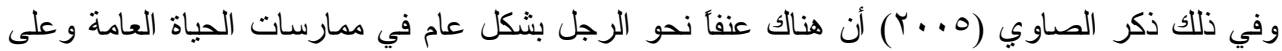

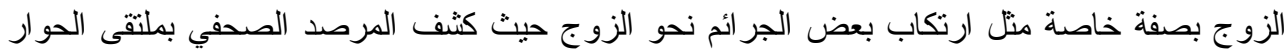

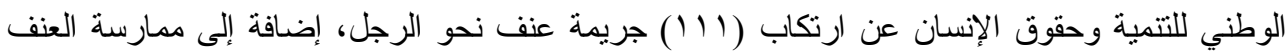

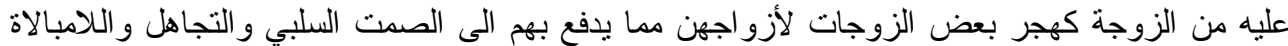




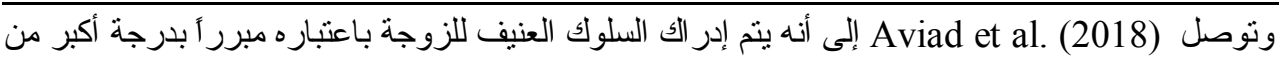

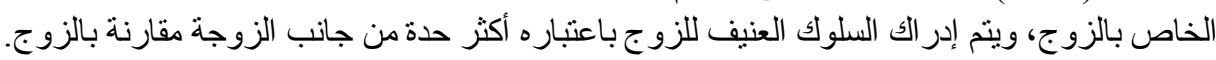

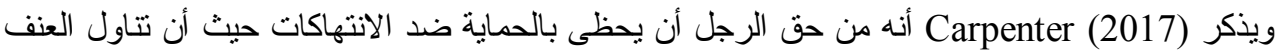

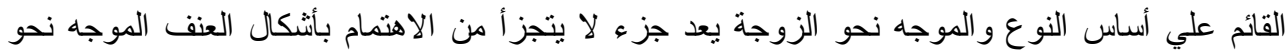

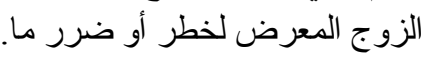

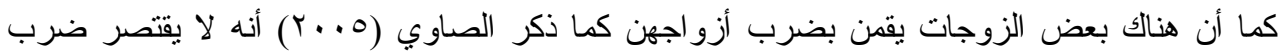

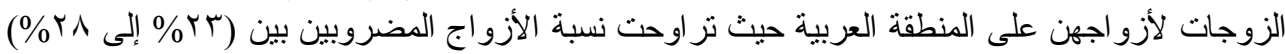

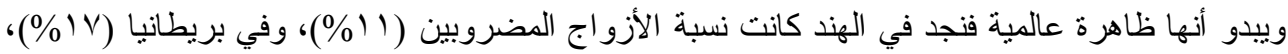
وفي أمريكا (Tr\%\%)، وتبين أن النسب الأعلى تكون في الأحياء الر اقية و الطبقات الاجتماعية الأعلى بينما

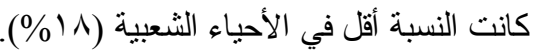
تعد إساءة معاملة الثريك مشكلة مهمة تتعلق بالصحة النفسية وترتبط بعدد من الاستجابات العاطفية السلبية

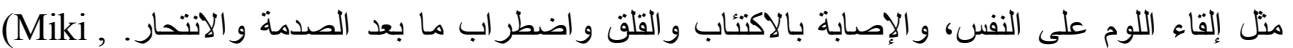
Learman,. Pulliam \& Mindfulness ,2015)

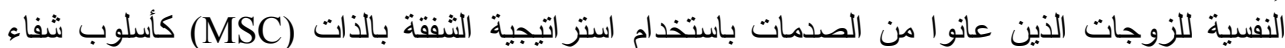

لأولنئك الذين لديهم خبرات مع العنف (Miki et al. 2015). وفي ذلك ترى الباحثة أن العنف الزواجي قد بقلل من مستوى الثفقة بالذات و الرحمة بها لإى الثين الثخص

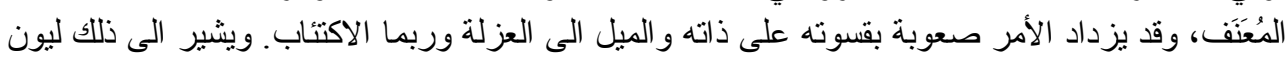

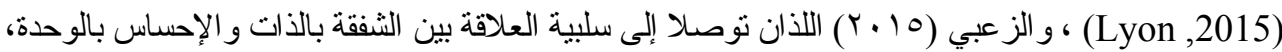

وتذكر (2015) Dzwonkowska and Lykus أن الثفقة بالذات ترنبط بالتظظيم الأفضل للانفعالات

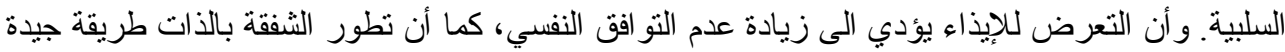

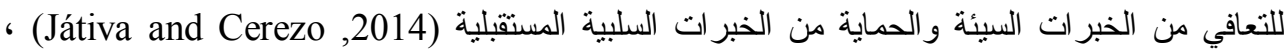

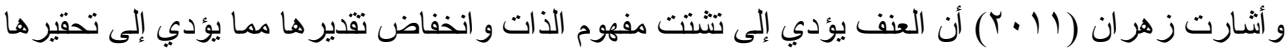

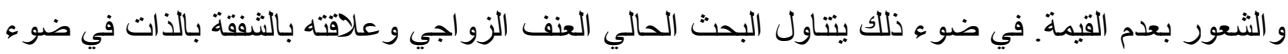
بعض المتغير ات الديموجر افية.

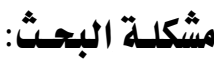

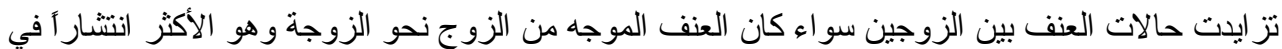

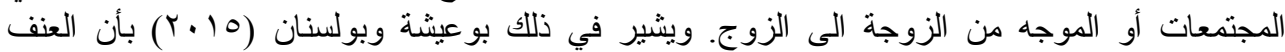

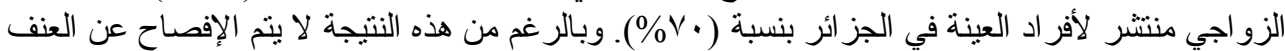

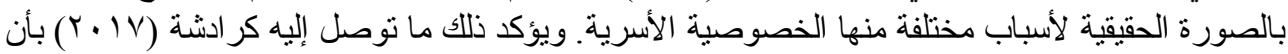

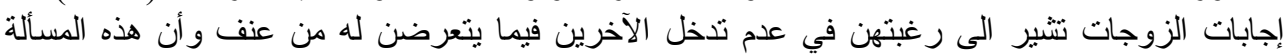

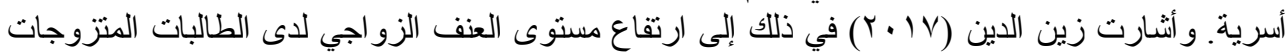

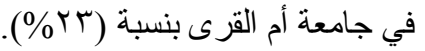


وذكر (2018) . Haack et al أن العنف الزواجي ظاهرة مركبة ومعقدة نستحق الاهنمام و الانتباه بسبب

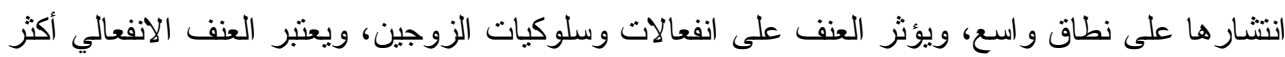

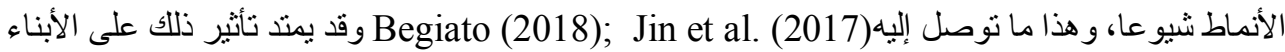

فينسمو ا بالعنف في حياتهم المسنقبلية.

قد يساعد العنف الزو اجي في زيادة عدم الرضا بالحياة الزوجية للطرفين مما قد يؤدي الى عدم استقر ارها ها لإيا

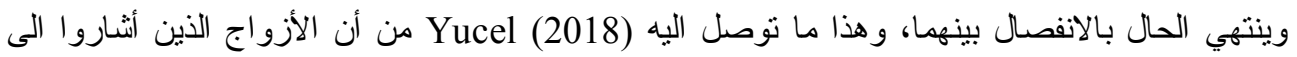

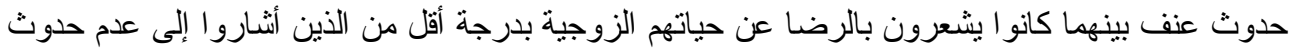
العنف.

و أنشار (2016) Oluremi إلى أن مستويات العنف نحو الزوجة تنز ايد، ففي اليوم الواحد تتعرض كل

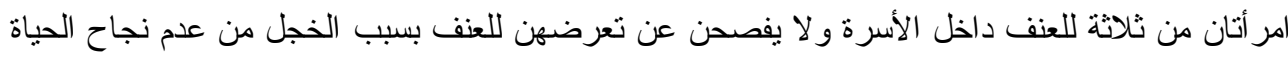

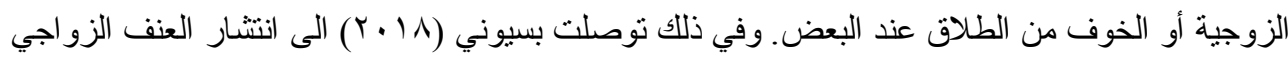

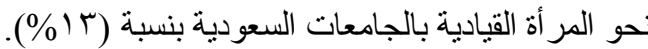

كما توصل Hassan (2018) إلى أن العنف الزو اجي يرنبط باضطر ابات الصحة النفسية للزوجة المعنفه.

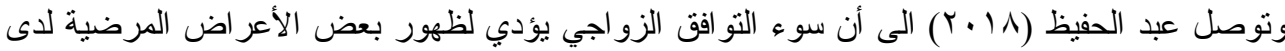

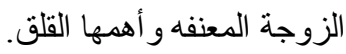
و أنشار (2019) Malik and Nadda إلى أنه دائمأ ما تهنم الأبحاث في كافة انحاء العالم بحالات الانتهاك

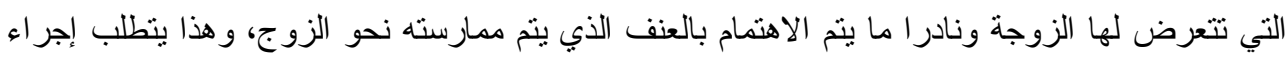

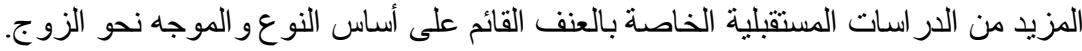

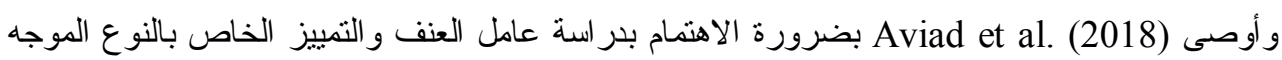

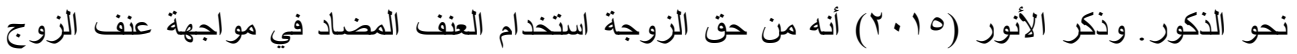

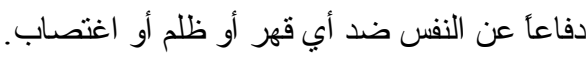

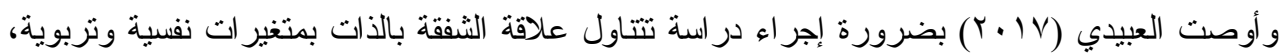

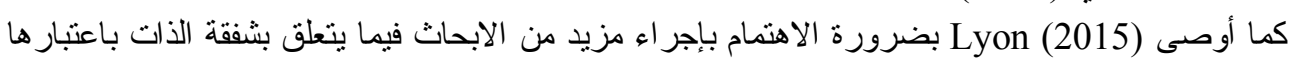
أداة تنتبؤ محتملة و علاج.

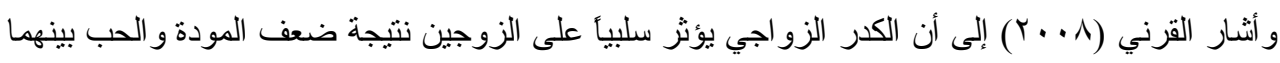
وسوء العلاقة مما يؤدي إلى معاناة الأسرة وضياع الأبناء. وبناء على ما تقدم تتحدد مشكلة البحث في التساؤ لات الثالية:

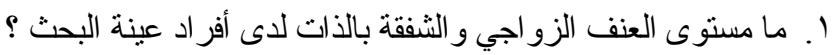

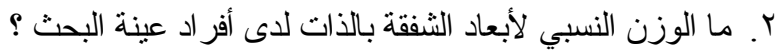

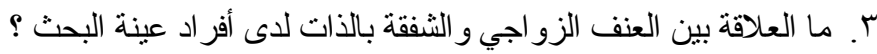




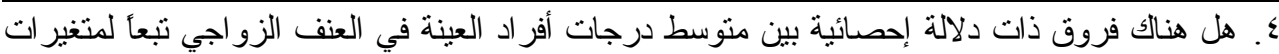

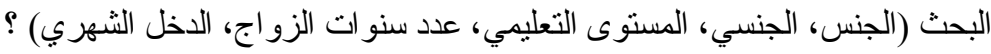

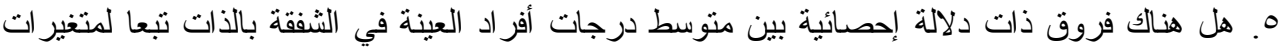

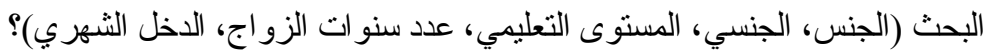

7. هل تختلف نسبة مشاركة العو امل المؤثرة على الثفيقة بالذات؟

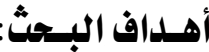

هدفت الباحثة من در استها الوقوف على و اقع الحياة الزوجية وما يشوبها من عنف يهدد أمنها و استقر ارها ومعرفة علاقة الثفقة بالذات كأحد المتغير ات الإيجابية في الصحة النفسية وذلك يتحدد بالكثف عن:

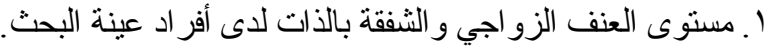

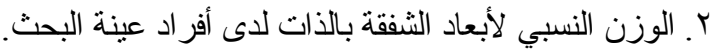

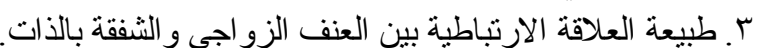

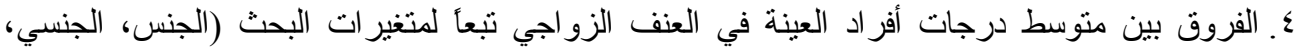

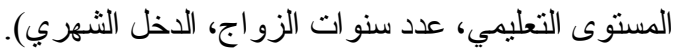

ه. الفروق بين منوسط درجات أفر اد العينة في الثفقة بالذات تبعا لمتغير ات البحث (الجنس، الجنسي، المستوى

$$
\text { التعليمي، عدد سنو ات الزو اج، الدخل الثنهري). }
$$

T. أختلاف نسبة مشاركة العو امل المؤثرة على الثفقة بالذات.

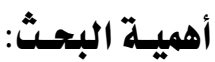

تظهر أهمية البحث النظرية والتطبيقية في:

ـ إلقاء مزيد من الضوء على تحديد مفهوم العنف الزو اجي و الثفقة بالذات.

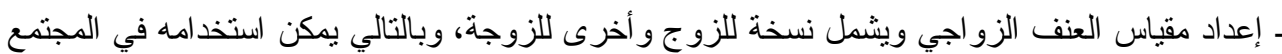

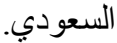

ــ الآثار النفسية و الاجتماعية السيئة التي تنتج عن العنف الزو اجي على كلا من الزوجة و الزورج و الأبناء،

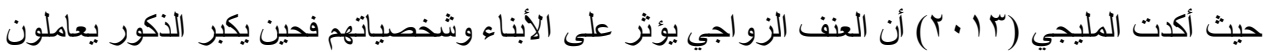

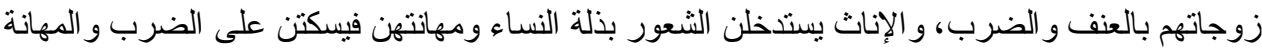

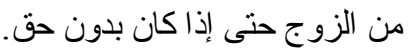

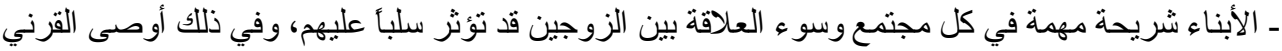

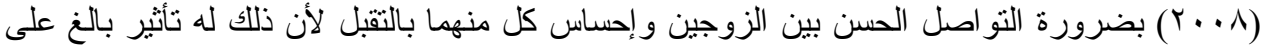

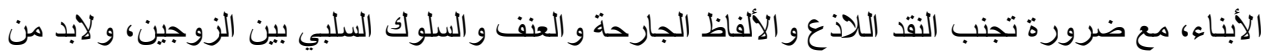

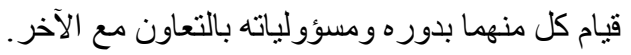
ـ يعتبر متغير الثفقة بالذات من عناصر الصحة النفسية التي تخفف على الذات لومها عندما تتعرض لخبرة 
ـ قلة الدراسات التي نتاولت العنف نحو الزوج أو الزوجة معأ وارتباطهما بالثفقة بالذات على حد علم

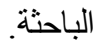

ــــــ إجر اء بر امج إرشادية للتخفيف من حدة العنف الأسري و الزو اجي، وبر امج أخرى للتمية الثفقة بالذات لدى

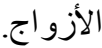

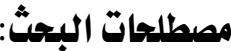

العنف الزو اجي (Spousal Violence): تعرف الباحثة العنف الزواجي اجي بأنه: "إيذاء الثريك الآخر في

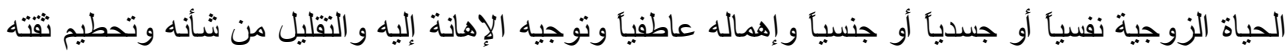

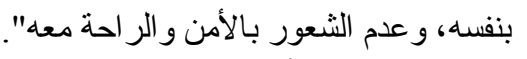

ويُعرف إجر ائيًا بأنه الدرجة التي يحصل عليها أفر اد العينة من خلال تطبيق مقياس العنف الزواجي إعداد

الباحثة.

الثفقة بالذات Neff (2003) Nelf-Compassion) مفهوم الثفقة بالذات بأنه "اتجاه إيجابي

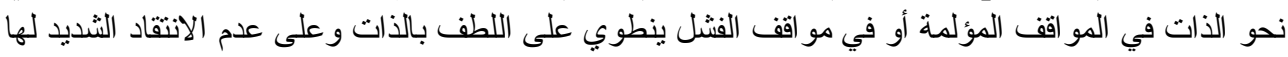

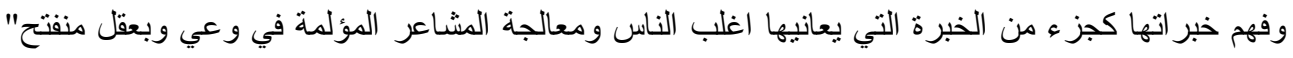

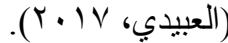
ويُعرف إجر ائياً بأنه الدرجة التي يحصل عليها أفر اد العينة من خلال تطبيق مقياس الثفقة بالذات إعداد نيف

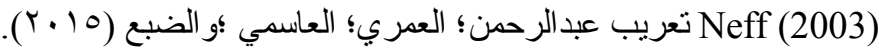

1. الحدود المكانية: تم تطبيق مقاييس البحث على العينة من خلال النوزيع الإلكتروني عبر وسائل التو اصل

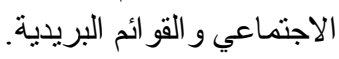

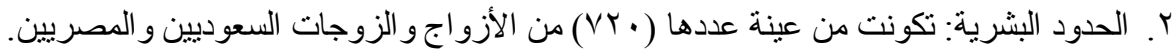

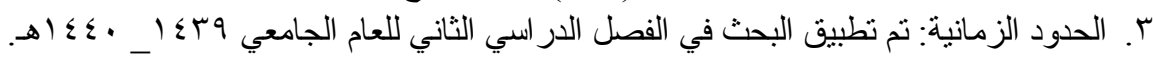

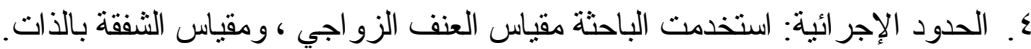

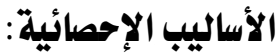

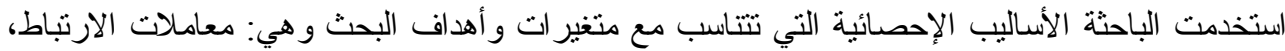
اختبار (ت) t-test، وتحليل التباين أحادي الاتجاه، و اختبار شيفيه للمقارنات المتعددة.

تعتبر الأسرة مصدر الأمان النفسي و الدفء العاطفي لكل فرد فيها، إلا أن الخلافات بين الأزواج قد تفكك

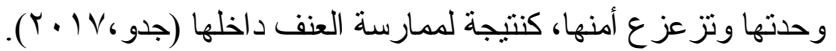

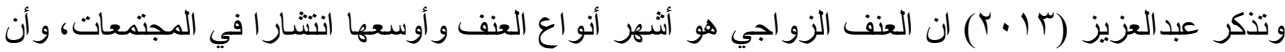

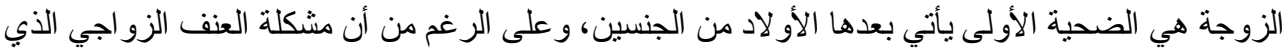

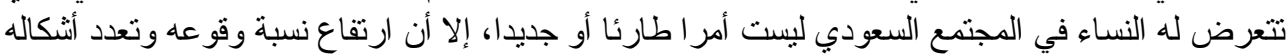


في الوقت الحاضر، يجعل من البحث في الموضوع وتحليل هذه الظاهرة الاجتماعية من جانب مختلف

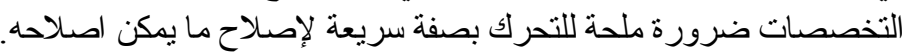

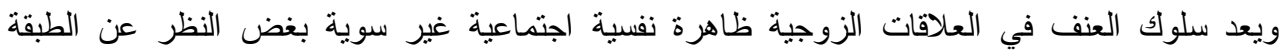

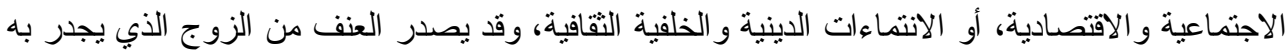

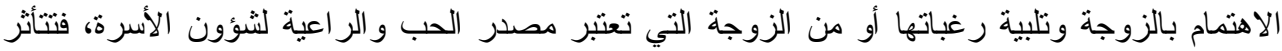

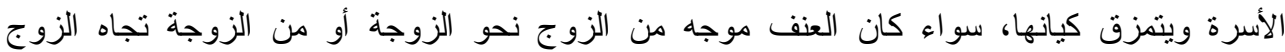

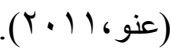

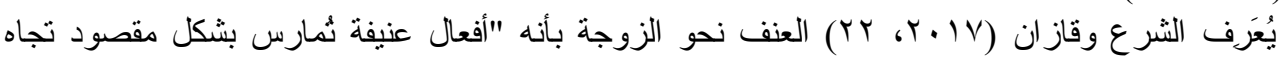

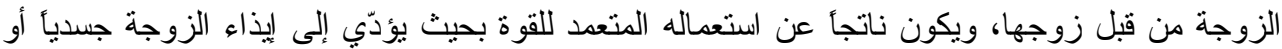
نفسياً أو لفظياً".

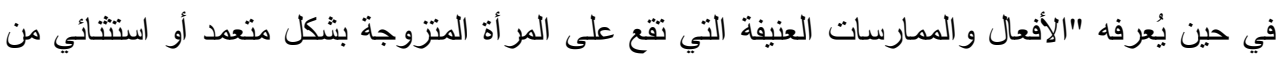

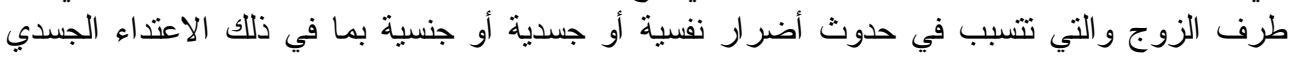

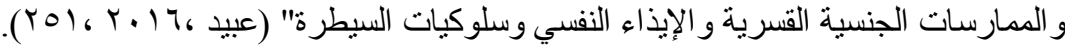

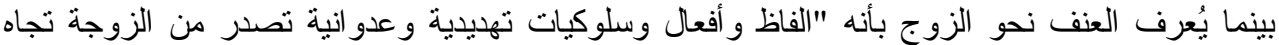

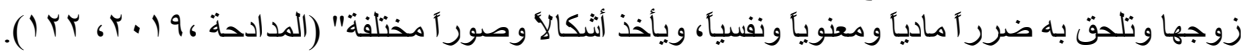

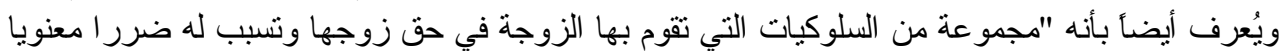

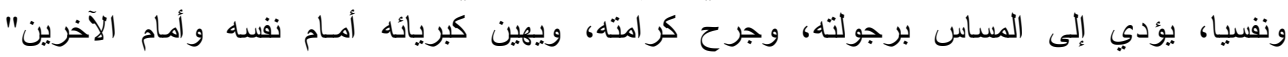

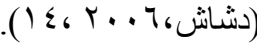

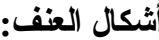

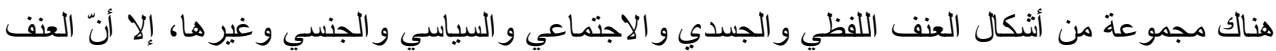

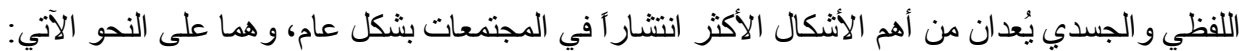

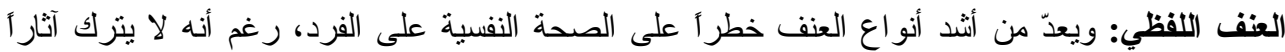

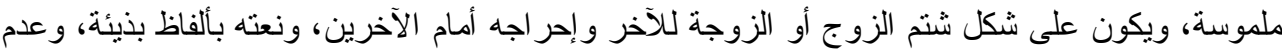

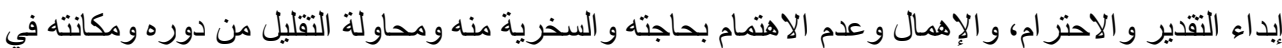

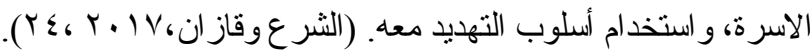

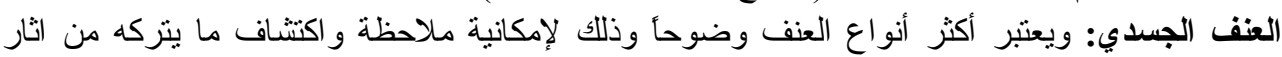

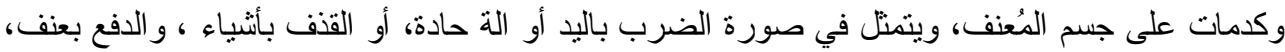

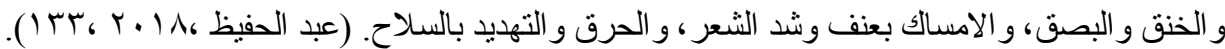

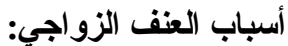

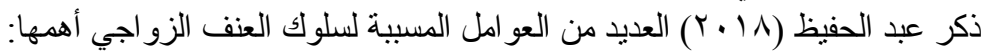

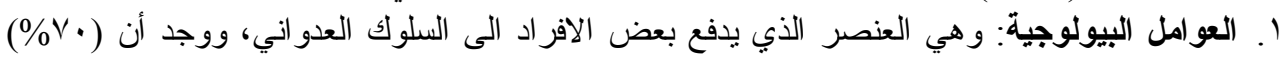

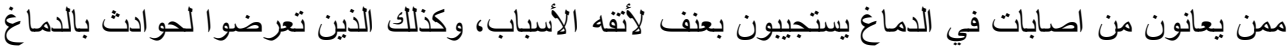

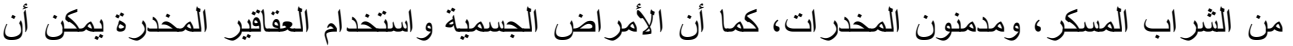

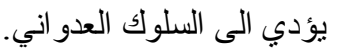


r. العو امل النفسية: وتتمثل في عدم إثباع حاجات الفرد العاطفية، وعجزه عن التكيف النفسي وقد تؤدي

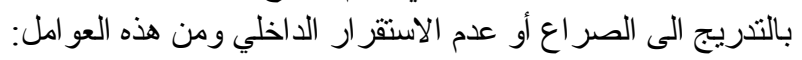

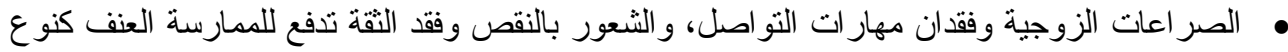
من التعويض لمشاعر النقص و الاحباط و الفثل، العجز عن القيام بالاستجابات المناسبة.

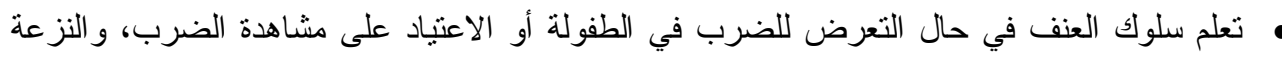

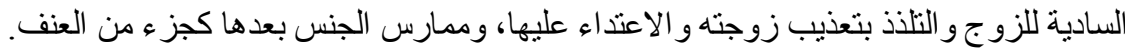

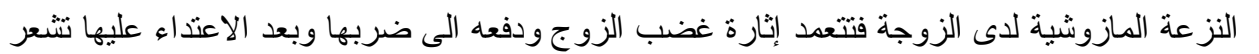

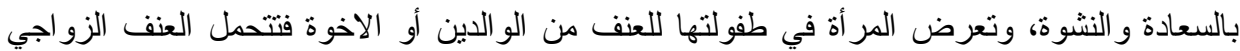

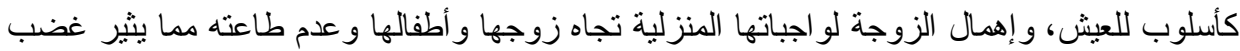

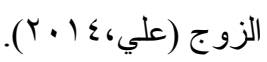

بـ العوامل الاجتماعية: التتشئة الاجتماعية التي تقوم على أساس التربية العنيفة نخلق شخصية ضعيفة وغير و انقة، وتعالج الضعف بالعنف في الدستقبل.

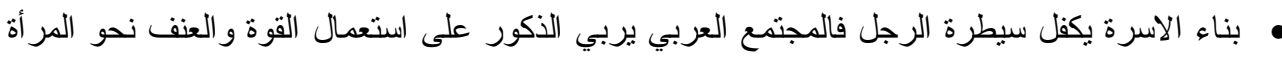
لتحقيق السلطة داخل الاسرة، ووجود الأطفال يدفع الزوجة إلى محاولة لإكلة الحفاظ على الاسرة من التنكك و التحمل من أجلهم. عدم وجود بديل أمام الزوجة، فقد يكون ليس لديها دخل فنتحمل الاذى حفاضأ على مصلحة أسرتها،

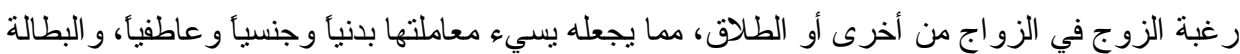

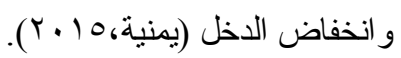

؛ـ العو امل الثقافية: التفاوت في المستوى التعليمي و المؤهلات الدر اسية بين الزوجين.

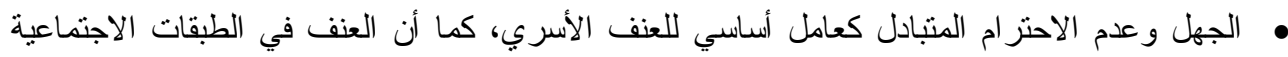

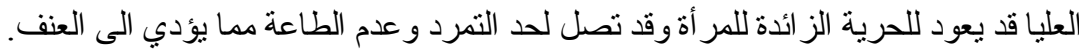

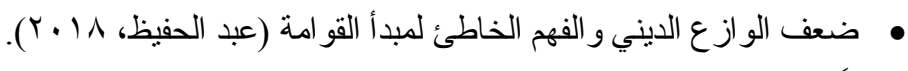

ثانياً : الشفقة بالذات

تعد الثفقة بالذات أحد الموضوعات الإيجايية التي تتاولتها الصحة النفسية حديثا، وتعرف بأنها "مفهوم يتضمن ثلاثة أبعاد رئيسية: اللطف بالذات في مقابل الحكم الذاتي، والإنسانية الإنية المشتركة في مقابل العزلة،

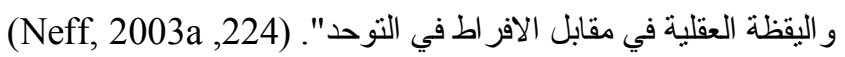

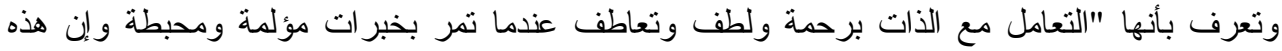

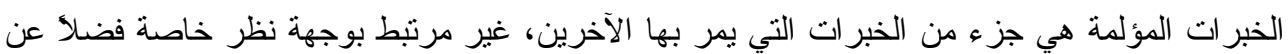

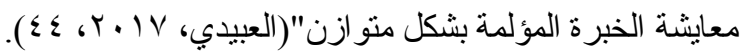

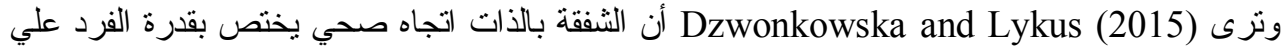
التو افق نحو الذات، ويتكون هذا الاتجاه من الاحساس بالعطف و إدرالك الذات، و الوعي بالخبرة الذاتية، 
و الاحساس بالخبر ات الإنسانية، وتتسم الثفقة بالذات من الناحية الوظيفية برثاء الذات و الاحساس بالأسف مما لوالئ

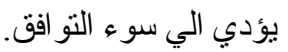
وتتضمن الثفقة بالذات "الفهم الو اعي للأات، ونظرة الفرد إلى خبر اته بأنها تمثل خبرة إنسانية مشتركة بدالا

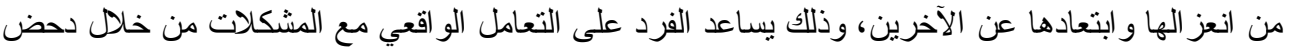

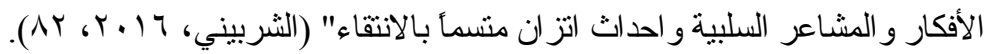

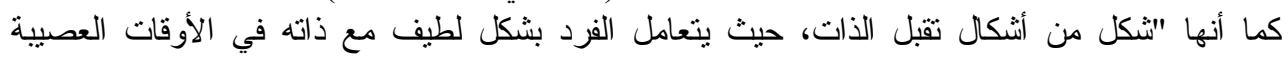

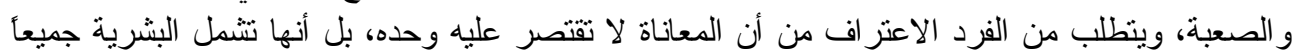

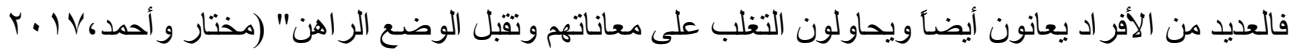

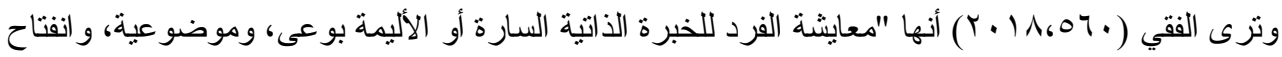

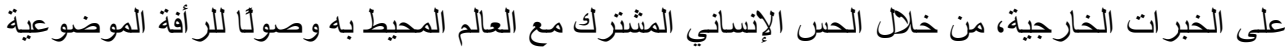

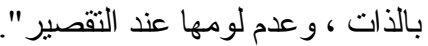

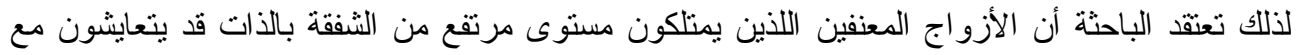

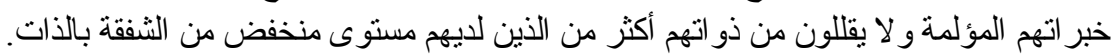

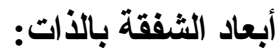

قسمت Neff (2003b الثفقة بالذات إلى ثلاثة أبعاد رئيسة، و أثنارت أن هذه الأبعاد تنقاعل فيما بينها لخلق

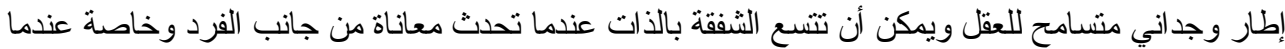

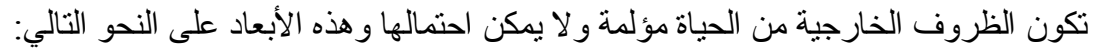

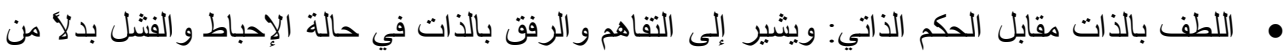

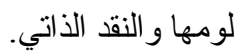
مالإنسانية المشتركة مقابل العزلة: أن خبر ات الفرد جزء من ما يعانيه معظم الأفر اد بدلا من رؤيتها بشكل

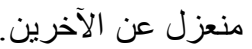
• اليقظة العقلية مقابل الافر اط في التوحد: حالة من الوعي المتو ازن في رؤية وتحديد الأفكار و المشاعر

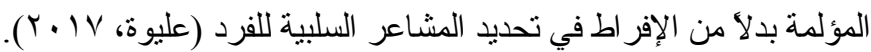

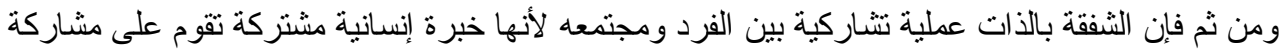

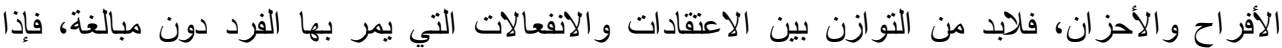

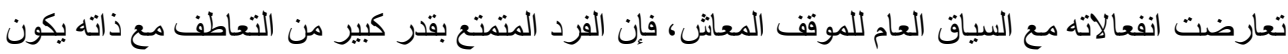

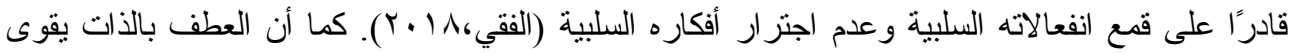

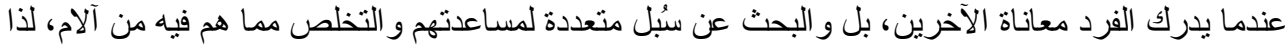
فهو يو ازن بين احتياجاته الثخصية واحتياجات الآخرين. (Neff, 2003)

الدراسات السابقة:

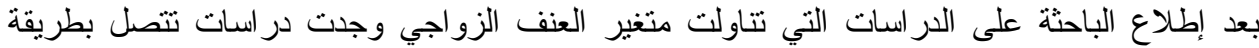
مبانشرة وغير مباثرة بموضوع البحث ، أما متغير الثنفة بالذات لم تجد الباحثة در اسات تتصل بطريقة 
مباثرة (على حد علم الباحثة) ومعظم ما سيتم عرضه يرتبط بطريقة غير مباشرة بالدر اسة وتم عرضهم لاستيضاح طبيعة المتغير.

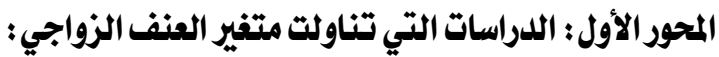

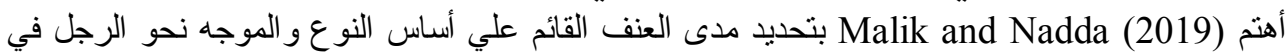
المناطق الريفية في هاريانا، والخصائص و العلاقات الارتباطية الاجنماعية الديموجر افية للعنف القائم علئ التئي

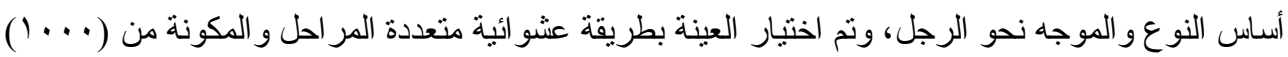

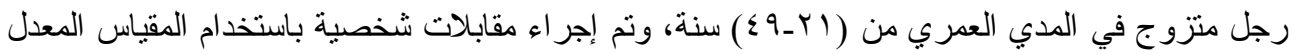

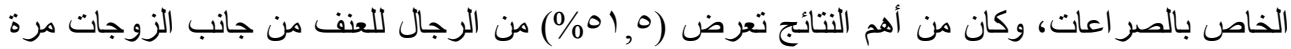

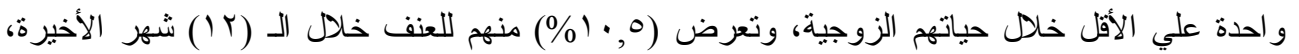

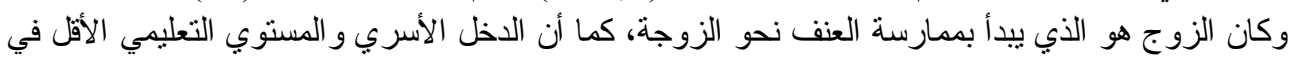

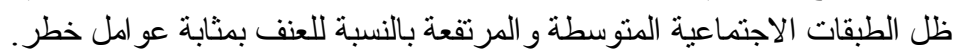

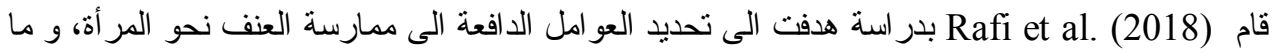

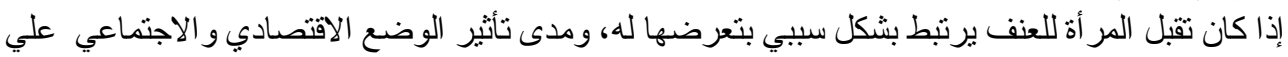

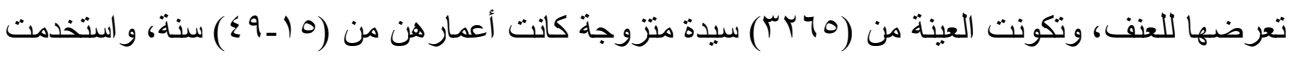

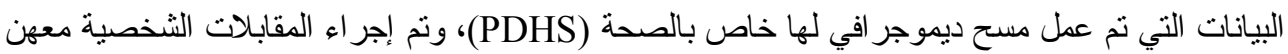

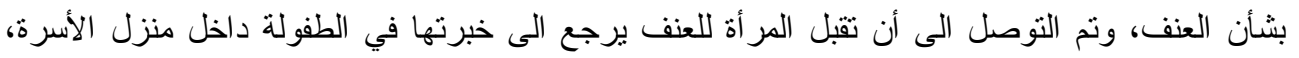

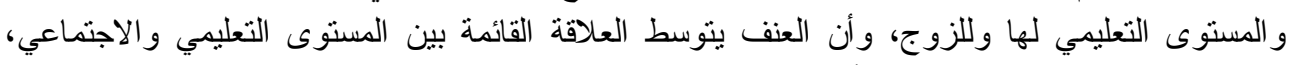

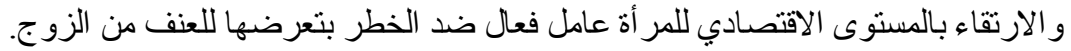

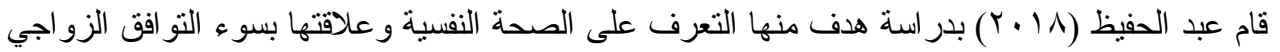

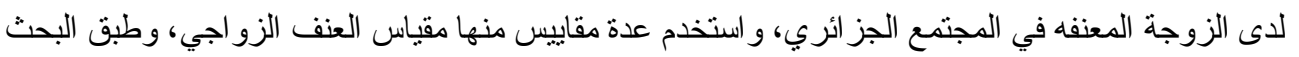

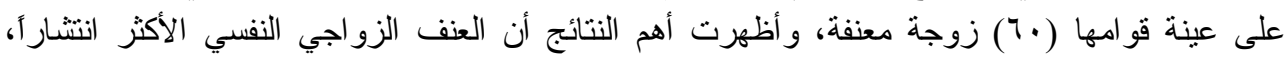

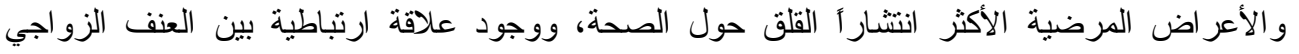

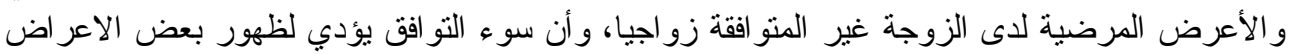

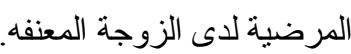

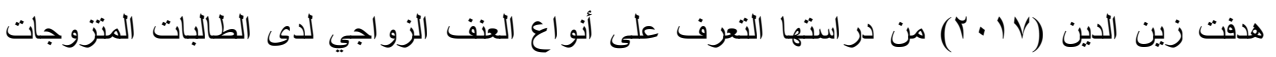

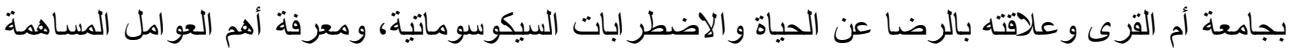

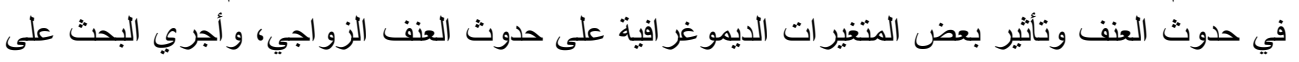

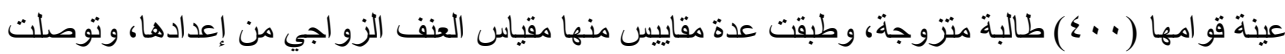

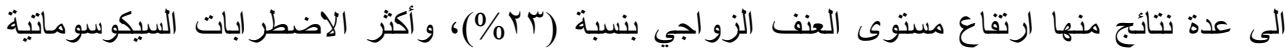
شيو عا لاى العينة هو التونز، الاكتئاب، القلق، الحساسية، عدم الكفاية.

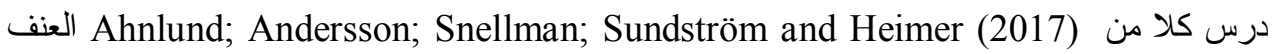

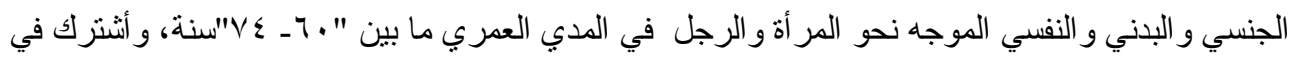




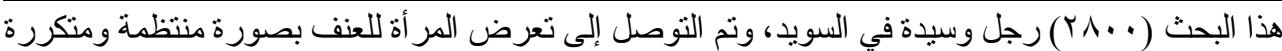

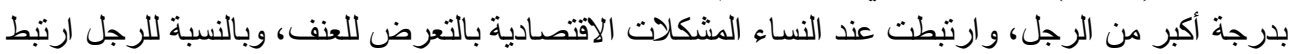

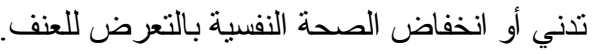

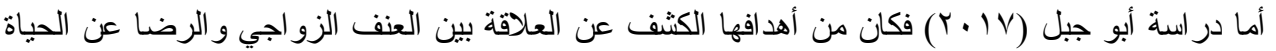

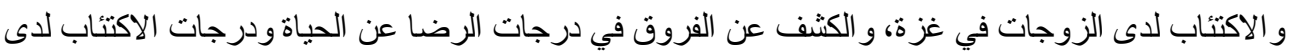

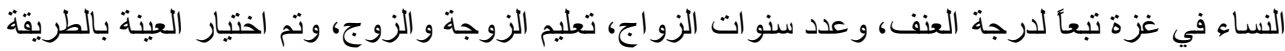

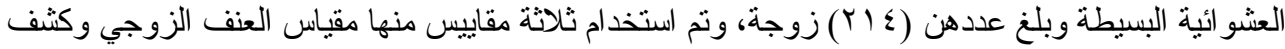

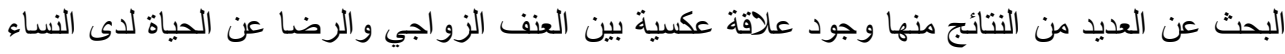

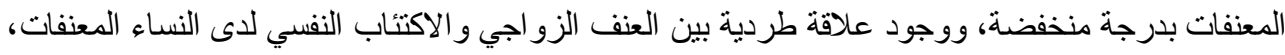

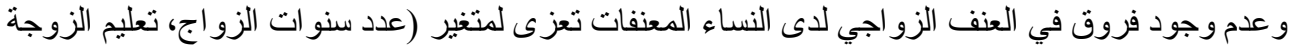

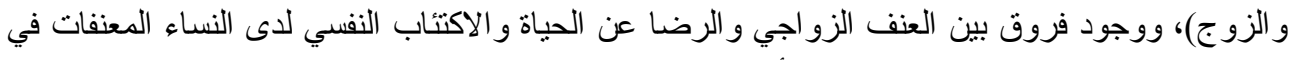

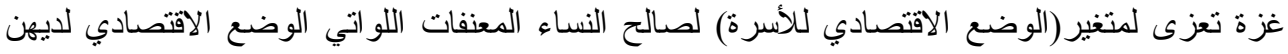
ضنعيف.

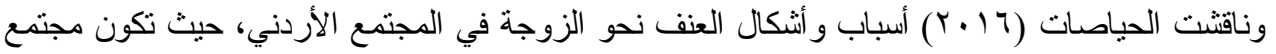

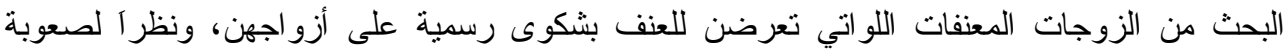

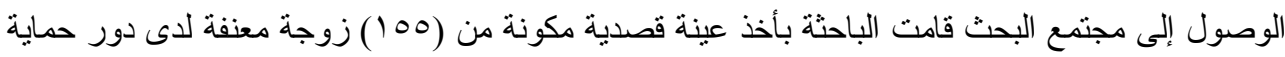

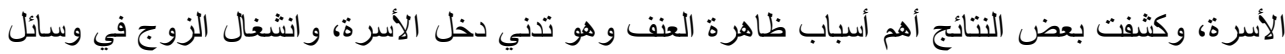

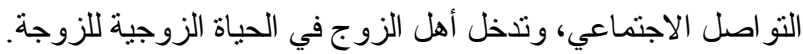

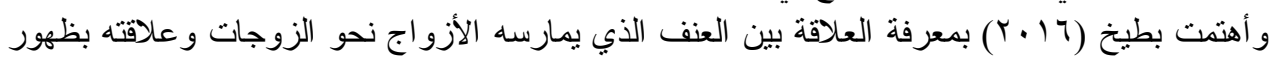

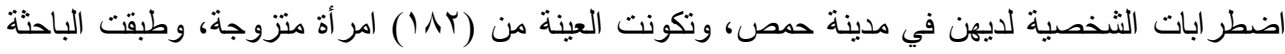

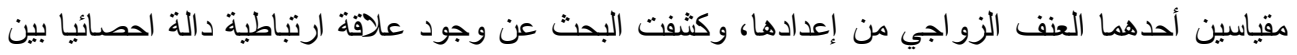

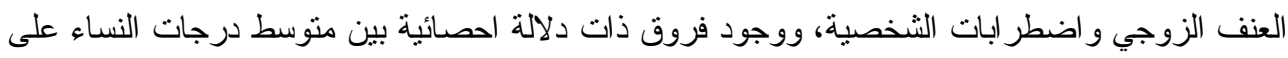
مقياس العنف الزوجي وفقا للمستوى النعليمي للمر أة لصالح النساء النساء الجامعيات.

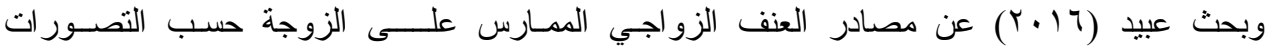

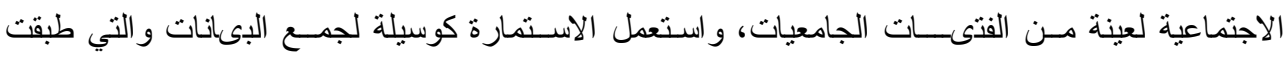

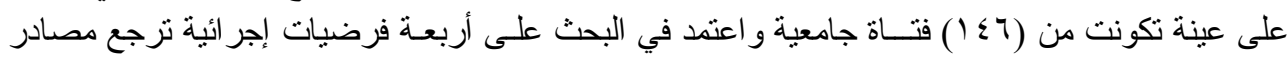

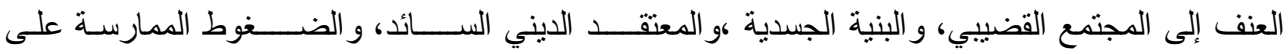

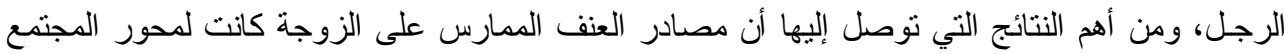

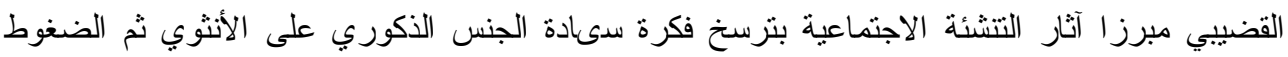

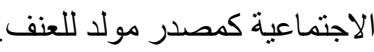

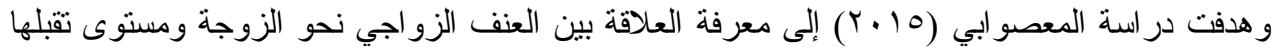

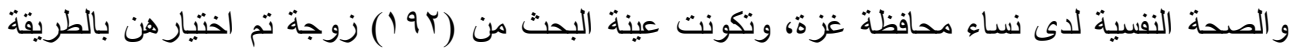
العنقودية العشو ائية، وشملت أدو ات البحث ثلاث مقاييس منها مقياس العنف، وتقبل العنب العنف من إعداد الباحثة، 


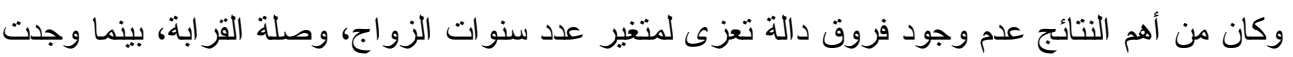

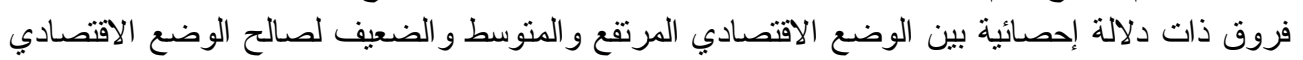

الضعيف.

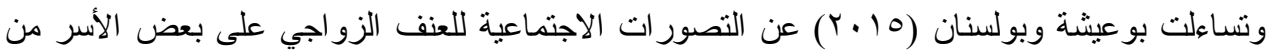

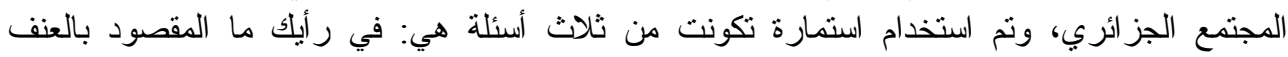

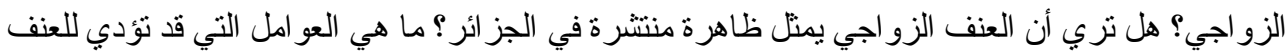

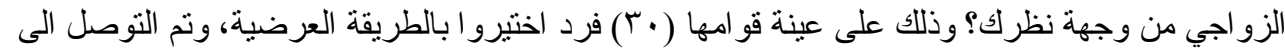

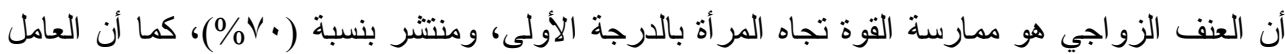

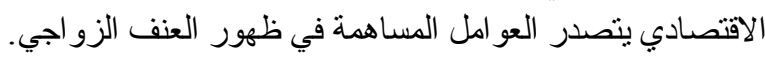

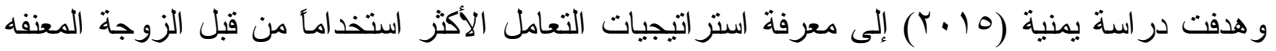

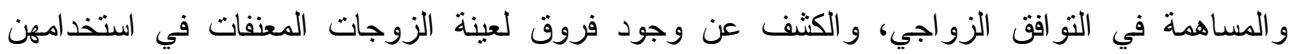

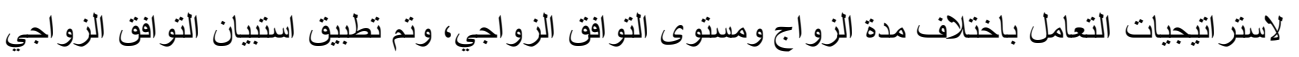

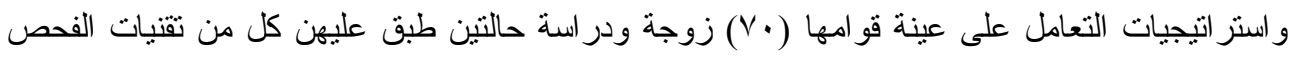

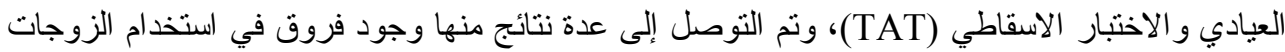

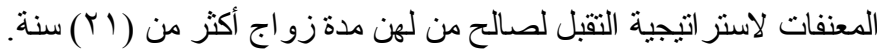

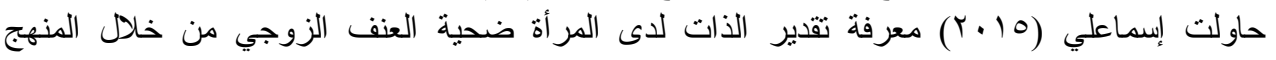

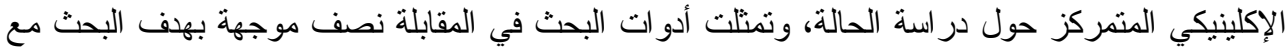

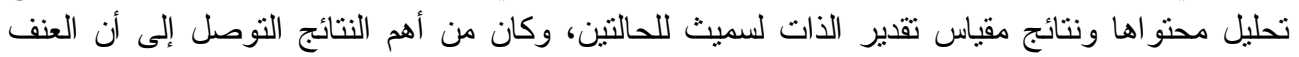

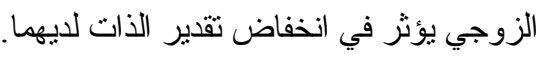

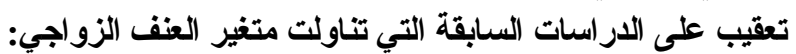

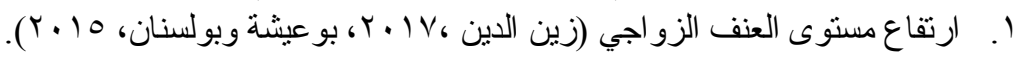

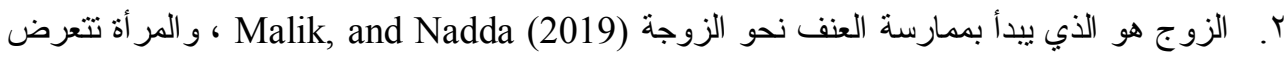

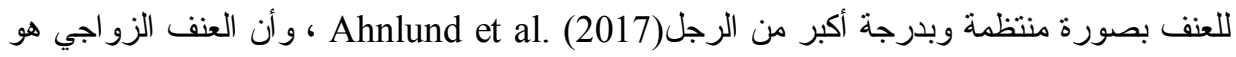

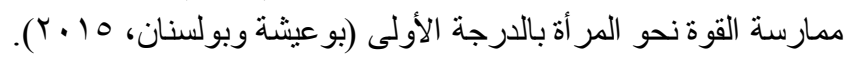

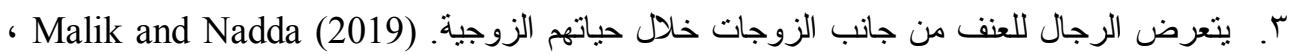

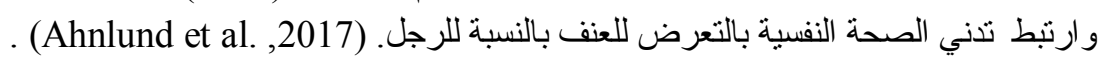

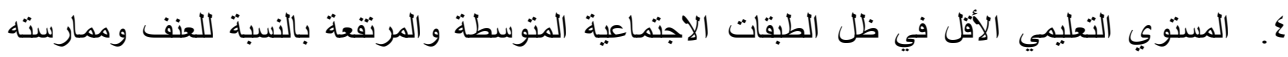

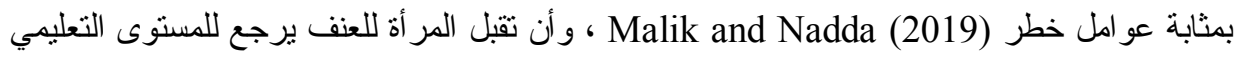

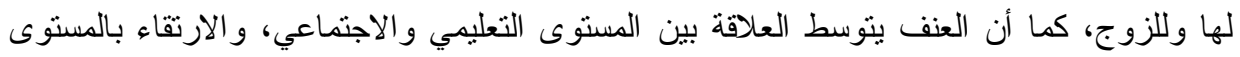

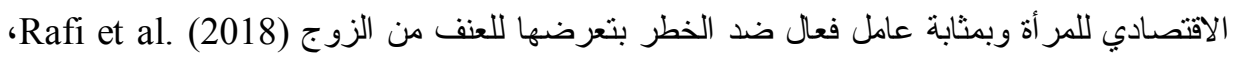

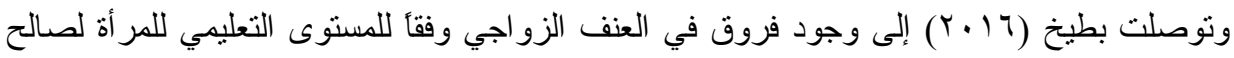

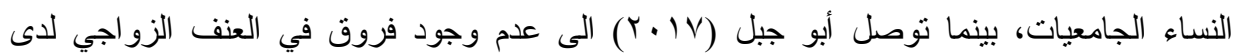
المعنفات تعزى لمتغير تعليم الزوجة و الزوبات 
ه. ارتبطت عند الزوجات المشكلات الاقتصادية بالتعرض للعنف.(2017) . Ahnlund et al. ، وأن أهم

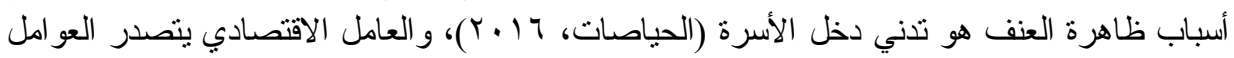

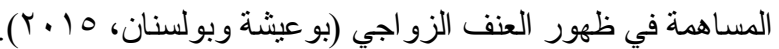

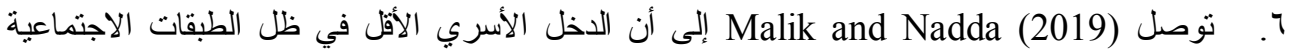

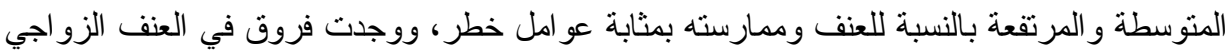

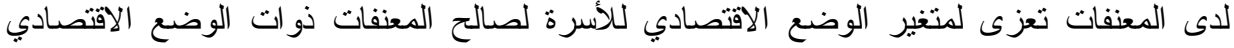

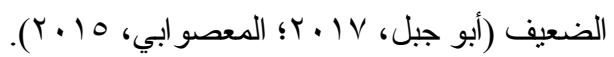

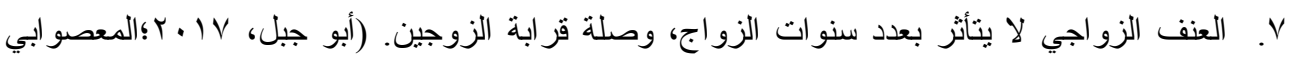

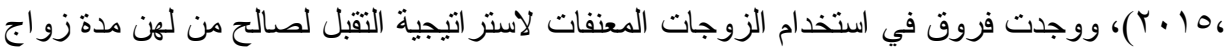

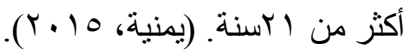
^. . وجود علاقة بين العنف الزو اجي و اضطر ابات الصحة النفسية، وأن الأعر اض المرضية الأكثر انتثار ا

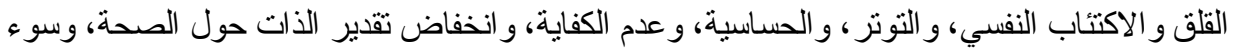

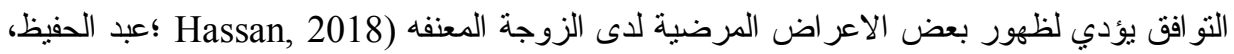

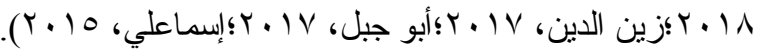

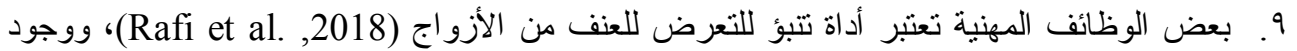

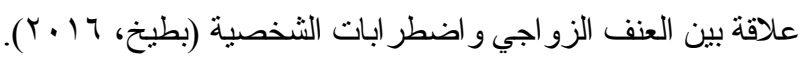

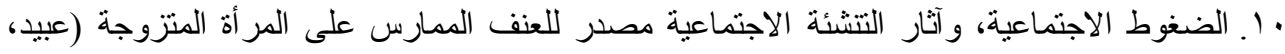

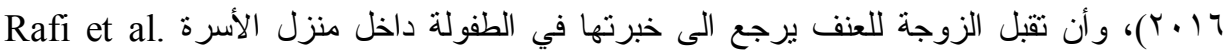

المحور الثاني : الدراسات التي تناولت متفير الشفقة بالذات:

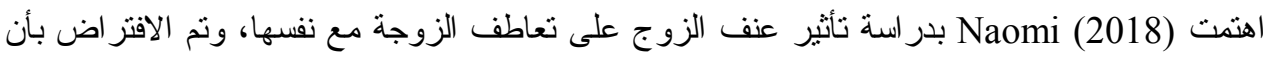

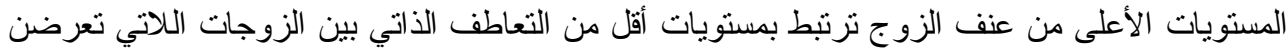

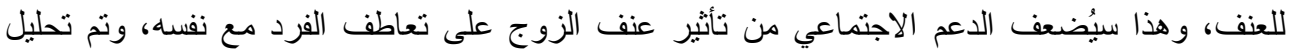

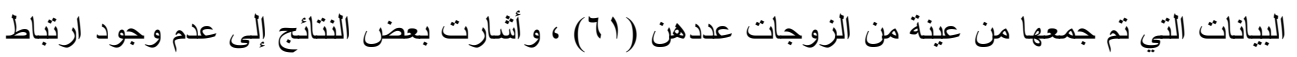

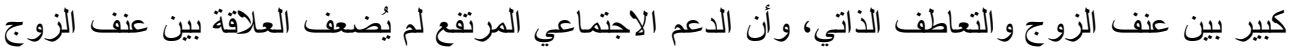

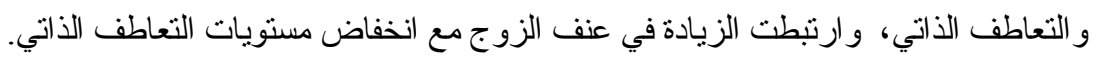

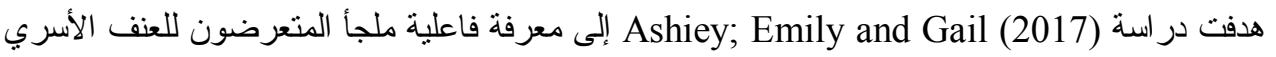

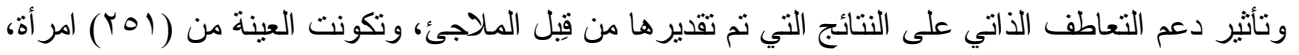

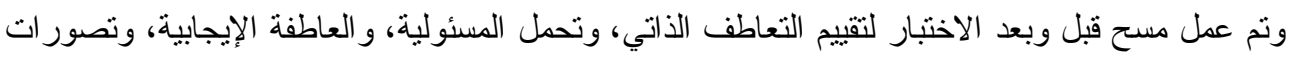

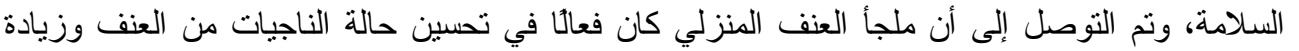

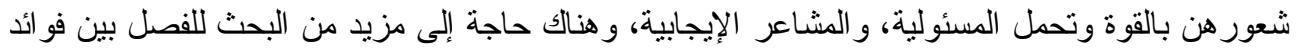

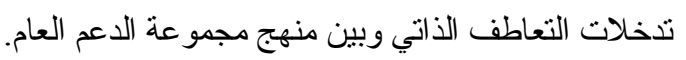


قام Eirini and Stalikas (2017) بدر اسة للتأكد من فعالية برنامج للتعاطف الذاني يسهم في الرفاهية

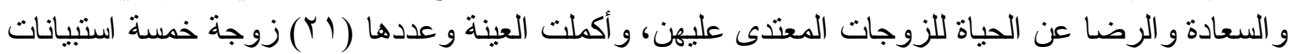

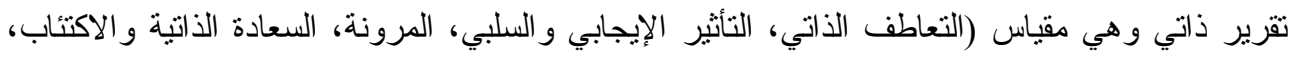

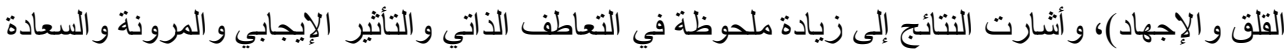

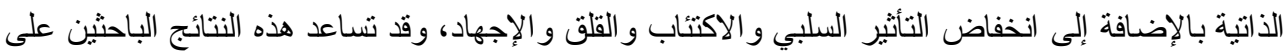

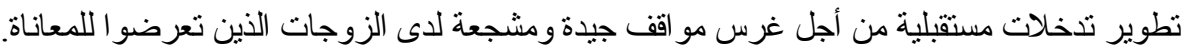

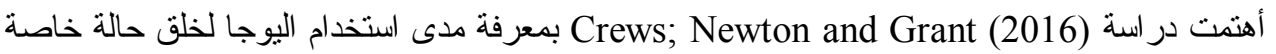

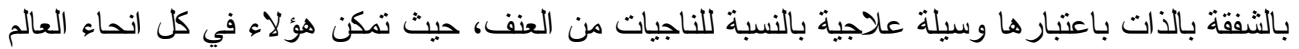

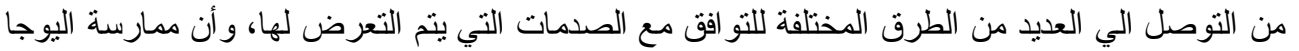

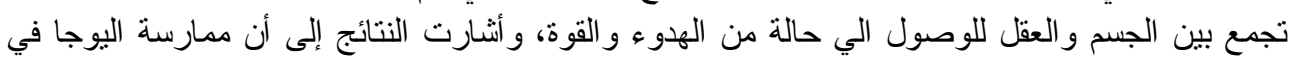

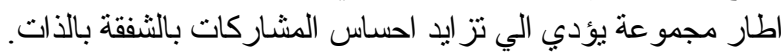

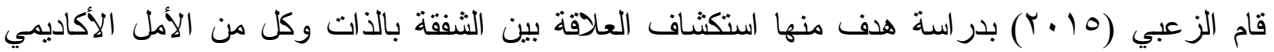

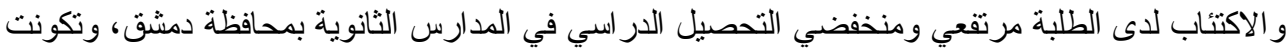

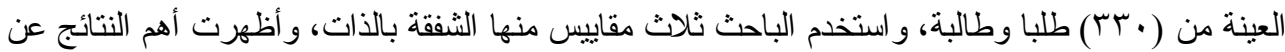

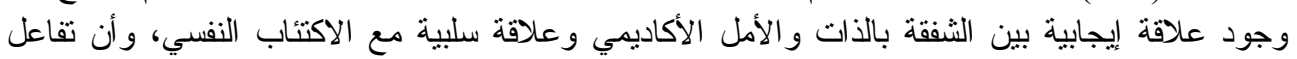

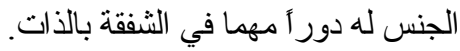

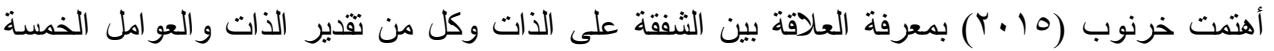

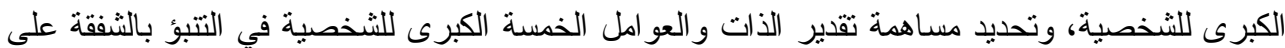

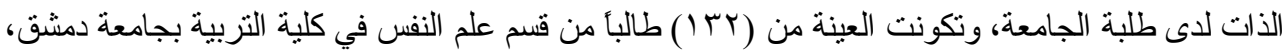

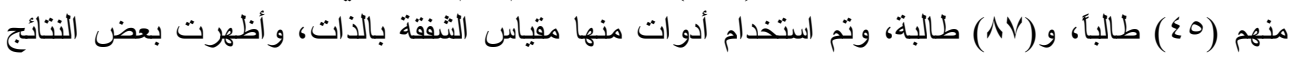

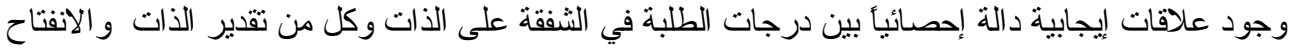
على الخبرة ويقظة الضمير، و أن تقدير الذات وعو امل الطيبة ويقظة الضمير أسهمت إسهامأ دالأ في التباين بالثفقة على الذات.

برى (2015) Lyon أن الاحساس بالوحدة تجربة عامة تتسم بالألم الثديد ومرتبطة بالنتائج السلبية

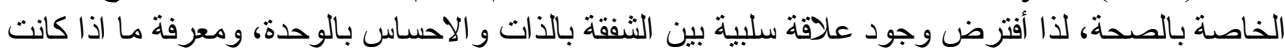

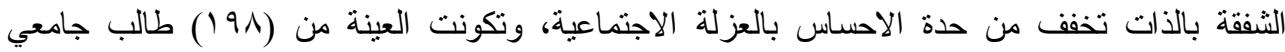

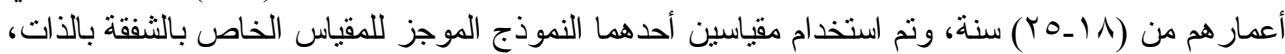

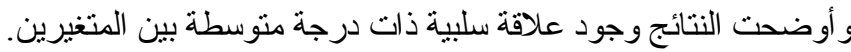

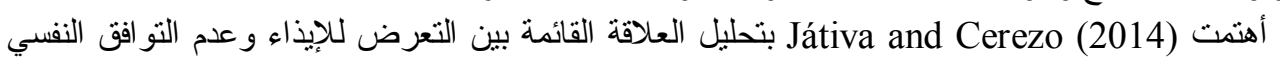

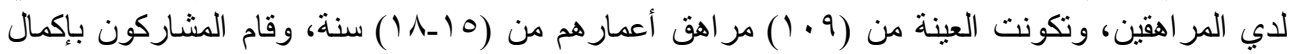

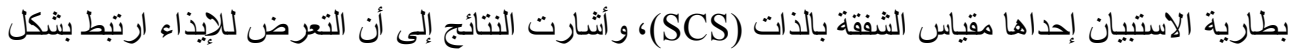

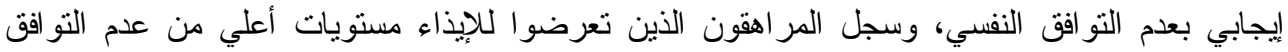

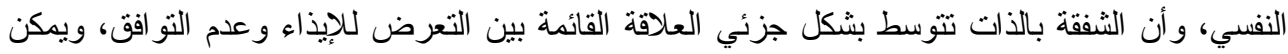

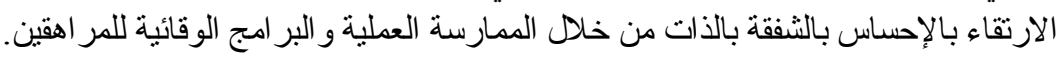




\section{تعقيب على الدراسات السابقة التي تناولت متفير الشفقة بالذات:}

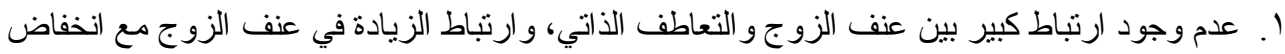

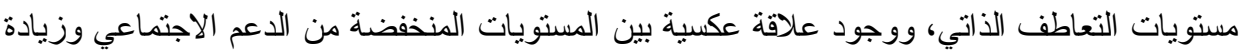

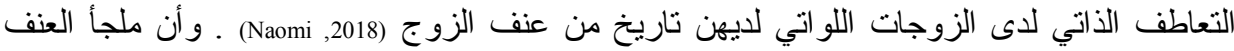

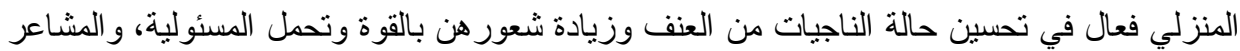
الإيجابية (Ashiey et al. 2017).

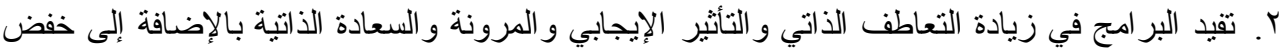

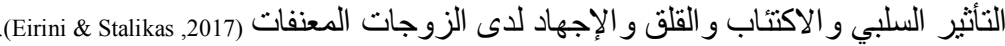

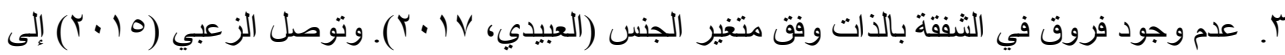
أن تفاعل الجنس له دور أ مهما في الثفقة بالذات.

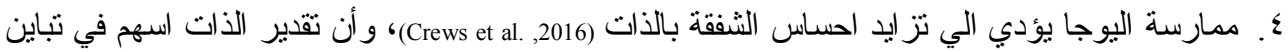
الثفقة بالذات، ووجود علاقات إيجابية في الثفقة بالذات وكل من الثات تلقدير الذات و والانفتاح على الخبرة

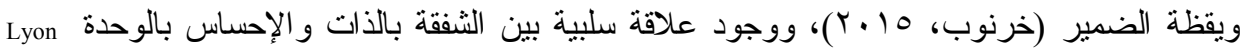
○. تتوسط الثفقة بالذات بشكل جزئي العلاقة القائمة بين التعرض للإيذاء وعدم النو افق، ويمكن الارتقاء بها

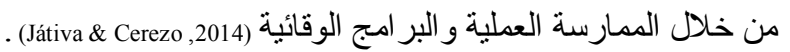

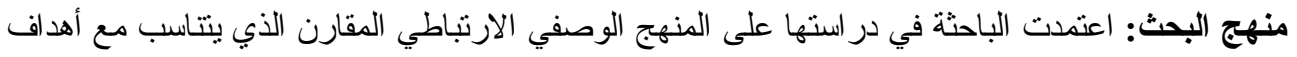

مجتمع البحث: تكون مجتمع البحث من الأزواج السعوديين و المصريين من الجنسين.

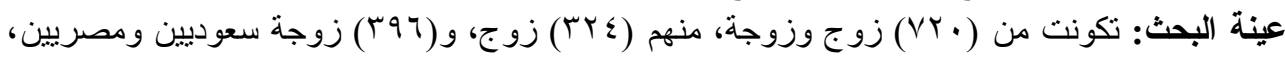

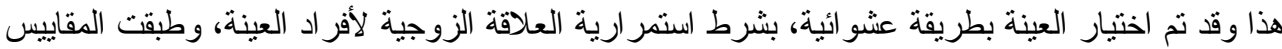

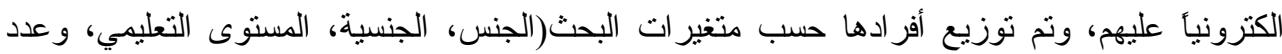

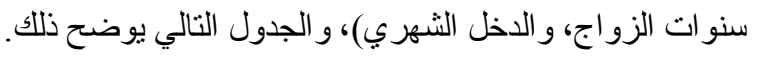

جدول (1) توزيع أفراد العينة تبعاً للمتغير ات اللايموجر افية محل البحث

\begin{tabular}{|c|c|c|c|c|c|}
\hline النسبة. & العلد & الجنسية & | النسبة. & العدد & الجنس \\
\hline$\%$ & $\xi \because \cdot$ & سعودي & $\%$ \$0 & rTE & ذكور \\
\hline 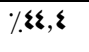 & Tr. & مصري & $\%$ & raq & إناث \\
\hline$\%$ & vr. & المجموع الكلي & $\%$ & vr. & المجموع الكلي \\
\hline النسبة. & العدد & حالة العلاقة الزوجية & | النسبة. & العدد & صلة قرابة بالزوج/الزوجة \\
\hline$\pi / \$ 7,1$ & TTY & مستقرة & $\% \bullet q, r$ & TAT & نعم \\
\hline$\%$ & TAT & غير مستقرة & $\% \eta \cdot, v$ & \&एV & $\boldsymbol{y}$ \\
\hline$\%$ & vr. & المجموع الكلي & $\% \cdots$ & rr. & المجموع الكلي \\
\hline
\end{tabular}




\begin{tabular}{|c|c|c|c|c|c|}
\hline |النسبة./ & 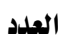 & الجنسية & |النسبة./ & العلد العد & 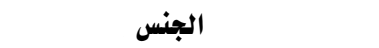 \\
\hline |النسبة./ & العلد & علد سنوات الزواج & النسبة. & العلد العد & المستوى التعليمي \\
\hline$\% \curlyvee \wedge, 7$ & $r \cdot \eta$ & اقل من • اسنوات & $\%$ \%r,O & 179 & الشُهادة التحوسطة فأقل \\
\hline$\%$ & TAY & من •اسنوات لأقل من 10 سنة & $\%$ \%r,O & TrE & الشهادة الثانوية \\
\hline$\%$ \%r,1 & MHI & من اسنة فأكثُر & $\% \llbracket \xi$ & TIV & الشهادة الجامعية \\
\hline$\% 1 \cdots$ & Vr. & المجموع الكلي & $\%$ & Vr. & المجموع الكلي \\
\hline النسبة. & العلد المد & الدخل الشهرية & النسبة.| & 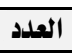 & الدخل الشهري \\
\hline$\% \Upsilon \Upsilon Y\}, \xi$ & IVף & من •.•0اريال إلي اقل من •...بrريال & $\% 1 \varepsilon$ & 1.1 & أقل من •.•0 ريال \\
\hline$\%$ \%r,I & 109 & 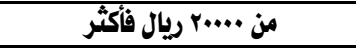 & $\% 19, r$ & $1 \% A$ & 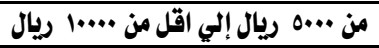 \\
\hline$\%$ & Vr. & المجموع الكلي & $\% r^{\prime}, r$ & $1 \leqslant 7$ & من ·...1 ريال إلي اقل من ·.•10 ريال \\
\hline
\end{tabular}

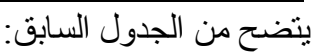

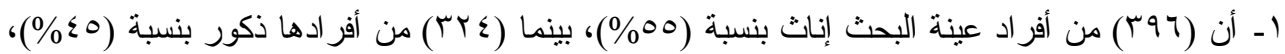

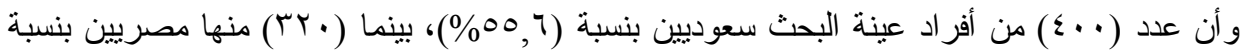

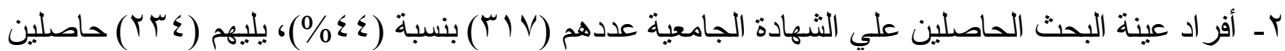

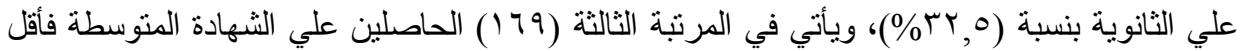

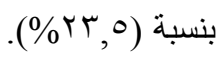

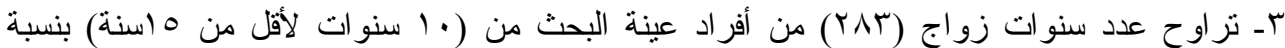

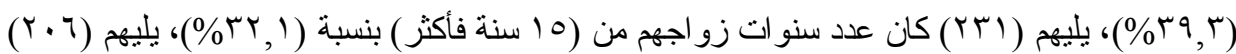

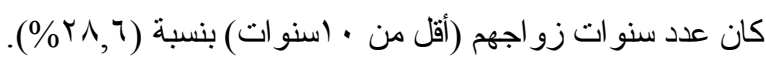

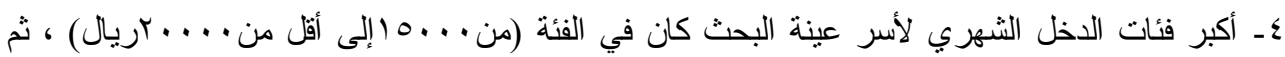

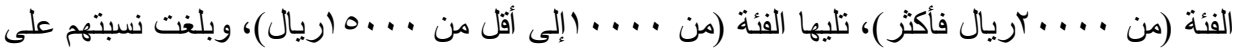

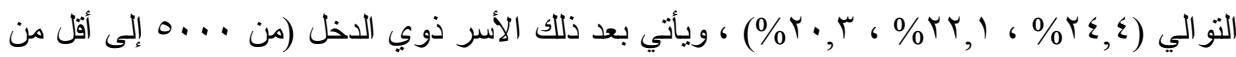

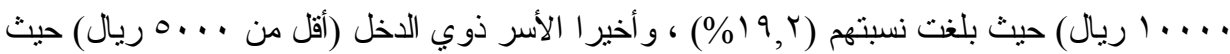

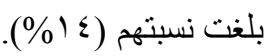

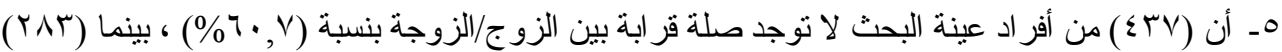

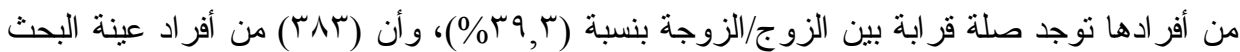

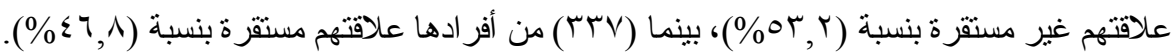

$$
\text { أدوات البحث: } 1 \text { ـ مقياس العنف الزواجي إعداد الباحثة }
$$

قامت الباحثة بإعداد مقياس العنف الزواجي نسخة للزو ج و أخرى للزوجة، وذللك بعد الاطلاع على الأطر

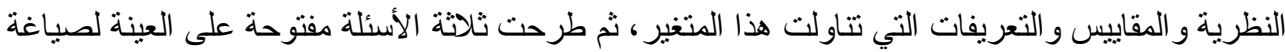




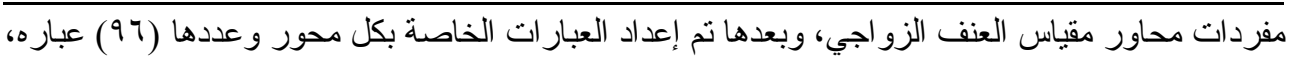

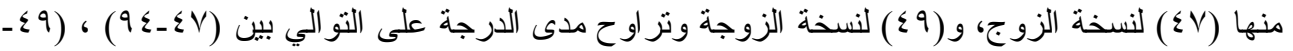

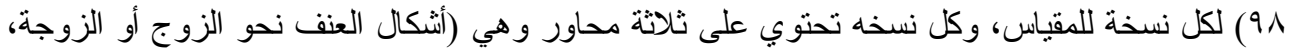

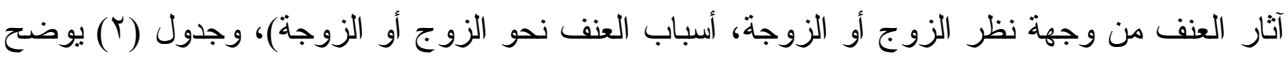

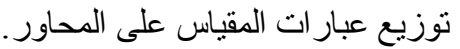

جدول (ץ) محاور وأرقام عبارات مقياس العنف الزواجي (سخة الزوج و الزوجة)

\begin{tabular}{|c|c|c|c|c|c|c|c|}
\hline العبارات & أرقام العبارات & محاور المقياس & $\hat{\imath}$ & العبارات & أرقام العبارات & نسخة الثياس & م \\
\hline 19 & 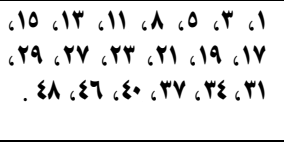 & أسباب العنف & 1 & $T \xi$ & 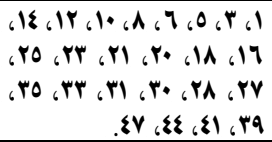 & ألعبفاب أزمو & 1 \\
\hline rr & 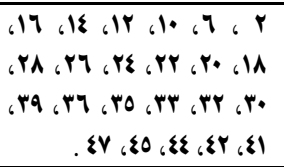 & أشكال العنف & $r$ & 1A & 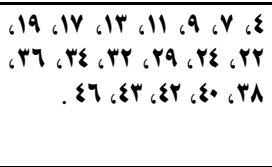 & الثنف نحوال الزفوج & $r$ \\
\hline v & \& & نظم آثار العنف & $r$ & 0 & 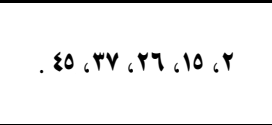 & نظار آثر الثنف & $r$ \\
\hline$\leqslant 9$ & \multicolumn{2}{|c|}{ المجموع الكلي لعبارات المقياس } & $\xi$ & \&V & \multicolumn{2}{|c|}{ المجموع الكلي لعبارات المقياس } & $\xi$ \\
\hline
\end{tabular}

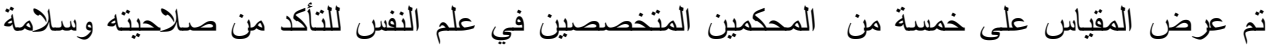

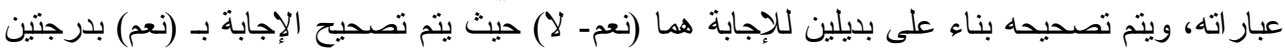

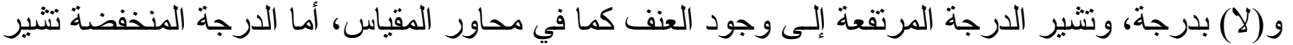

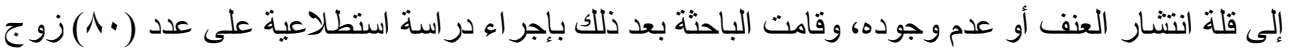

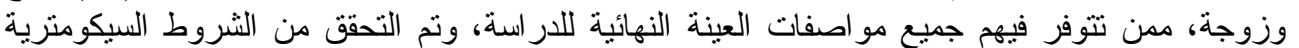

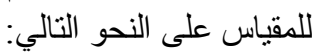

\section{الخصائص السيكومترية لمقياس العنف الزواجي:}

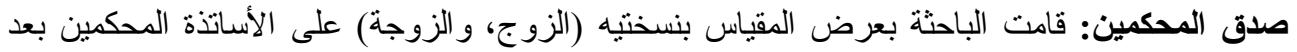

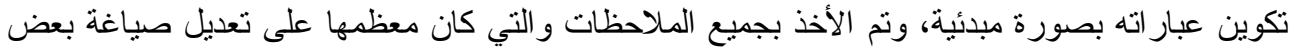

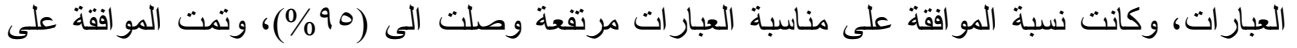

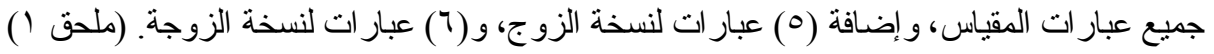

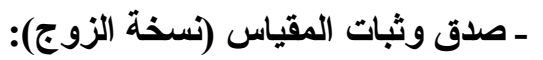

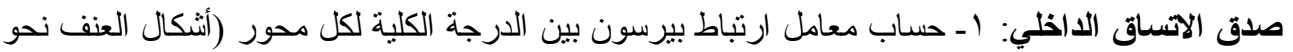

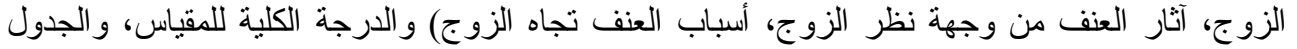
التالي يوضح النتيجة. 


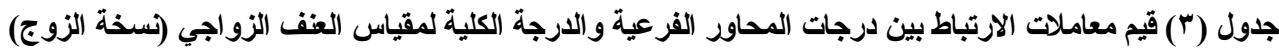
$(\wedge \cdot=\dot{0})$

\begin{tabular}{|c|c|c|}
\hline 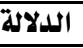 & الارتباط & محاور مقياس العنف الزواجي \\
\hline$\bullet,+1$ & •,AAY & أسباب العنف نحو الزوج \\
\hline$\cdot, \cdot 1$ & •, YOY & أشكال العنف نحو الزوج \\
\hline$\bullet,+1$ & $\cdot, 9 \cdot 1$ & آثار العنف من وجهة نظر الزوج \\
\hline
\end{tabular}

يتضح من الجدول السابق أن قيم معاملات الارتباط جميعها مرتفعة ودالة عند مستوى (1 ل, · ) مما يدل على صدق وتجانس محاور المقياس.

r - حساب معاملات ارتباط بيرسون بين درجة كل عبارة و الدرجة الكلية للمقياس، و الجدول التالي يوضح

جدول ( ) قيم معاملات الارتباط بين درجة كل عبارة والارجة الكلية لمقياس العنف الزواجي (نسخة

$$
\text { النتيجة. }
$$

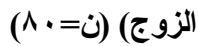

\begin{tabular}{|c|c|c|c|c|c|c|c|c|c|c|c|}
\hline الدلالة & الارتباط & P & الدلالة & الارتباط & P & الدلالة & الارتباط & P & اللدلالة & الارتباط & P \\
\hline$\cdot, \cdot 0$ & $\cdot, 7 \cdot Y$ & בr & $\cdot, \cdot 1$ & -,$v \leqslant 0$ & -ro & $\cdot, \cdot 1$ & •, var & תו & $\cdot, \cdot 1$ & $\cdot, 9 \cdot 1$ & -1 \\
\hline$\bullet,+1$ & •, VOA & - rA & $\cdot, \cdot 1$ & •, बrr & -rY & $\cdot, \cdot 1$ & $\cdot, \wedge \wedge 0$ & $-1 \varepsilon$ & $\cdot, \cdot 1$ & •, Yor & -r \\
\hline$\cdot, \cdot 1$ & $\cdot$, AV々 & . & $\cdot, \cdot 1$ & •, VIV & - & $\cdot, \cdot 1$ & $\cdot, v \circ v$ & -10 & $\cdot, \cdot 1$ & $\cdot, A Y V$ & -r \\
\hline$\cdot, \cdot 1$ & $\cdot, 9 \cdot 7$ & S & $\bullet, \cdot 1$ & $\cdot, \Lambda \cdot 9$ & $-r \Lambda$ & $\cdot, \cdot 1$ & $\cdot, \mathrm{ATA}$ & -17 & $\cdot, \cdot 1$ & •, YYY & كـ \\
\hline$\cdot, \cdot 1$ & $\cdot, 110$ & (8) & $\cdot, .0$ & $\cdot, 7 \xi 1$ & $-r q$ & $\cdot, \cdot 0$ & - , 7ro & -IV & $\cdot, .0$ & $\cdot, 7 Y \wedge$ & -0 \\
\hline$\cdot, \cdot 1$ & - Vฯ & SY & $\cdot, \cdot 1$ & - ^৭४ & -r. & $\cdot, \cdot 1$ & •, $r M$ & -11 & 0,0 &., 7.4 & -7 \\
\hline$\cdot, \cdot 0$ & - & ST & $\cdot, \cdot 1$ & $\cdot, \mathrm{YAl}$ & ו ו- & $\cdot, \cdot 0$ & $\cdot, 71 \mathrm{~V}$ & -19 & $\because .1$ & •, 941 & $-Y$ \\
\hline$\cdot, \cdot 1$ & - AOY & ב & $\cdot, \cdot 0$ & - , 7rq & & $\cdot, \cdot 1$ & - 940 & $-r$. & $\cdot, \cdot 1$ & $\cdot$, AIV & $-\Lambda$ \\
\hline$\cdot, \cdot 1$ & •, Vrr & 20 & $\cdot, \cdot 1$ & $\cdot, 170$ & - & $\cdot, \cdot 1$ & $\cdot, \mathrm{VYA}$ & $-r I$ & $\cdot, \cdot 1$ & $\cdot, \times 70$ & -9 \\
\hline$\cdot, \cdot 0$ & •, 711 & ـ57 & $\cdot, \cdot 1$ & •, 9rr & ש & $\cdot, \cdot 1$ & $\cdot, \wedge \leqslant 1$ & - & $\cdot, \cdot 1$ & $\cdot, \wedge 0\}$ & - I. \\
\hline$\cdot, \cdot 1$ & $\cdot, 914$ & ב. & $\cdot, \cdot 1$ & •, YY\& & -ro & $\cdot, \cdot 1$ & •, YAY & Tr & $\cdot, \cdot 1$ & $\cdot$, Vrq & -11 \\
\hline & & & $\cdot, \cdot 1$ & $\cdot, \wedge \leqslant 0$ & -ry & $\cdot, \cdot 1$ & •, АT々 & -r\& & $\cdot, \cdot 1$ & $\cdot, 91 Y$ & $-I r$ \\
\hline
\end{tabular}

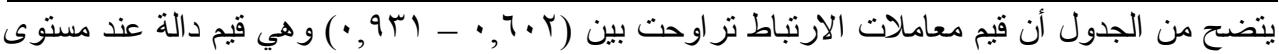

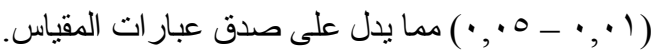

الثبات: تم حساب الثبات عن طريق معامل الفا كرونباخ، و التجزئة النصفية، وجنمان و الجدول التالي يوضح النتيجة.

جدول (•) قيم معاملات الثبات لمحاور مقياس العنف الزواجي (نسخة الزوج) (ن=. ^)

\begin{tabular}{|c|c|c|c|}
\hline جتمان & التجزئة النصفية & الفا كرونباخ & محاور مقياس العنف الزواجي \\
\hline$\cdot, \vee \vee \xi$ & $\cdot, \wedge 10-\cdot, \mathrm{V} \leqslant \varepsilon$ & $\cdot, \vee \vee \vee Y$ & أسباب العنف نحو الزوج \\
\hline$\cdot, \wedge 01$ & $\cdot, 9 \cdot 9-\cdot$, ANI & $\cdot$, ATt & أشكال العنف نحو الزوج \\
\hline •,А৭ץ & $\cdot$, १६I-•,AVr & $\cdot, 9 \cdot 0$ & آثار العنف من وجهة نظر الزوج \\
\hline$\cdot$, Al. & $\cdot, \wedge q r-\cdot, v q$. & $\cdot, A M$ & اللدرجة الكلية للمقياس \\
\hline
\end{tabular}




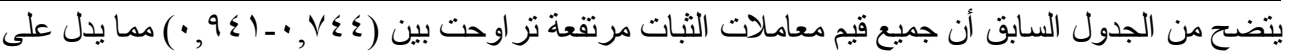

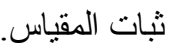

\section{ـ صدق وثبات المقياس (نسخة الزوجة):} صدق الاتساق الداخلي: الـ حساب معامل ارتباط بيرسون بين الدرجة الكلية لكل محور (أثنكال العنف نحو

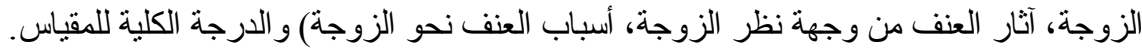

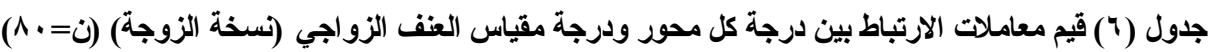

\begin{tabular}{|c|c|c|}
\hline اللالالة & الارتباط & محاور مقياس العنف الزواجي \\
\hline$\cdot, \cdot 1$ & $\cdot, \wedge 0 \xi$ & أسباب العنف نهو الزوجة \\
\hline$\cdot, \cdot 1$ & $\cdot, 94 \wedge$ & أشُكال العنف ندو الزوجة \\
\hline$\cdot, \cdot 1$ & •, var & آثُر العنف من وجهة نظر الزوجة \\
\hline
\end{tabular}

يتضح من الجدول أن قيم معاملات الارتباط جميعها مرتفعة ودالة عند مستوى ( ( , ·) مما يدل على صدق وتجانس محاور المقياس. r - حساب قيم معاملات ارتباط بيرسون بين درجة كل عبارة و الدرجة الكلية للمقياس، و الجدول التالي يوضح جدول (v) قيم معاملات الارتباط بين درجة كل عبارة و الارجة الكلية لمقياس العنف الزواجي (نذة النتيجة.

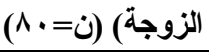

\begin{tabular}{|c|c|c|c|c|c|c|c|c|c|c|c|}
\hline الدلالة & الارتباط & P & الللالة & الارتباط & P & الللالة & الارتباط & A & الللالة & الارتباط & A \\
\hline$\cdot,+1$ & •, Y90 & بـ & $\cdot, \cdot 1$ & $\cdot, \wedge 17$ & - & $\cdot, \cdot 1$ & $\cdot, \wedge T \pi$ & $-1 \varepsilon$ & $\cdot, \cdot 1$ & $\cdot, \times 71$ & -1 \\
\hline 0,0 & -, 7.9 & الــ & •, 1 & •,वसह & ה & •, & -, rVo & -10 & •, & • AOr & $-r$ \\
\hline •, & צr & Tr & •, & •, Yoo & פוף & •, & •, 191 & -17 & •, & •, & $-r$ \\
\hline •, & •, 91ई & r"זב & •, 1 & •,AVY & -r. & •., & צ & - IV & •, & - & كـ \\
\hline •, & • & 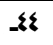 & •, & -, 9.9 & ו"ז- & •, & ri, & -11 & •, & •, & -0 \\
\hline •, & $\cdot, \mathrm{v} \leqslant 1$ & 20 & •, & - • VIT & Tr & •, & זור, • & -19 & •, & • & -7 \\
\hline •, & •, ATV & & •, & • & זrזה & •, & •, & r. & •, & $\because .991$ & $-\gamma$ \\
\hline •, 1 & •, VI & 攺 & •, 1 & $\cdot, \wedge \wedge \mathcal{E}$ & & •, & •,ATM & - r & •, & •.AAV & $-\Lambda$ \\
\hline •, & •,ATY & - & •, & •, & סO & •, & •,901 & - & •., & TI, T\& & -9 \\
\hline$\cdot, \cdot 0$ & •, Tצ६ & 299 & •, & $\cdot, r+9$ & דוזה & •, & •, $Y A F$ & -Tr & •, & $\cdot, r \cdot 4$ & -10 \\
\hline & & & 况, & • & rr & •, & •, АEY & ז & •, & - • & -11 \\
\hline & & & •, & •, AOT & הו & •, & - Tro & STo & •, & $\cdot, \Lambda \cdot V$ & - Ir \\
\hline & & & •, & • • VTr & - & •, & •,VYA & & •, & •, VST & זו- \\
\hline
\end{tabular}

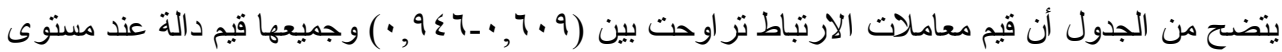
) الثبات: تم حساب الثبات عن طريق معامل الفا كرونباخ، و التجزئة النصفية، وجتمان، و الجدول النالي يوضح 


$$
\text { جدول (^) قيم معاملات الثبات لمحاور مقياس العنف الزواجي (نسخة الزوجة) (ن=•^) }
$$

\begin{tabular}{|c|c|c|c|}
\hline جتمان & التجزئية النصفية & الفا كرونباخ & محاور مقياس العنف الزواجي \\
\hline$\cdot, 9.7$ & $\cdot, 901-\cdot, \wedge 10$ & $\cdot, 911$ & أسباب العنف نحو الزوجة \\
\hline - var & $\cdot, \wedge \xi 1-\cdot, \vee \vee \vee O$ & $\cdot, \Lambda \cdot V$ & أشكال العنف نحو الزوجة \\
\hline •, v\&r & $\cdot, \mathrm{Vqr}-\cdot, \mathrm{Vrq}$ & $\cdot, \mathrm{VOA}$ & آثار العنف من وجهة نظر الزوجة \\
\hline •,ATI & $\cdot, \wedge \wedge q-\cdot, \wedge १ \vee$ & •, $\wedge \llbracket \xi$ & اللدرجة الكلية للمقياس \\
\hline
\end{tabular}

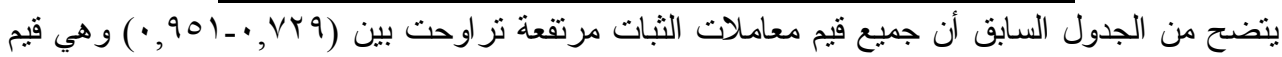

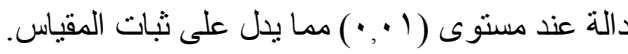

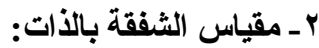

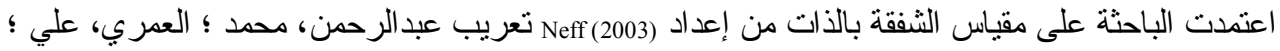

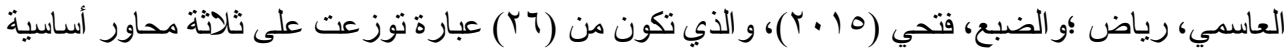
و و(7) فرعية على النحو النالي: ا . اللطف بالذات (أحاول أنّ أكون رفيقاً بنفسي عندما نو اجهني مشكلة ما)، في مقابل الحكم الذاتي (عندما

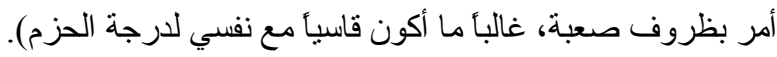

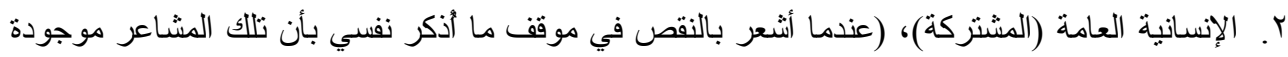
لاى معظم الناس) في مقابل العزلة (يأخذني الثعور بالعزلة الفئة عندما أفكر في أخطائي).

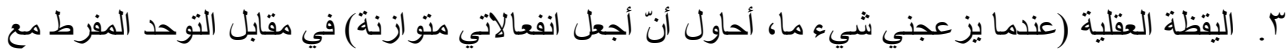

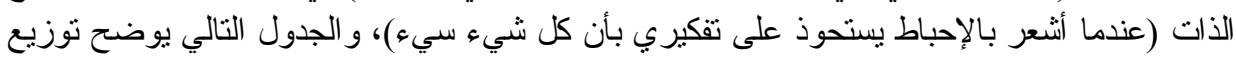

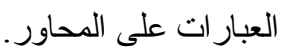
جدول (9) محاور وأرقام العبارات لمقياس الثفقة بالذات

\begin{tabular}{|c|c|c|c|c|c|c|c|c|c|}
\hline العبارات & العبارات & أرقام العبارات & المحور & $A$ & العبارات & العبارات & أرقام العبارات & المحور & $\hat{~}$ \\
\hline$\xi$ & - & $\begin{array}{c}-11-1 r-\varepsilon \\
\text { ro }\end{array}$ & العزلة & $\xi$ & 0 & - & $\begin{array}{c}r r-19-1 r-0 \\
r q .\end{array}$ & الرحمة & 1 \\
\hline$\xi$ & - & $\begin{array}{c}-1 Y-1 \xi-9 \\
r r\end{array}$ & اليقظة العقلية & 0 & 0 & - & $\begin{array}{c}17-11-\wedge-1 \\
r 1\end{array}$ & الحكم الذاتي & r \\
\hline$\xi$ & - & $\begin{array}{c}-r \cdot-\eta-r \\
r \xi\end{array}$ & الإفراط في & 7 & $\xi$ & - & $10-1 \cdot-r_{-} r$ & الإنسانية & $r$ \\
\hline
\end{tabular}

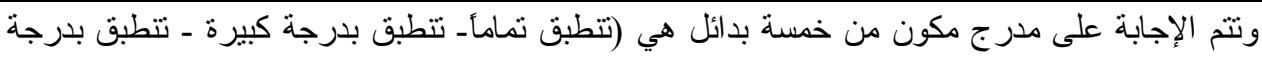

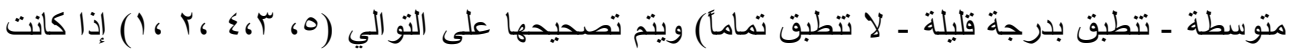

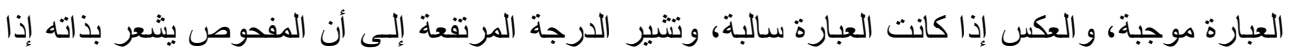

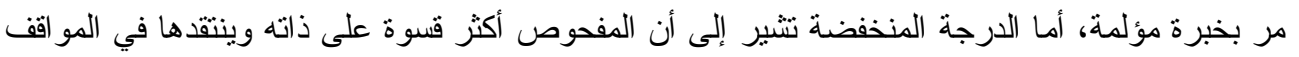




\section{الخصائص السيكومترية لمقياس الشفقة بالذات؛}

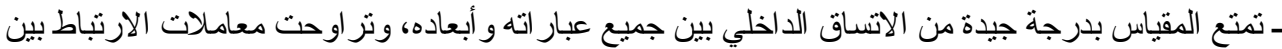

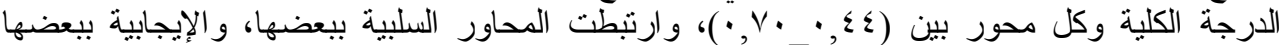

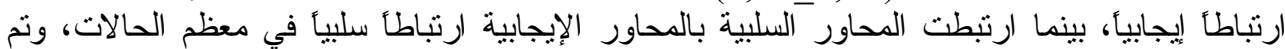

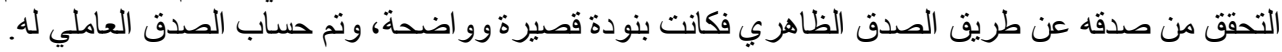

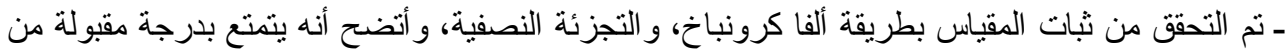

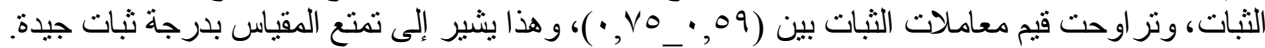

\section{الخصائص السيكومترية للمقياس في البحث:}

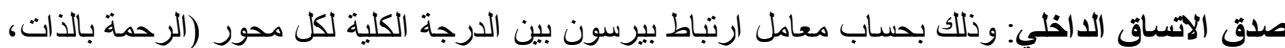

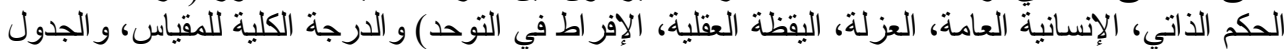

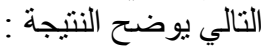

جدول ( • 1) قيم معاملات الارتباط بين درجة كل محور ودرجة مقياس الثفقة بالذات (ن= • ^)

\begin{tabular}{|c|c|c|c|c|c|}
\hline الدلالة & الارتباط & محاور مقياس الشفقة بالذات & الدلالة & الارتباط & محاور مقياس الشفقة بالذات \\
\hline •, & $\bullet, \wedge 9 \bullet$ & العزلة & •, & $\cdot, \lambda \cdot 7$ & الرحمة بالذات \\
\hline$\bullet,+1$ & - 901 & اليقظة العقلية & •, & •, qYZ & الحكم الذاتي \\
\hline •, & •, VYY & الإفراط في التوحد & $\bullet,+1$ & •, $\mathrm{YVY}$ & الإنسانية العامة \\
\hline
\end{tabular}

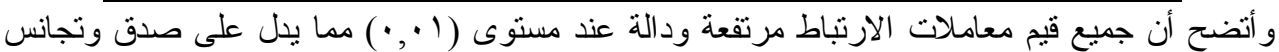

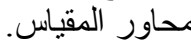
الثبات: تم حساب الثبات عن طريق معامل الفا كرونباخ، و التجزئة النصفية، وجتمان_و الجدول النالي يوضح النتيجة.

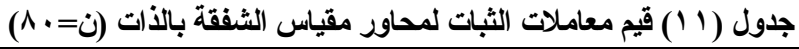

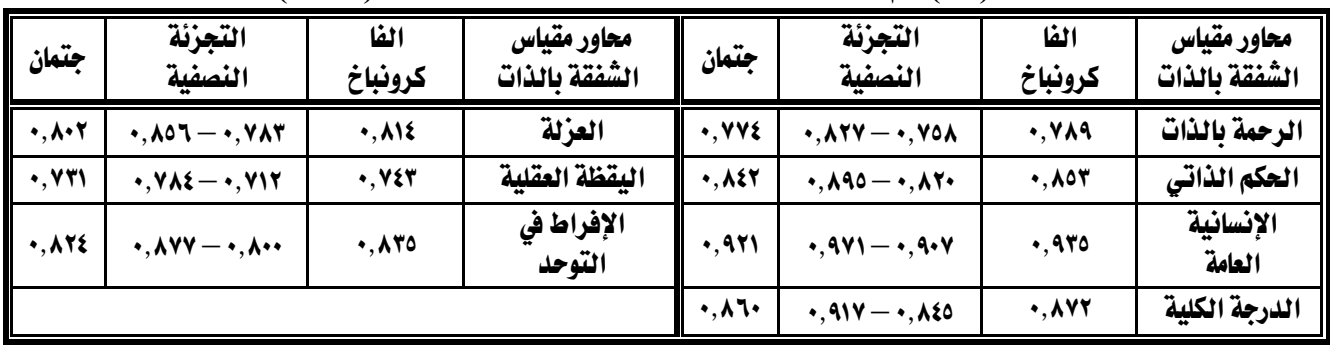

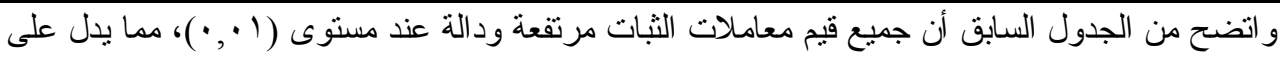
ثبات المقياس.

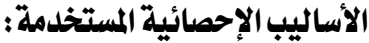

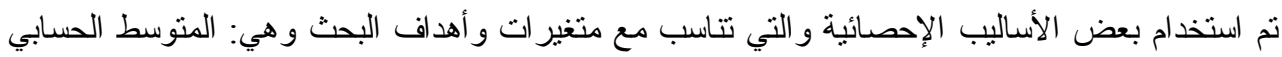

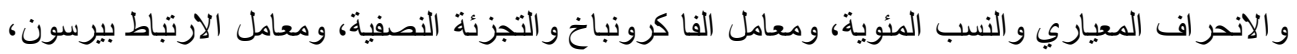
و اختبار (ت) test، وتحليل التباين أحادي الاتجاه، و اختبار شيفيه للمقارنات المرنة المتعددة. 


\section{تثائج البحث وتفسيرها:}

التساؤل الأول: ما مستوى العنف الزواجي و الثفقة بالذات لادى أفراد عينة البحث ؟

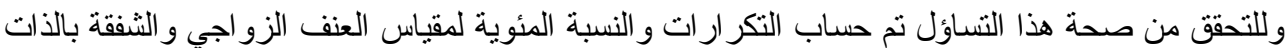
لدى أفر اد عينة البحث ، و والجدول التالي يوضح التبح النتيجة.

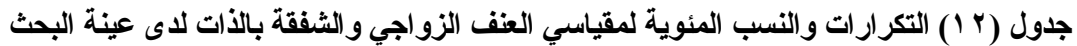

\begin{tabular}{|c|c|c|c|c|c|c|c|c|}
\hline \multicolumn{2}{|c|}{ المجموع الكلي } & \multicolumn{2}{|c|}{ اقل من •0 \% إلى 00\% } & \multicolumn{2}{|c|}{ 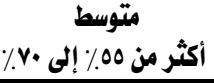 } & \multicolumn{2}{|c|}{ أكثر من • مرتفع } & المستوى \\
\hline النسبة. & العلد & النسبة. & العلد & النسبة. & العلدد & النسبة. & العلد & المقياس \\
\hline$\%$ & Vr. & $\%$ ro, $\mathrm{Y}$ & 110 & $\% \xi r, r$ & III & $\%$ & TY\& & العنف الزواجي \\
\hline$\%$ & rr. & $\%$ rı, r & r.६ & \% & Y \$O & $\%$ \% , & PYI & الشفقة بالذات \\
\hline
\end{tabular}

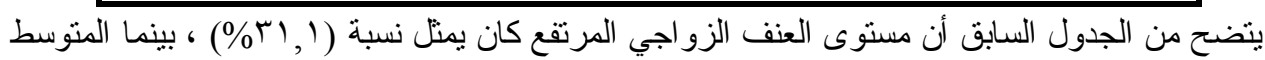

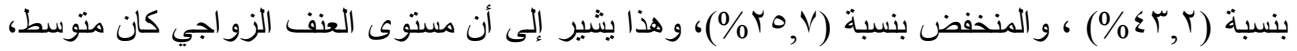

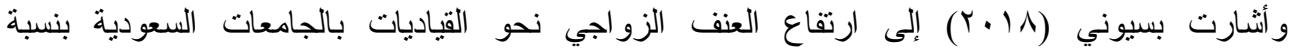

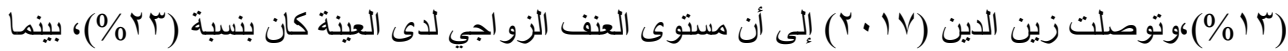

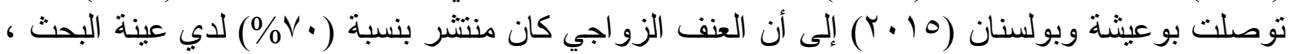

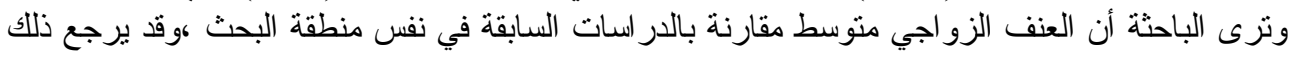

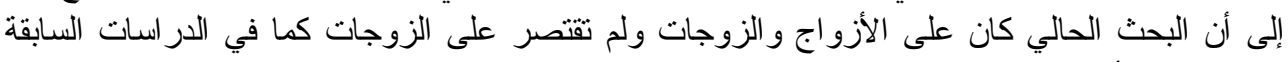

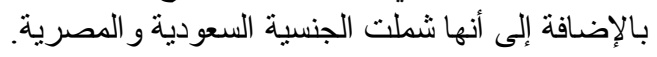

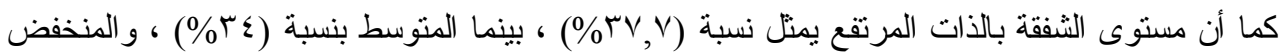

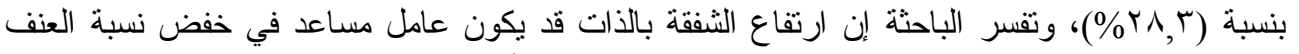

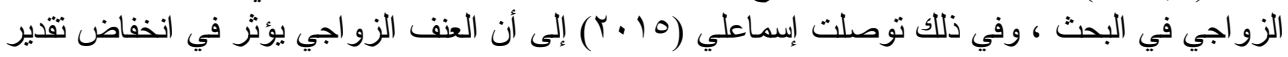

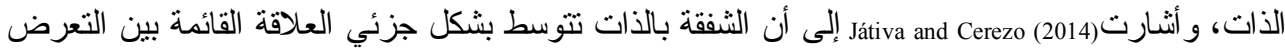

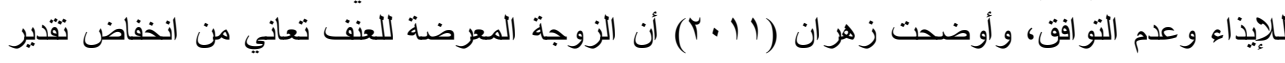

التساؤل الثاني: ما الوزن النسبي لأبعاد الثفقة بالذات لاى أفراد عينة البحث ؟

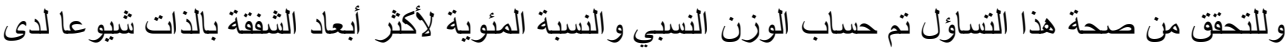

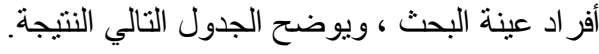

جدول (r ا ) الأوزان النسبية و النسب المئوية لمحاور الثفقة بالذات الأكثر شيوعا لاى أفراد عينة البحث

\begin{tabular}{|c|c|c|c|c|c|c|c|}
\hline الترتيب & المئنبة & الوزن النسبي & الشفقة بالذات & الترتيب & المئوية & النسبي & الشفقة بالذات \\
\hline السادس & $\% 10,0$ & VTrT & العزلة & الأول & $\% \mathrm{IY, \Lambda}$ & 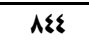 & الرحمة بالذات \\
\hline الثاني & $\% \vee Y, \xi$ & ArY & اليقظة العقلية & الرابع & $\% 19,0$ & VAr & الحكم الذاتي \\
\hline الخامس & $\% 10,9$ & vol & الإفراطد في & الثالثً & $\% 19,9$ & $\Lambda \cdot 1$ & الإنسانية العامة \\
\hline \multicolumn{5}{|c|}{ - } & $\%$ & EVTY & المجموع الكلي \\
\hline
\end{tabular}


يتضح من الجدول السابق أن أكثر أبعاد الثفقة بالذات شيوعا لاى أفراد عينة البحث كان الرحمة بالذات

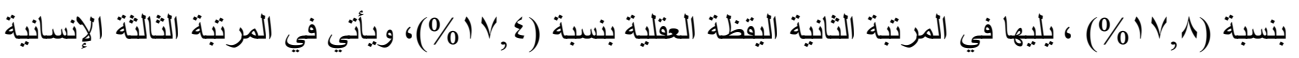

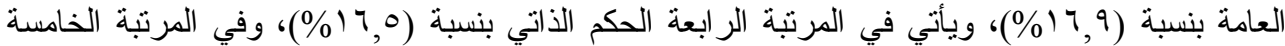

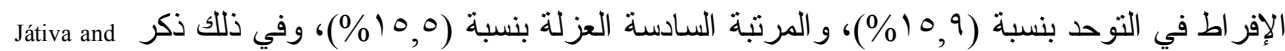

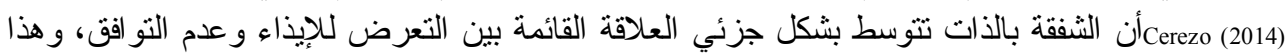

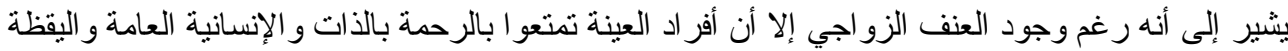

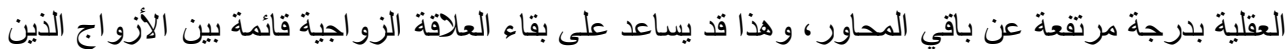

تم اختيار هم على اساس استمر ارية العلاقة الزو اجية. التساؤل الثالث: هل هناك علاقة ارتباطية دالة احصائياً بين العنف الزواجي والثفقة بالأات؟

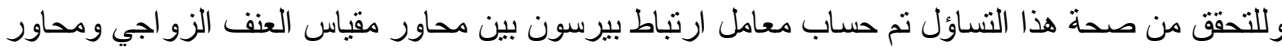

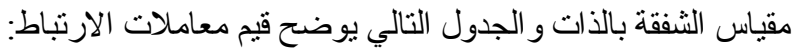
جدول (ع () مصفوفة قيم معاملات ارتباط بيرسون بين محاور مقياس العف الزواجي ومحاور مقياس الثفقة بالأات

\begin{tabular}{|c|c|c|c|c|c|c|c|}
\hline الكلية & الإفراط في & الإقظلة & العزلة & الإنسانية & الذاتي & بالذات & البالذاتة الزفقة \\
\hline **, rro_ & **, qrr & **, , \А & $*, 7.9$ & $* *, \wedge q_{*}$ & *, , tro & **, , 0 Y & ألعباب \\
\hline$* *$, AVI & **.v v r & *, Тז & **, , qसร & $*, 7 \cdot 7$ & $* * \cdot, \Lambda \cdot r$ & **, АTE & أشكال \\
\hline$* *_{*}, \mathrm{AlO}$ & $*, 711$ & $* *, r \cdot \lambda$ & $* *$, AOr & $* *_{\bullet}, \mathrm{V} \leqslant 1$ & $* *, 910$ & $*_{*}^{*, 7 \leqslant .}$ & آثار العنف \\
\hline$*_{*}$, var_ & **, , A\&I & $* *_{\bullet}$, YOA & **, ArY & $* *$, หIa & $* *, \wedge 77$ & $* *$, , $\vee \varepsilon$ & الكلية \\
\hline
\end{tabular}

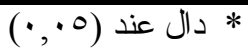

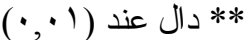

يتضح من الجدول السابق وجود علاقة ارتباطية عكسية بين محاور مقياس العنف الزو اجي وبعض محاور

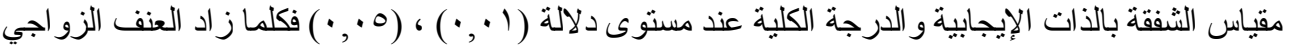

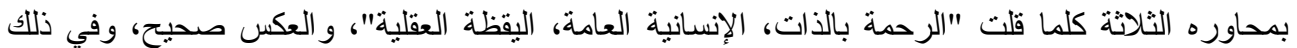

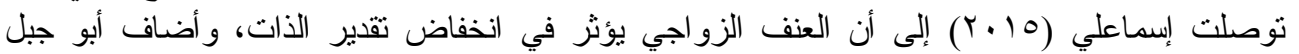

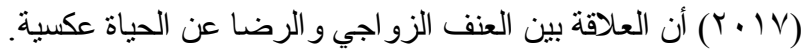

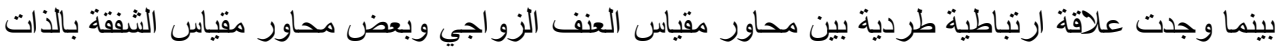

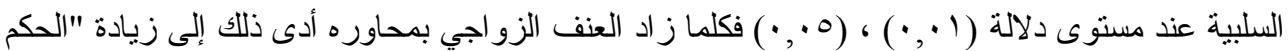

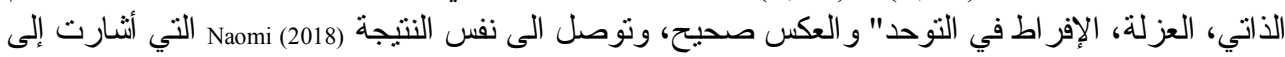

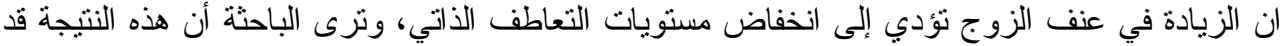

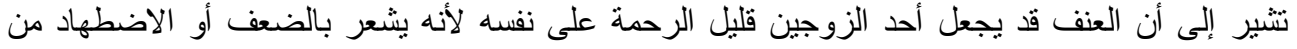


الطرف الآخر ، وكلما أثتد العنف تجاهه ز ادت قسوته و الحكم على ذاته وشعوره بأنه الوحيد الذي يعاني دون الأخرين فتضطرب انفعالاته ويفكر في كل ما هو سلبي. التساؤل الر ابع: هل هناك فروق ذات دلالة إحصائية بين منتوسطات درجات أفر اد العينة في العنف الزو اجي

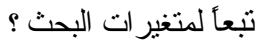
وللتحقق من هذا التساؤل تم استخدام اختبار (ت)، واختبار تحليل التباين الأحادي لدرجات أفر اد العينة في

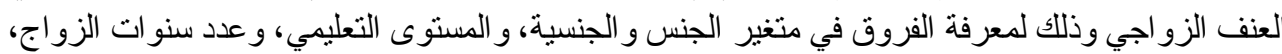
و الدخل الثهري و الجدول التالي يوضيح النتيجة:

| - - متغير الجنس والجنسية:

جدول (0 10) الفروق في متوسطات درجات مقياس العنف الزواجي تبعا لمتغيري الجنس والجنسية

\begin{tabular}{|c|c|c|c|c|c|c|c|}
\hline الدلالة & (ت) & درجات الحرية & العينة & الالانحراف & الحتوسط & \multicolumn{2}{|c|}{ المتفير } \\
\hline \multirow{2}{*}{ لدال عند (ال•,·) } & \multirow{2}{*}{$r r, q .1$} & \multirow{2}{*}{ Min } & rYs & $\Lambda, \cdot 9 Y$ & $11 \%$, roy & الزوج & \multirow{2}{*}{ الجنس } \\
\hline & & & raq & $7, Y Y I$ & $\wedge \wedge, V+1$ & الزوجة & \\
\hline \multirow{2}{*}{ 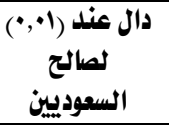 } & \multirow[b]{2}{*}{ Ir, זq. } & \multirow[b]{2}{*}{ VIA } & $\xi \cdots$ & $\Lambda, 11 Y$ & $1.0,011$ & سعودي & \multirow[b]{2}{*}{ الجنسية } \\
\hline & & & rr. & $v \cdot$, ro & $91,\{\cdots$ & مصري & \\
\hline
\end{tabular}

يتضح من الجدول السابق وجود فروق بين الجنسين في مقياس العنف الزواجي حيث بلغت قيمة (ت)

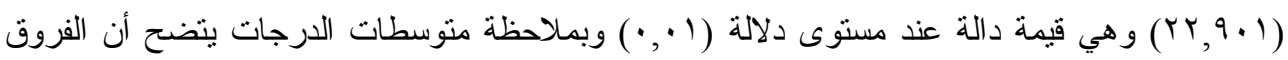

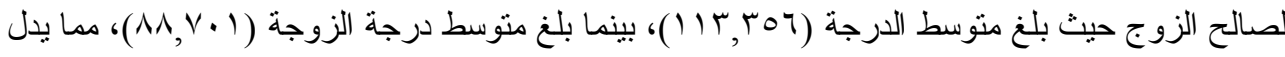

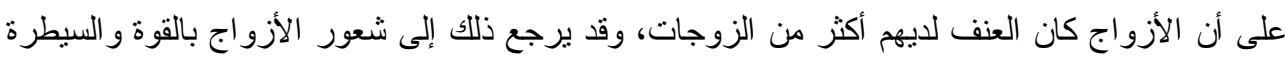

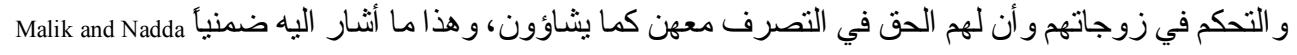

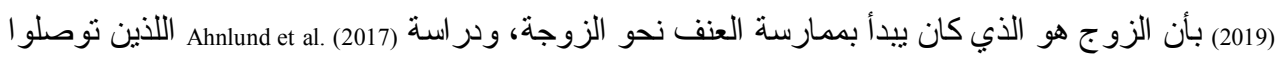

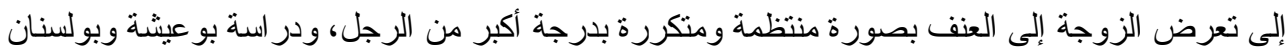

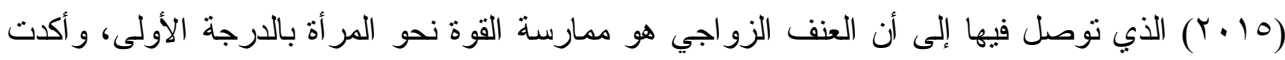

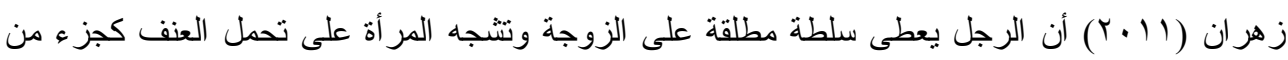
دور ها في سبيل الحفاظ على أسرتها.

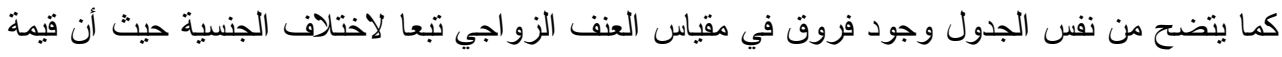

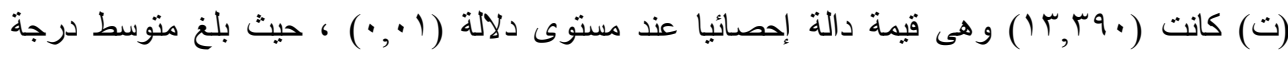

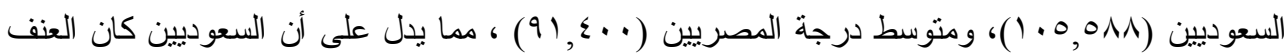

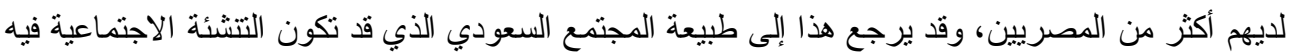

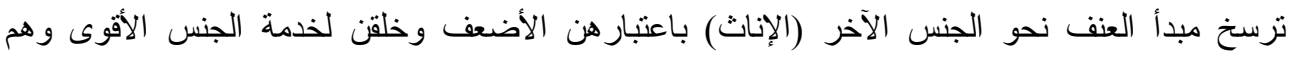

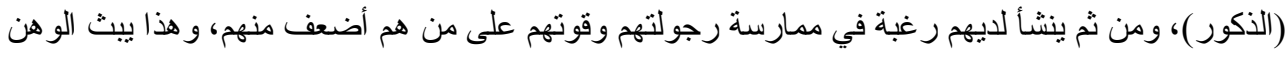


و الضعف و التسامح لاىى الإناث وقبولهن بالذل و المهانة، مما يشعر الزوجة بضعفها و عدم القدرة على مو اجهة

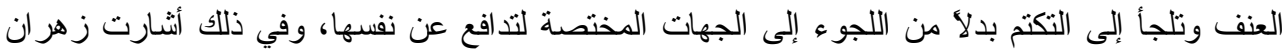

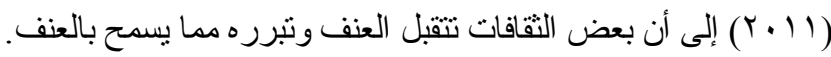

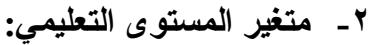

جدول (1 1) الفروق في منوسطات درجات مقياس العنف الزواجي تبعا لمتغير المستوى التعليمي

\begin{tabular}{|c|c|c|c|c|c|}
\hline الدلالة & قيمة (ف) & درجة الحرية & متوسط المربعات & مجموع المربعات & المستوى التعليمي \\
\hline \multirow{3}{*}{ 1י,•• دال } & \multirow{3}{*}{$\Delta 0, \cdot \varepsilon r$} & $r$ & $|r Y q \cdot, r \||$ & rOON•,ZYY & بين المججموعات \\
\hline & & VIV & FrY, rYY & $1777 \cdot 7,0.8$ & داخل المجموعات \\
\hline & & $\mathrm{VIq}$ & & 19rIA7,9Y9 & المجموع الكلي \\
\hline
\end{tabular}

يتضح من الجدول السابق إن قيمة (ف) كانت (Tـ •,00) و هى قيمة دالة إحصائيا عند مستوى (1 •, • )، مما يدل على وجود فروق بين درجات أفر اد العينة في العنف الزواجي تبعا لمتغير المستوى التعليمي، ولمعرفة وفئ

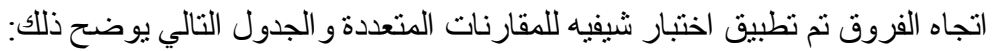

جدول (IV) المقارنات المتعددة في درجات مقياس العنف الزواجي تبعا للمستوى التعليمي

\begin{tabular}{|c|c|c|c|}
\hline 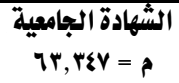 & الشهادة الثانوية & 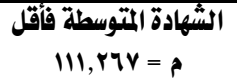 & المستوى التعليمي \\
\hline & & - & الشهادة المتوسطة فأقل \\
\hline & - & **ץч, 974 & الشهادة الثانوية \\
\hline - & $*_{*} *_{\varphi}, 90 \xi$ & $* * \xi Y, q r$. & الشهادة الجامعية \\
\hline
\end{tabular}

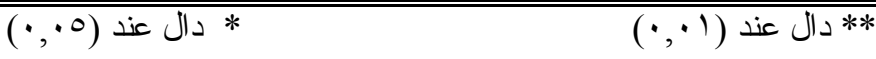

يتضح من الجدول السابق وجود فروق في العنف الزو اجي بين أفر اد العينة الحاصلين علي الثهادة المتوسطة

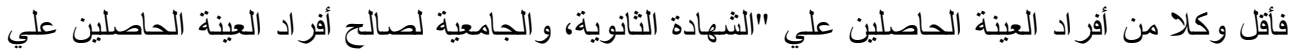

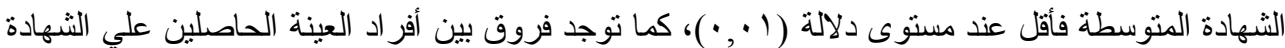

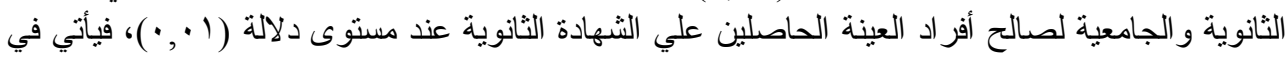
المرتبة الأولى أفر اد العينة الحاصلين علي الثهادة المتوسطة فأقل حيث كان العنف لديهم أكثر ، ثم أفر اد العينة الحاصلين علي الثهادة الثانوية في المرنبة الثانية، يلي ذلك الحاصلين علي الثهادة الجادعية في المادية المرنبة الأخيرة، وهذا يوضح ضرورة الاهتمام بتعليم المر أة الذي يجعلها على وعي بكيفية مقاومة العنف الو اقع فئ عليها، و هذا ما توصل اليه (2019) Malik and Nadda حيث أثنار ا الى أن مستوى التعليم الأقل يمثل

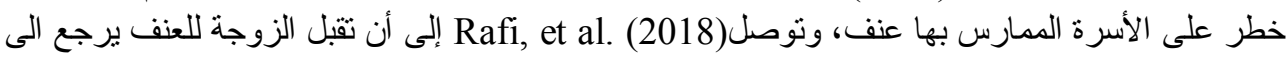

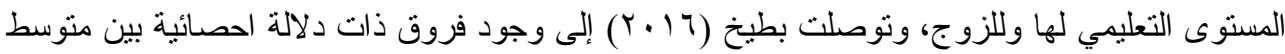
درجات الزوجات على مقياس العنف الزوجي وفقا للمستوى التعليمي للمر أة لصالح النساء الجامعيات، بينما

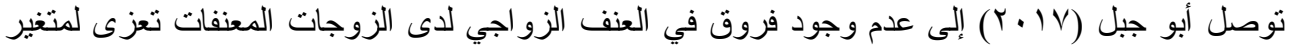

$$
\text { تعليم الزوجة و الزوج، تون }
$$

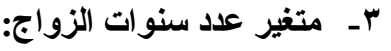


جدول (1 1 ) الفروق في درجات مقياس العنف الزواجي تبعاً لمتغير عدد سنوات الزواج

\begin{tabular}{|c|c|c|c|c|c|}
\hline الدلالة & قيمة (ف) & درجات الحرية & متوسط المربعات & مجموع المربعات & عدد سنوات الزواج \\
\hline \multirow{3}{*}{ ו•.• دال } & \multirow{3}{*}{ ro, 000} & $r$ & IrrYY, r.O & $r \xi 00 \xi, \xi \cdot 9$ & بين المجهوعات \\
\hline & & vir & $r \leqslant 0, r \cdot r$ & TEYOAY, 10. & داخل المجموعات \\
\hline & & $\mathrm{YIq}$ & & FrYITY,OOQ & المجموع الكلي \\
\hline
\end{tabular}

يتضح من الجدول السابق إن قيمة (ف) كانت (10,000) و هى قيمة دالة إحصائيا عند مسنوى (1 (, •) ،

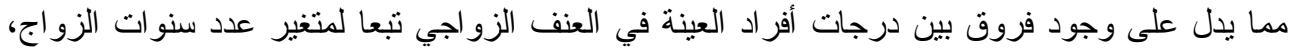

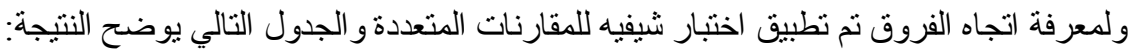

جدول (9 () المقارنات المتعددة في درجات مقياس العنف الزواجي تبعاً لمتغير عدد سنوات الزواج

\begin{tabular}{|c|c|c|c|}
\hline 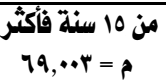 & 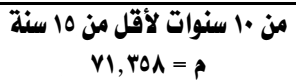 & 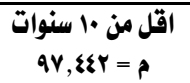 & عدد سنوات الزواج \\
\hline & & & اقل من •1 سنوات \\
\hline & - & $* * r y, \bullet \wedge \varepsilon$ & من •اسنوات لأقل من اسنة \\
\hline- & $*_{r, r o 0}$ & $* * r \wedge,\{r q$ & من ماسنة فأكثَر \\
\hline
\end{tabular}

يتضح من الجدول السابق وجود فروق في العنف الزو اجي اللذين كانت مدة زو اجهم اقل من • ل سنوات

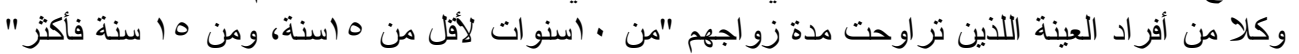

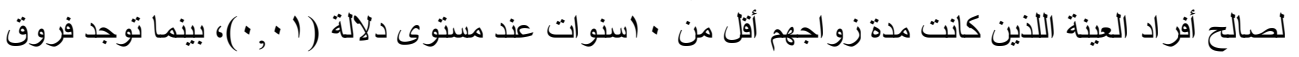

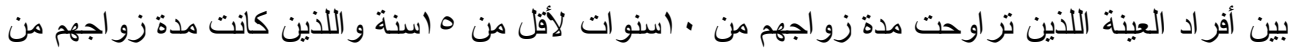

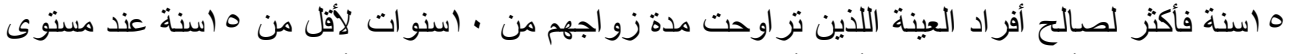

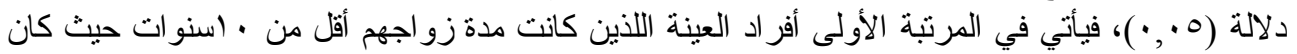

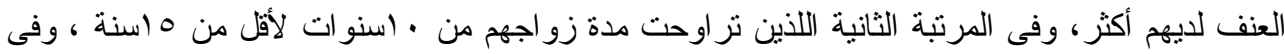

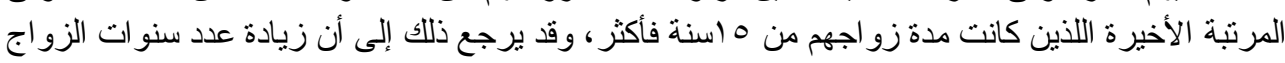

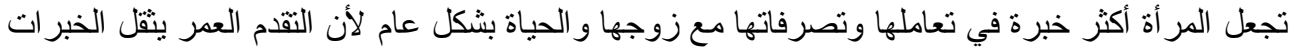

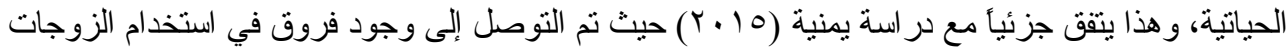

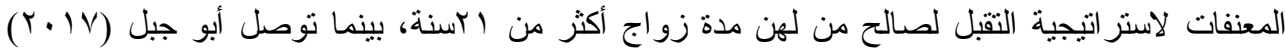

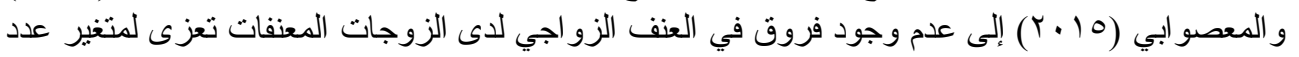

$$
\text { سنو ات الزواج. }
$$

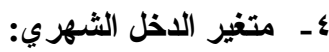

جدول (· r) الفروق في درجات مقياس العنف الزواجي تبعاً لمتغير الاخل الثهري

\begin{tabular}{|c|c|c|c|c|c|}
\hline الدلالة & قيمة (ف) & درجات الحرية & متوسط المربعات & مجموع المربعات & الدخل الشهري \\
\hline \multirow{2}{*}{ ו•,•• داJ } & \multirow{2}{*}{$\varepsilon r, O Y \xi$} & $r$ & $1 Y \leqslant 07,19$. & r\&qIr, rYq & سين المحمهعات \\
\hline & & VIV & rar,OV\& & r.qrvo,^91 & داخل المجموعات \\
\hline & & $\mathrm{V19}$ & & rrSTAA, rV. & المججموع الكلي \\
\hline
\end{tabular}




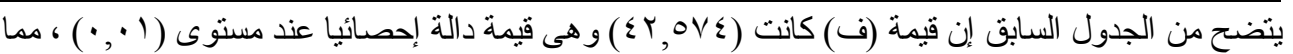

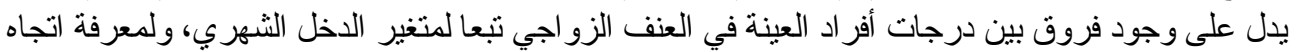

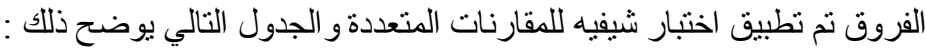
جدول (r) المقارنات المتعدة في درجات مقياس العفف الزواجي تبعاً لمتغير الاخل الثهري

\begin{tabular}{|c|c|c|c|}
\hline 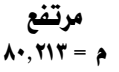 & $\begin{array}{c}\text { متوسط } \\
99, \text { PYY = }\end{array}$ & منغ = مثض = & الدخل الشهري \\
\hline & & - & منخفض \\
\hline & - & $* * 10,: \leqslant 1$ & متوسط \\
\hline - & $* * 19,019$ & $* * r \xi, 07 \gamma$ & مرتفع \\
\hline
\end{tabular}

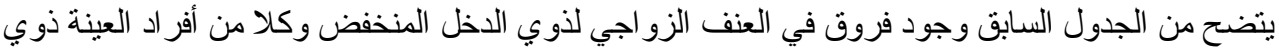

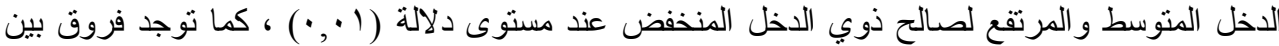

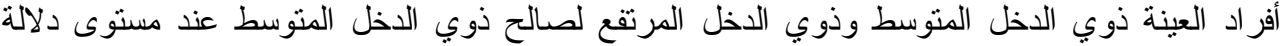

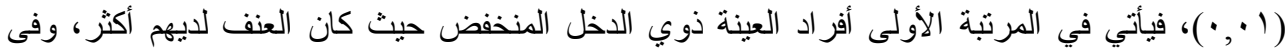

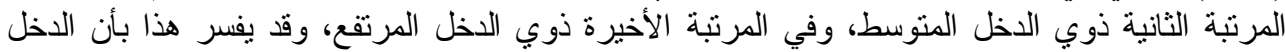

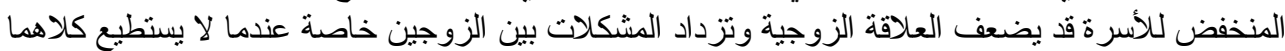

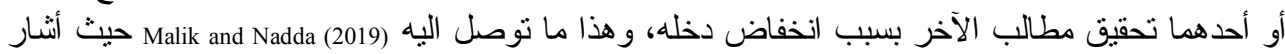

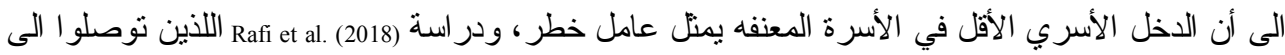

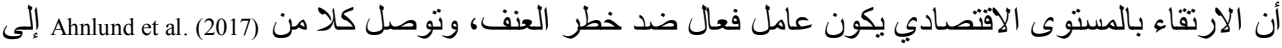

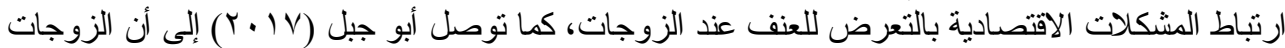

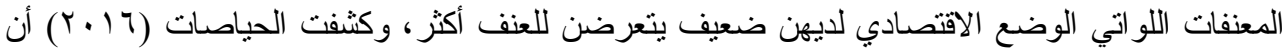

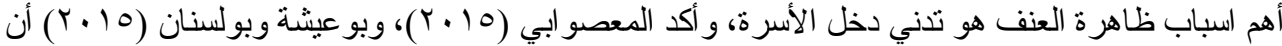

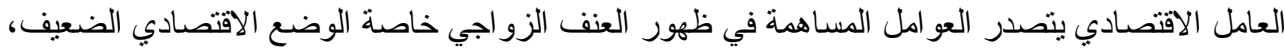

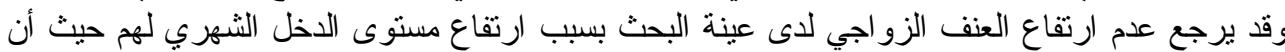

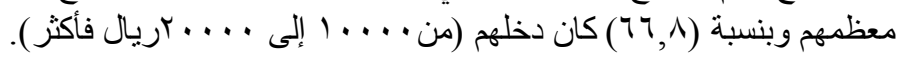
التساؤل الخامس: هل هناك فروق ذات دلالة إحصائية بين منوسط درجات أفر اد العينة في الثفقة بالذات

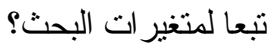

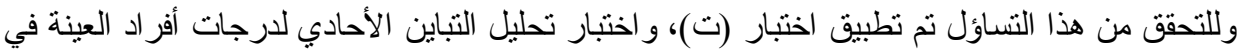

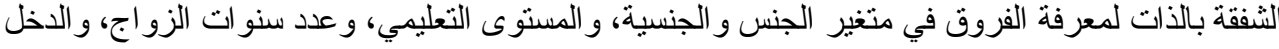

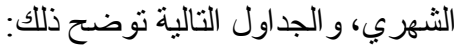

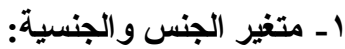

جدول (r r) الفروق في درجات مقياس الثنفقة بالذات تبعاً لمتغير الجنس و الجنسية

\begin{tabular}{|c|c|c|c|c|c|c|}
\hline الدلالة & قيمة & درجات الحرية & العينة & الالعياري & الحابوسطي & المتفير \\
\hline دال عند ا,, & $r \cdot, r q \cdot$ & $V M$ & TYE & $\xi, \cdot \bullet r$ & $\xi 1, r 19$ & الأزواج \\
\hline
\end{tabular}




\begin{tabular}{|c|c|c|c|c|c|c|c|}
\hline الدلالة & قيمة & درجات الحرية & العينة & الالمعياري & الحسابي & \multicolumn{2}{|c|}{ المتفير } \\
\hline لصالح الزوجات & & & Taq & 0,194 & 70, rYo & الزوجات & \\
\hline دال عند ا•,• & 11, TAV & & \&י. & $\xi, \wedge 9 Y$ & $\{v, 7,1$ & السعوديين & \\
\hline لصالح المصريين & & & rr. & 0, orr & $7 \cdot, \$ 90$ & المصريين & بـتيكي \\
\hline
\end{tabular}

يتضح من الجدول السابق وجود فروق دالة احصائيا في منوسطات درجات مقياس الثفقة بالذات تبعا للجنس

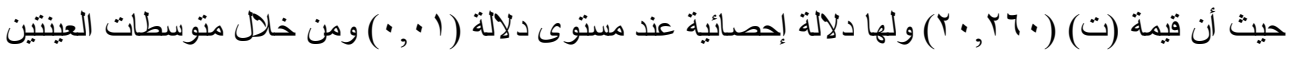

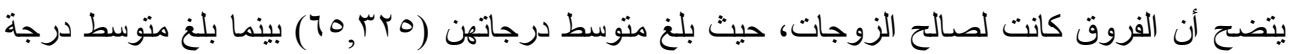

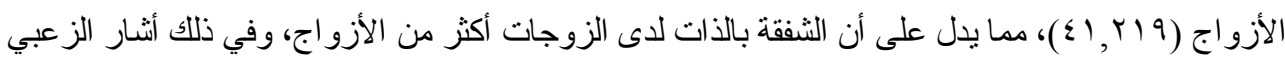

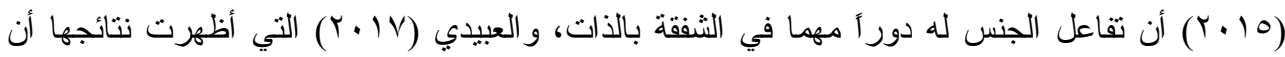

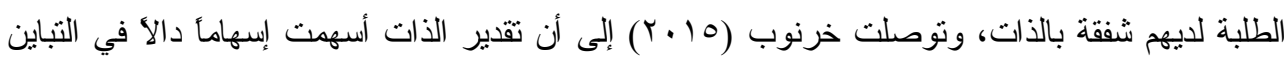

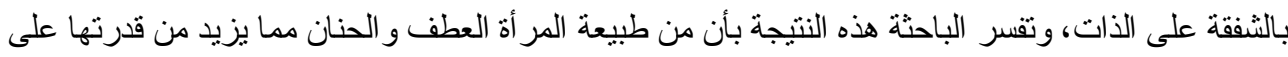

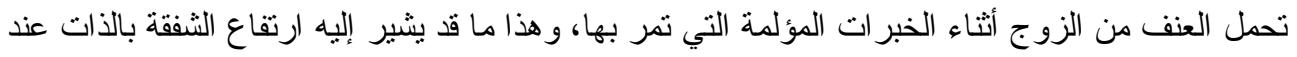

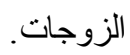

ويتضح من نفس الجدول وجود فروق بين السعوديين و المصريين في منوسطات مقياس الثفقة بالذات حيث

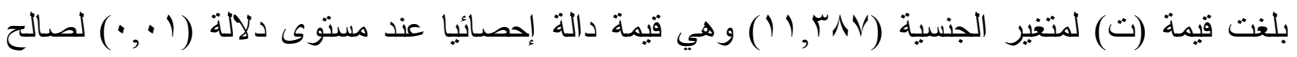

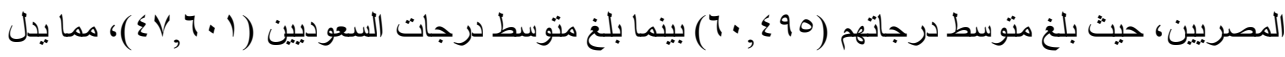

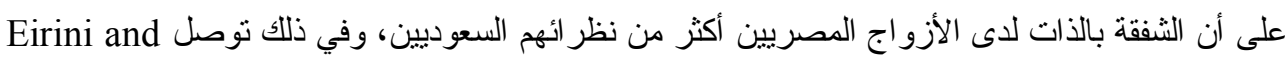

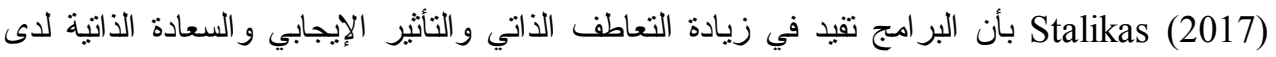

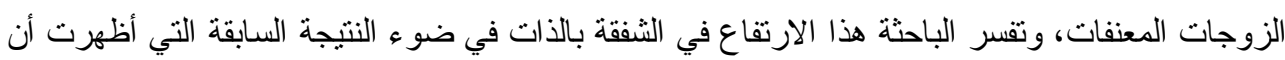

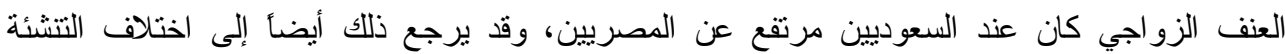
الاجتماعية وطبيعة الثقافة وطبيعة الحياة لدي الجنسيتين.

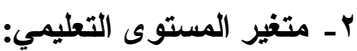

جدول (YT) الفروق في متوسطات درجات مقياس الثفقة بالذات تبعاً لمتغير المستوى التعليمي

\begin{tabular}{|c|c|c|c|c|c|}
\hline الللالة & قيمة (ض) & درجة الحرية & متوسط المربعات & مجموع المربعات & المستوى التعليمي \\
\hline \multirow{3}{*}{ اי•, دال } & \multirow{3}{*}{$\eta_{\cdot}, \cdot \cdot 1$} & $r$ & IrA99,OVY & rovar, lor & بين المجموعات \\
\hline & & viv & $\overline{Y \xi, q \xi 0 .}$ & 108111,911 & داخل المجموعات \\
\hline & & $\mathrm{V} 19$ & & $1 \vee 99 \cdot 0, \cdot v \cdot$ & المجموع الكلي \\
\hline
\end{tabular}

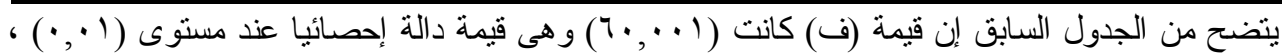

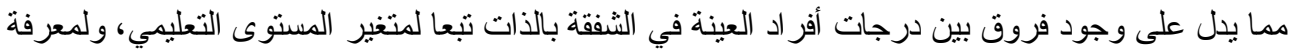

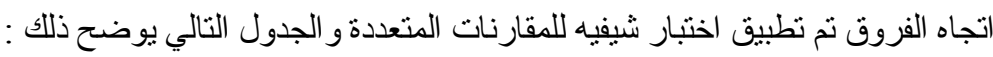


كانت مدة زو اجهم من (0 اسنة فأكثر) عند مستوى دلالة ( ا •, ·)، كما توجد فروق بين أفر اد العينة اللذين

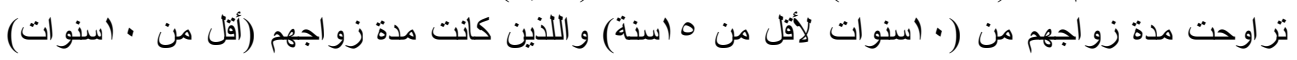

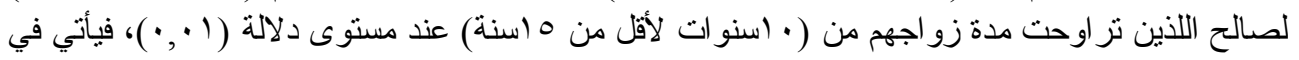

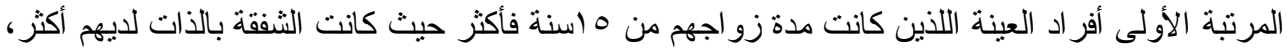

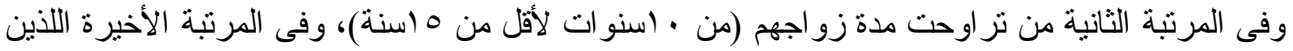

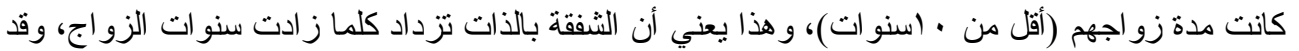

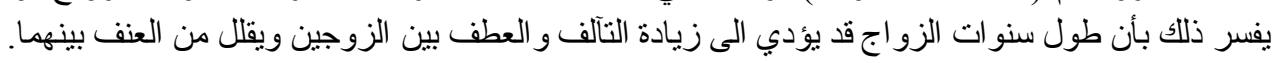

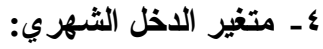
جدول (YV) الفروق في متوسطات درجات مقياس الثفقة بالذات تبعاً لمتغير الدخل الثهري

\begin{tabular}{|c|c|c|c|c|c|}
\hline الدلالة & قيمة (ف) & درجات الحرية & متوسط المربعات & مجموع المربعات & الدخل الشهري \\
\hline \multirow{3}{*}{ ו•,• دال } & \multirow{3}{*}{$r \wedge, 090$} & $r$ & Irrar, $\cdot * 0$ & 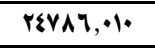 & بين المججموعات \\
\hline & & VIV & $r Y I, 1 \cdot V$ & rrorrr,,$A \cdot \Lambda$ & داخل المجموعات \\
\hline & & $\mathrm{V19}$ & & roo.19,\$1A & المجموع الكلي \\
\hline
\end{tabular}

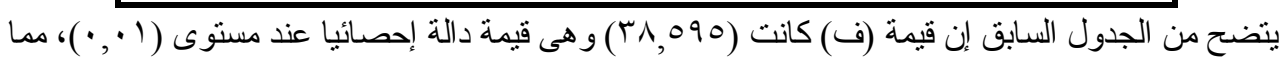

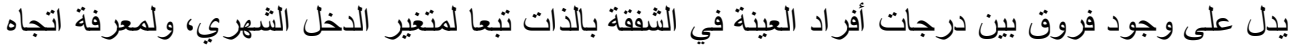

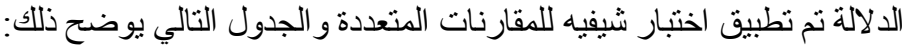

\begin{tabular}{|c|c|c|c|}
\hline م = مرتفع & 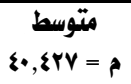 & 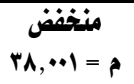 & الدخل الشهري \\
\hline & & - & منخفض \\
\hline & - & $*_{Y, \& Y Y}$ & متوسط \\
\hline - & $* *, r, 970$ & $* * 10, \mathrm{ral}$ & مرتفع \\
\hline
\end{tabular}

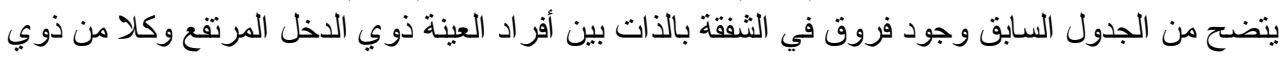

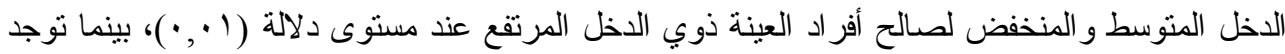

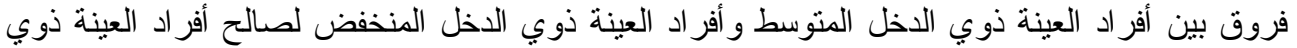

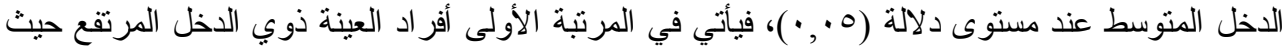

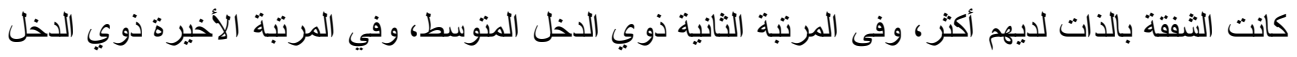

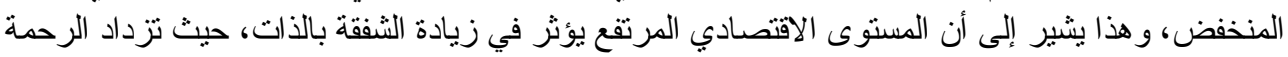

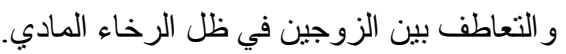

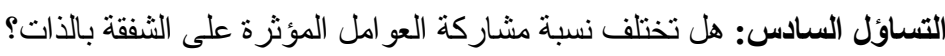

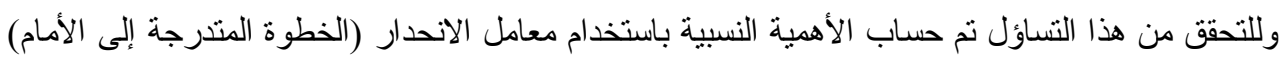

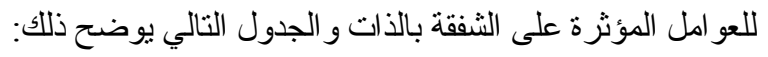


جدول (ج ץ) استخام معامل الاحدار (الخطوة المتارجة إلى الأمام) للعو امل المؤثرة على الثفقة بالذات

\begin{tabular}{|c|c|c|c|c|c|c|c|c|}
\hline الدلالة & قيمة & الانحلار & الدلالة & قيمة & المشاركة & الارتباط & المتفير المستقل & \\
\hline$\cdot, \cdot 1$ & Ir,OAT & •,OAई & $\cdot, \cdot 1$ & 101, rTr & $\cdot, \wedge$. & •, Arr & المستوى التعليمي & $E$ \\
\hline$\cdot, \cdot 1$ & А, 947 & •, \{1\} & $\cdot, \cdot 1$ & $\vee \neg, \wedge \leqslant \wedge$ & $\cdot, \mathrm{V} \xi 1$ & $\bullet, \wedge \uparrow$ & العلاقة الزوجية & $t^{t}$ \\
\hline$\cdot, \cdot 1$ & v, vo. & דוr, & $\cdot, \cdot 1$ & $7 \cdot, \cdot 7 r$ & $\cdot, 711$ & •,AYT & علده سنوات & \\
\hline$\cdot, \cdot 1$ & $7, \wedge 79$ & - , rqA & $\cdot, \cdot 1$ & $\{V .|A|$ & $\cdot, 7 \mathrm{Tr}$ & $\cdot$ - VAr & صلة القرابة & \\
\hline
\end{tabular}

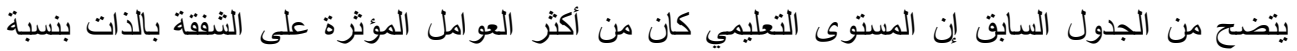

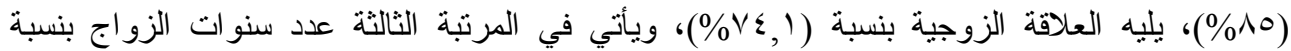

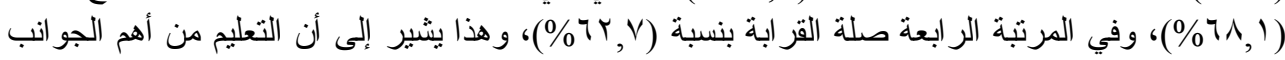

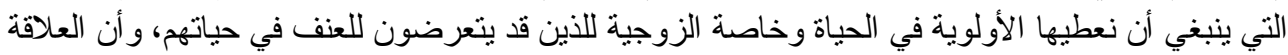

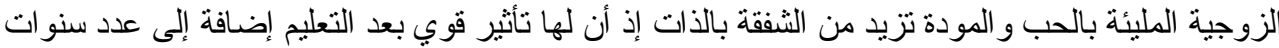

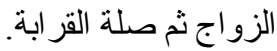
توصيات البحث:

اـ إنشاء مر اكز للإرشاد الأسري و الزو اجي في المجتمع لتقديم البرامج الإرشادية الوقائية للمعنفين التي

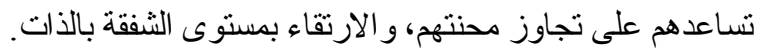
r- زيادة وعي المر أة بأهمية اكمال مسيرتها التعليمية وزيادة دخلها المادي من خلال الدورات التوعوية

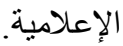
r- حث المُُنفين على ممارسة الرياضة لرفع الإحساس بالثفقة بالذات لديهم، و ذللك من قبل المسؤولين عن دور الرعاية الخاصة بهذه الفئة. 


\section{ملحســق (1) \\ مقياس العنف الزواجي \\ إعداد الباحثة/ د. عبير محمد الصبان}

أخي الزوج/ الزوجة

تقوم الباحثة بيحث عن العنف الزواجي لذلك آمل من سعادتكم الاستجابة على الاستبيان المرفق بصراحة،

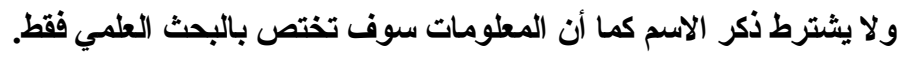

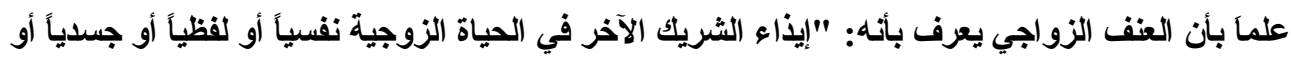

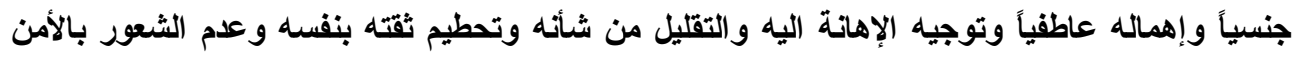

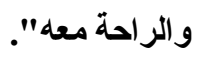

البيانات الأولية: - النية

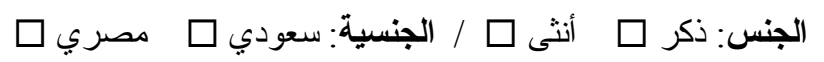

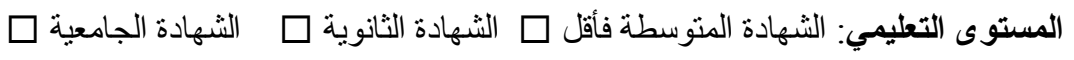

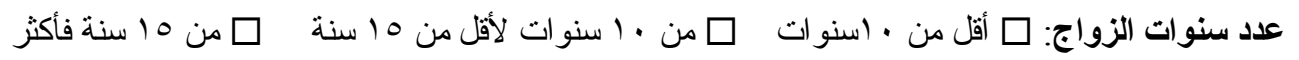

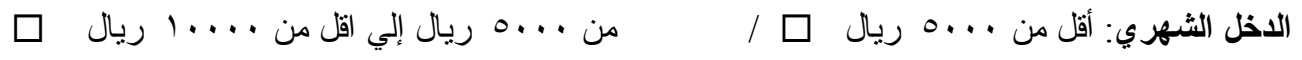

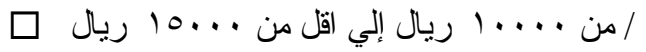

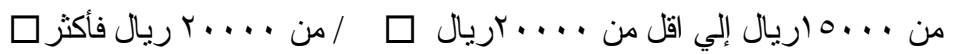

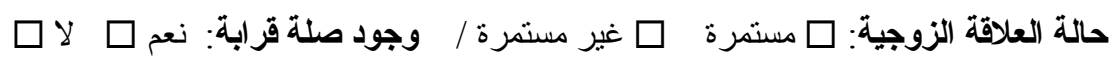

\begin{tabular}{|c|c|c|c|}
\hline $\mathbf{y}$ & نمم & 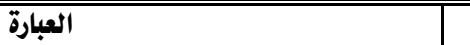 & p \\
\hline & & تقتز زوجتي بنفسها. & .1 \\
\hline & & أشعر بعلم استقرار حياتي مع زوجتي. &.$r$ \\
\hline & & تقتنق زوجتي أفكار خاطئة. &.$r$ \\
\hline & & تنتقد زوجتي أي تصرف أقوم به. & $\varepsilon$ \\
\hline & & زوجتي عنيفة لمرافقتها صديقات السوو. & .0 \\
\hline & & زوجتي لا تهتم بنفسها. & .7 \\
\hline & & ترفع زوجتي صوتها دون مبرر. &.$v$ \\
\hline & & تنسى زوجتي كثير من أمور حياتتا. & .1 \\
\hline & & تصفني زوجتي بعلم الفهـ. & .9 \\
\hline & & زوجتي لا تخاف من اللّه. & . \\
\hline
\end{tabular}
(أ) نسخة الزوج 


\begin{tabular}{|c|c|c|c|}
\hline$y$ & نمي & العبارة & $P$ \\
\hline & & ت تتجاهل زوجتي مشاعري. & $\overline{.11}$ \\
\hline & & تشعر زوجتي بالنقص واللدونية. & $.1 \%$ \\
\hline & & تلومني زوجتي على أخطائها. & .14 \\
\hline & & اختلف مع زوجتي في أسلوب تربية أبنائنا. & .18 \\
\hline & & أشعر بالإرهاق والتعب من حياتي الزوجية. & .10 \\
\hline & & تتصف زوجتي بحب التملك. & .17 \\
\hline & & تحطم زوجتي الأثثاث أثناء حليثنا. & $.1 \mathrm{~s}$ \\
\hline & & تستفل زوجتي نفوذ أفراد عائلتها. & .11 \\
\hline & & تسخر زوجتي من شكلي. & .19 \\
\hline & & تهمل زوجتي حقوقي الزوجية. & .r. \\
\hline & & تدرك زوجتي أنه يصعب علي بناء بيت جديد. &.$M$ \\
\hline & & تقلل زوجتي من إحترامي أهام الآخرين. &.$r$ \\
\hline & & تستخدم زوجتي وسائل التواصل الاجتماعي فترات طويلة. &.$T r$ \\
\hline & & تكثر زوجتي من اللدعاء عليّ. &. $\mathrm{\varepsilon}$ \\
\hline & & تلومني زوجتي على علدم تلبية طلباتها. &. ro \\
\hline & & أتثنى أن أمارس العنف تجاه زوجتي. &. $\mathrm{rq}$ \\
\hline & & علدم اكتمال زوجتي تعليمها يجعلها عنيفة. & Tr \\
\hline & & تعلم زوجتي عدم قدرتي على طلاقها. &. $\mathrm{rA}$ \\
\hline & & تنشفل زوجتي عني باهتمامها بالأبناء. & .99 \\
\hline & & علدم وجود دخل لزوجتي يجعلها عنيفة. &.$\%$ \\
\hline & & تستفل زوجتي رغبتي في الحفاظ على أبنائي. &.$T$ \\
\hline & & تتعمد زوجتي حرماني من حقوقي الجنسية. &.$r r$ \\
\hline & & تشعرني زوجتي بالاستعلاء. & $. \pi / 4$ \\
\hline & & تتعمد زوجتي التقصير في واجباتها لاستفزازي. &. $\mathrm{rq}$ \\
\hline & & غيرة زوجتي بلدون سبب. &.$r 0$ \\
\hline & & ترفض زوجتي الخروج معي للتنزه. & .79 \\
\hline & & أفكر بالزواج بأخرى على زوجتي. &.$r v$ \\
\hline & & تسبني زوجتي أمام أفراد عائلتها. &. $\mathrm{ra}$ \\
\hline & & فقد الحب بيني وزوجتي. & .19 \\
\hline & & تتعمل زوجتي علدم الحديثُ معي. &. \\
\hline & & زوجتي لا ترضى عن حياتنا الزوجية. & .81 \\
\hline & & تتعمد زوجتي نومها بمفردها. & $.8 Y$ \\
\hline & & تتعمدل زوجتي إخفاء إعجابها بتصرفاتي. & $.8 T$ \\
\hline & & تهتم زوجتي بتفاصيل الأمور. &.$\xi \varepsilon$ \\
\hline & & أفكر في الانفصال عن زوجتي. &.$\$ 0$ \\
\hline & & تترصد زوجتي أخطائي. & .87 \\
\hline & & تعاني زوجتي من ضفوط نفسية. & \&v \\
\hline
\end{tabular}


(ب) نسخة الزوجة

\begin{tabular}{|c|c|c|c|}
\hline ע & نعم & العبارة & P \\
\hline & & اعتزاز زوجى بصفته الرجولية سبب عنفه & 1 \\
\hline & & يهملني زوجي تتيجة كثرة أعماله. & $r$ \\
\hline & & يستمع زوجي لأصدقاء السوك & $r$ \\
\hline & & أرغب في الانقصال عن زوجي. & $\varepsilon$ \\
\hline & & يعتنق زوجي أفكار خاطئة عن الزواج & 0 \\
\hline & & يتجاهل زوجي مشاعري نحوه & .7 \\
\hline & & أتثنى أن أمارس العنف تجاه زوجي. & 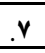 \\
\hline & & زوجبي لا يرضى عن حياته & .1 \\
\hline & & عنف زوجي يشعرني بالإرهاق والتعب & .9 \\
\hline & & أوقات جلوسي مع زوجي قليلة جدا & .1. \\
\hline & & يعاني زوجي من الضفوط النفسية & .11 \\
\hline & & يلعنني زوجي دون سبب. &.$i r$ \\
\hline & & يعنفني زوجي لعلدم خوفه من الله & .14 \\
\hline & & يقلل زوجي من احترامي أهام أبنائي. & $1 \xi$ \\
\hline & & يستخدم زوجي وسائل التواصل الاجتماعي لفترات طويلة & .10 \\
\hline & & يعطم زوجي ثقتي بنفسي.. & .17 \\
\hline & & يعنفني زوجي لزواجه من أخرى & $.1 v$ \\
\hline & & يناديني زوجي بـألفاظغير لائقة. & .11 \\
\hline & & الحب والمودة لا وجود لها بيني وزوجي. & .19 \\
\hline & & يضربني زوجي دون سبب واضح. & $r$. \\
\hline & & يعنفني زوجي لضعف شُخصيته & $\pi$ \\
\hline & & يجقر زوجي من شأني بالإيماءات . & $\bar{r}$ \\
\hline & & يستفل زوجي رغبتي في المحافظة على ابنائي. & Tr \\
\hline & & يستهزأ زوجي بشكلي. & $r \xi$ \\
\hline & & أصابني زوجي بعاهة مستديمة & ro \\
\hline & & يتههني زوجي بعلم الفهم . . &.$r$ \\
\hline & & يعنفني زوجي ششعوره بالنقص والدونية & rr \\
\hline & & ينتقد زوجي تصرفاتي حتى إن كانت طبيعية. & Th \\
\hline & & اختلف مع زوجي في أسلوب تربية أبنائنا &. $\mathrm{rq}$ \\
\hline & & يعاملني زوجي بقسوة. &. \\
\hline & & يستفل زوجي خوفي من الطلاق & .11 \\
\hline & & يخفي عني زوجي كل ما يخصه &.$r$ \\
\hline & & هجرني زوجي بعد زواجه من أخرى & . \\
\hline & & زوجي له يكمل تعليهل. & . \\
\hline & & يحملني زوجي مسؤولية أكبر من طاقتي. & .10 \\
\hline & & أفتقدل الحوار مع زوجي في أي موضوع. & 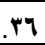 \\
\hline
\end{tabular}




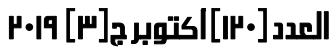

مجلة كلية التربية ببنها

\begin{tabular}{|c|c|c|c|}
\hline $\bar{y}$ & نعم & العبارة & a \\
\hline & & تعرض زوجي للعنف في صفره. & $r v$ \\
\hline & & أتثنى وفاة زوجي. & ה r. \\
\hline & & يحرمني زوجي من الخروج معه للتنزه. &.$r q$ \\
\hline & & زوجي لديه علاقاته غير الشرعية & •. \\
\hline & & يتعمد زوجي تجاهل رأي في القرارات العائلية. & 1). \\
\hline & & يسافر زوجي لوحده حتى لو طلبت أسافر معه & Sr. \\
\hline & & أشعر بعلدم استقرار حياتي مع زوجي & r \\
\hline & & يبخل عليّ زوجي وأولاده ماديا لإزلاننا. &.$\xi$ \\
\hline & & يهجرني زوجي لأي سبب & .80 \\
\hline & & يعنفني زوجي بسبب نقص الإمكانيات المادية & . \\
\hline & & يتعمد زوجي إخفاء إعجابه بي وبتصرفاتي. & s \\
\hline & & وفاة والد زوجي في صفر سنه سبب تعنفيه لي. & $\$ 1$ \\
\hline & & يعاني أبنائي من مشكلات نقسية لكثرة خلافاتي مع والدهم. & .89 \\
\hline
\end{tabular}




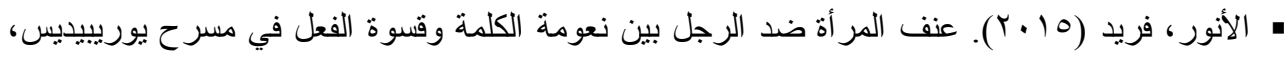

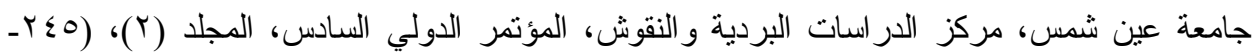

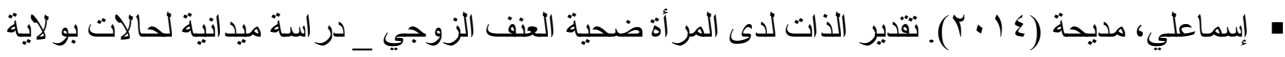

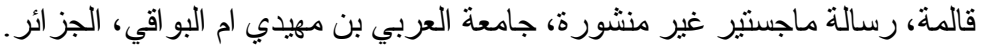

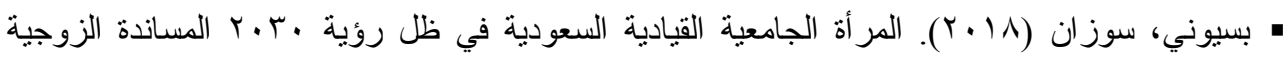

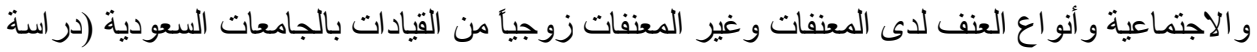

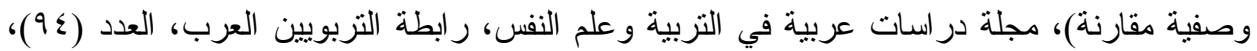

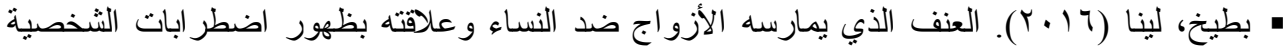

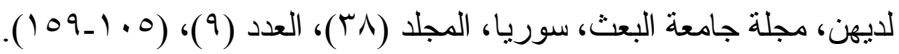

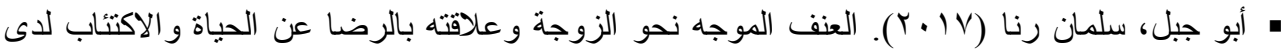

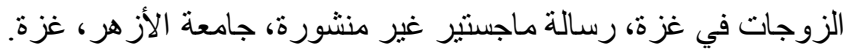

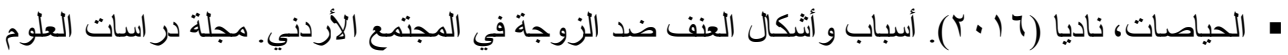

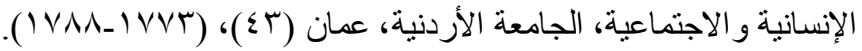

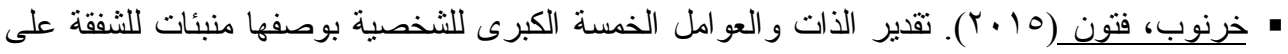

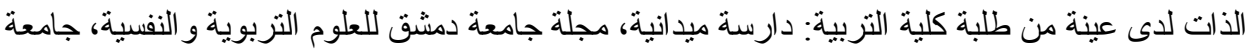

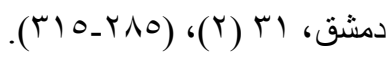

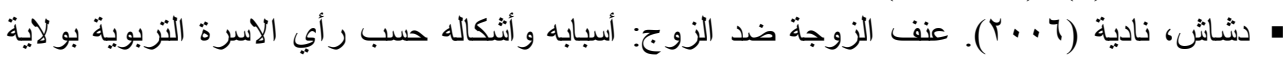

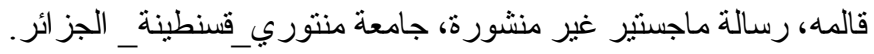

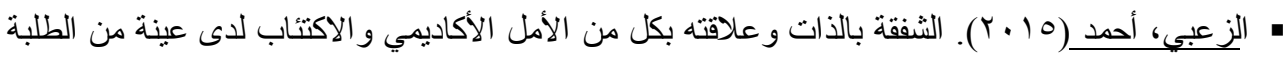

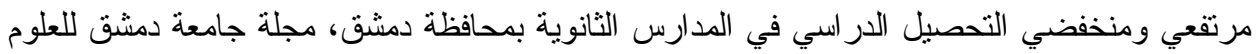

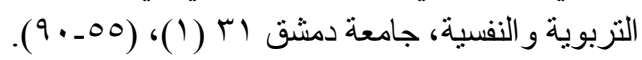

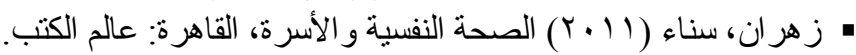

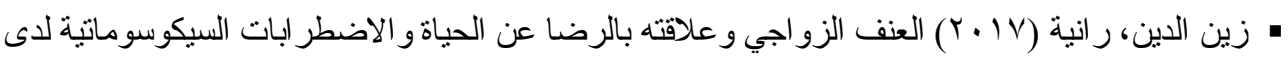

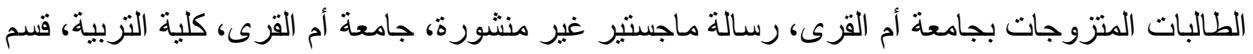
علم النفس.

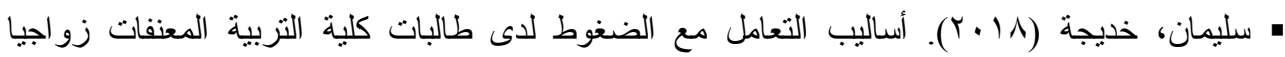

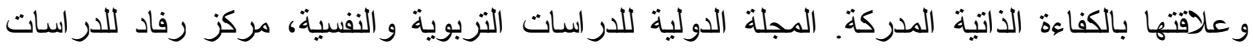


• الثربيني، السيد كامل (17 (Y). المرونة النفسية و العصابية و الثفقة بالذات و الأساليب الوجدانية لاى

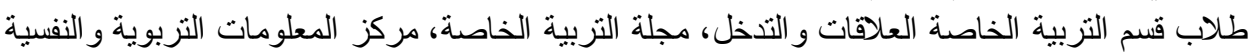

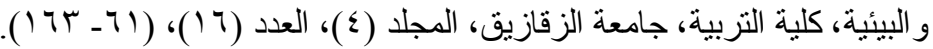

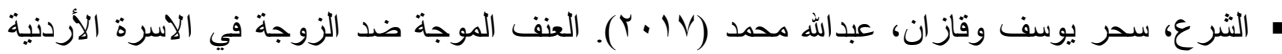

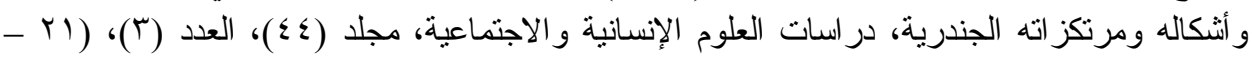

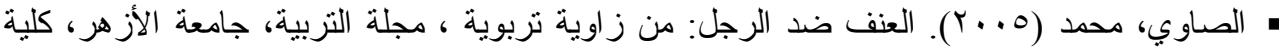

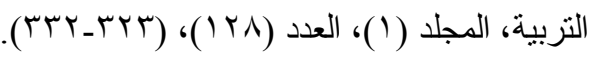

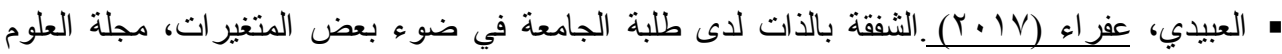

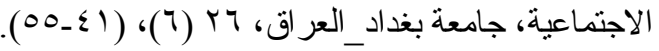

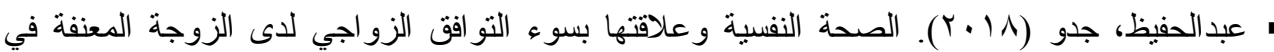

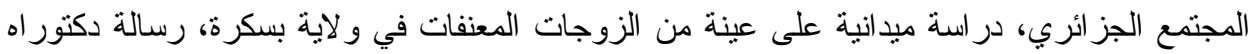

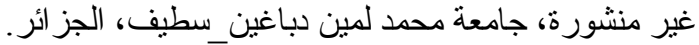

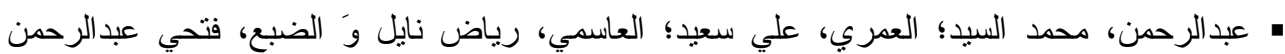

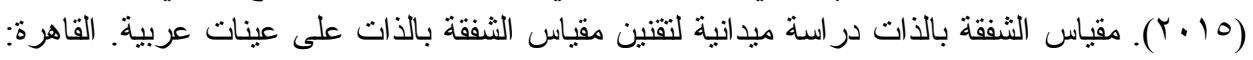

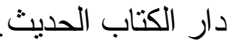

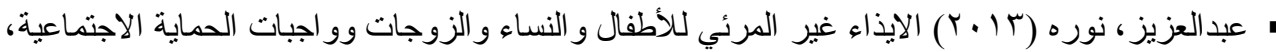

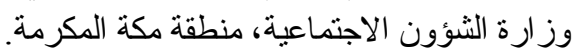

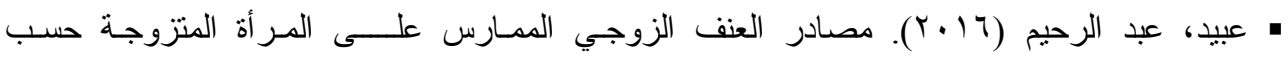

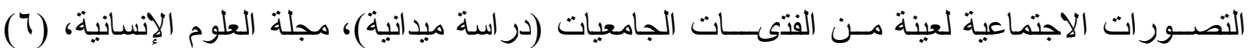
( ( MTr_r r 1 )

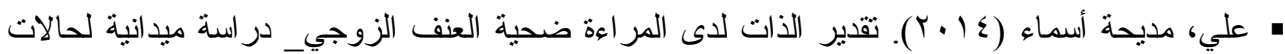

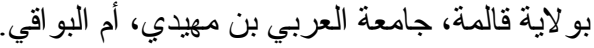

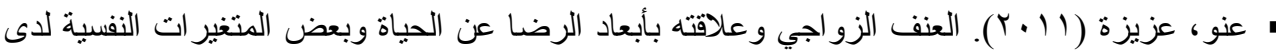

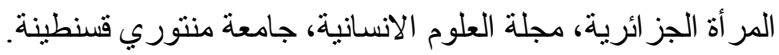

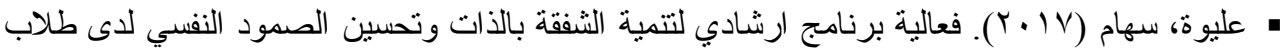

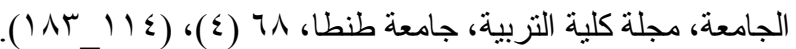

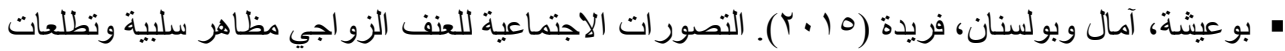
إيجايية (دراسة على عينة من أسر المجتمع الجزائري)، مجلة الباحث في العلوم الإلى الإنسانية و الاجتماعية،

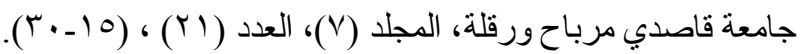

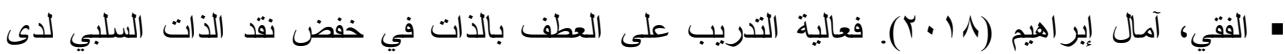

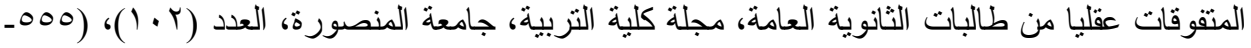




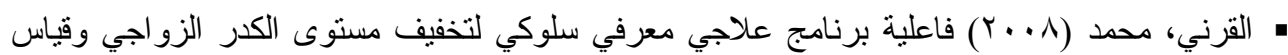

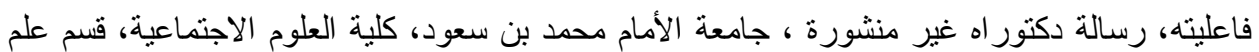

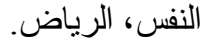

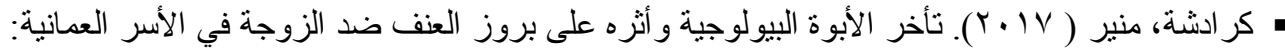

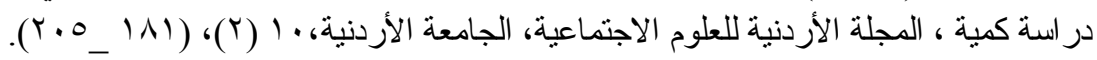

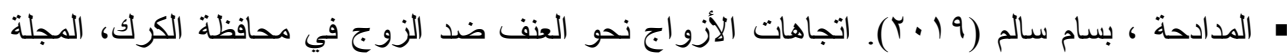

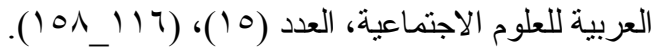

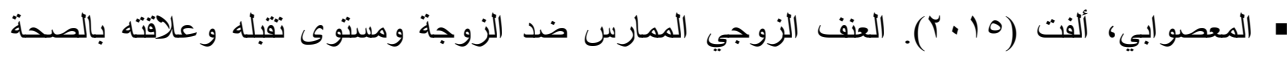

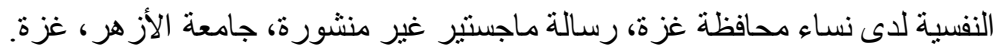

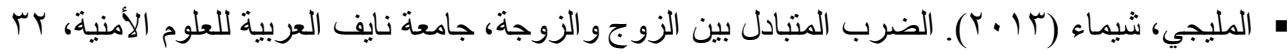
. (Tr_-07) (TVO)

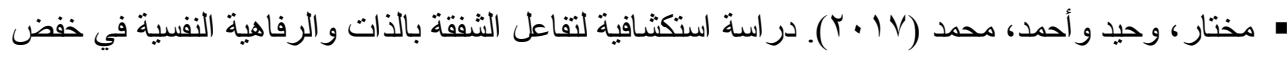
الاكتئاب لدى أمهات الأطفال ذوي الإعاقة العقلية، مجلة كلية التربية، جامعة المنوفية، كلية التربية، المجلد

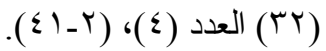

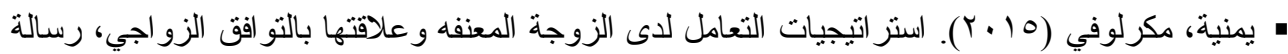
ماجستير غير منشورة، جامعة وهر ان، الجز ائر.

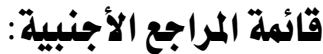

- Ashiey Batts Aiien,Emily Robertson, and Gail A.Batin.(2017) Improving Emotional and Cognitive Outcomes for Domestic Violence ,Survivors: The Impact of Shelter Stay and Self-Compassion Support group, Journal of Interpersonal Violence (1-27)

- Aviad Wilchek, Y., Haviv Neeman, Shagan V., N., shushan ota, A.(2018). The Public Perception of Female and Male Violence in Marital Relationships,Smith College Studies in Social Work, 88 (4), (312-328).

- Ahnlund, P., Andersson, T., Snellman, F., Sundström, M., Heimer.(2017) Prevalence and Correlates of Sexual, Physical, and Psychological Violence Against Women and Men of 60 to 74 Years in Sweden. Journal of Interpersonal Violence, . Article in Press. Cited 1 time.

- Begiato, J. (2018) Beyond the rule of thumb: The materiality of marital violence in England c. 17001857 Cultural and Social History, 15 (1), (39-59). 
- Crews Douglas, Newton Mary and Grant Natalie (2016) The use of yoga to build self-compassion as a healing method for survivors of sexual violence, Journal of Religion \& Spirituality in Social Work: Social Thought, ISSN: 15426432 (Print) 1542-6440.

- Carpenter, R.C. (2017) Recognizing gender-based violence against civilian men and boys in conflict situations The Criminology of War, (377-398).

- Cheung,adam \& Choi, Susanne (2016) Non-Traditional Wives With Traditional Husbands: Gender Ideology and Husband-To Wife Physical Violence in Chinese Society, Violence Against Women, Vol. 22(14) 1704 -1724 (C) The Author (s) 2016 Reprints and permissions: sagepub.com/journals Permissions .nav DOI: 10.1177/1077801216632615 vaw.sagepub.com

- Dzwonkowska Irena \& Lykus Alicja (2015) Self-compassion and social functioning of people - research review, Polish Psychological Bulletin, vol 46(1), 82-87 DOI - 10.1515/ppb-2015-0009.

- Eirini Karakasidou, Anastasios Stalikas (2017). Empowering the Battered Women: The Effectiveness of a Self-Compassion Program, Psychology (8), pp (2200-2214). https://doi.org/10.4236/psych.2017.813140

- Haack, K.R., Pressi, J., Falcke, D. (2018) Predictors of marital physical violence: Personal and relational characteristics Psico-USF, 23 (2), pp. (241252). Cited 1 time

- Hassan Mohammed (2018) violence against the wife and its relation to mental health in diyala governorate, Route educational \& social science Journal volume 5 (12), pp (359-377).

- Játiva, Raquel \& Cerezo,Angeles (2014) The mediating role of self-compassion in the relationship between victimization and psychological maladjustment in a sample of adolescents, Child Abuse \& Neglect (38) (1180-1190)

- Jin, X., Yang, T., Feldman, M.W. (2017) Intergenerational transmission of marital violence among rural migrants in china: Evidence from a survey in shenzhen .Journal of Contemporary China, 26 (108), (931-947).

- Krause, Kathleen H, Roberts, Rachel Gordon, VanderEnde Kristin, Schuler, Sidney Ruth and Yount Kathryn M (2015) Why Do Women Justify Violence Against Wives More Often Than Do Men in Vietnam? Journal of Interpersonal Violence 2016, Vol. 31(19) pp (3150 -3173) (C) The Author (s) 2015 Reprints and permissions: sagepub.com/journals Permissions.nav DOI: 10.1177/0886260515584343 jiv.sagepub.com 
- Karim, R.,\& Swahnberg, K. (2018) Does Female Authority Prevent Male Marital Violence? Evidence From Rural Bangladesh . Journal of Interpersonal Violence, $\mathrm{J}$ Interpers Violence. Article in Press

- Lyon (2015) Self-Compassion as a Predictor of Loneliness: The Relationship Between Self-Evaluation Processes and Perceptions of Social Connection, .Selected Honors Theses .Paper 37

- Malik,J \& Nadda, A (2019) A cross-sectional study of gender-based violence against men in the rural area of Haryana, India, Indian ,Journal of Community Medicine, 44 (1), (35-38).

- Miki Tesh, Joy Learman, Rose M. Pulliam,Mindfulness (2015) Mindful SelfCompassion Strategies for Survivors of Intimate Partner Abuse,April, Volume 6, Issue 2, 192-201

- Murshid, N.S., Murshid, N. (2018) Intergenerational Transmission of Marital Violence: Results From a Nationally Representative Sample of Men ,Journal of Interpersonal Violence, 33 (2), pp. 211-227. Cited 2 times.

- Naomi Bracha Le Vine. (2018) Self-Compassion Among Women With Abuse Eexperinces: The Role Of Socail Support, Master of science, University Of Maryland, college Park.

- Neff, Kristin (2003). Self-compassion: An alternative conceptualization of a healthy attitude toward oneself. Self and identity, 2(2), 85-101.

- Neff, Kristin (2003a). The Development and Validation of a Scale to Measure Self-Compassion, Self and Identity, vol 2(3), 223-250.

- Neff, Kristin (2003b). Understanding how universal goals of independence and interdependence are manifested within particular cultural contexts. Human Development, 46, (5), 321-318.

- Oluremi ,Fareo (2016) Domestic Violence Against Women in Nigeria, European journal of psychology research, Vol.2 No. 1,Issn 2057-4794.

- Rafi amer, Shameem Fatima and shazia aziz (2018) Is Attitudinal Acceptance of Violence a Risk Factor? An Analysis of Domestic Violence Against Women in Pakistan, Journal of Interpersonal Violence , 1 -28 (C) The Author (s) 2018 Reprints and permissions: sagepub.com/journals Permissions nav DOI: 10.1177/0886260518787809 journals.sagepub.com/home/jiv.

- Yucel, D. (2018) Intimate partner violence and marital satisfaction: The mediating role of marital communication and the moderating role of gender Partner Abuse, 9 (2), 137-157. 